Reconhecimento de faces utilizando um modelo conexionista baseado em populações de neurônios 

SERVIÇO DE PÓS-GRADUAÇÃO DO ICMC-USP

Data de Depósito:

Assinatura:

\section{Reconhecimento de faces utilizando um modelo conexionista baseado em populações de neurônios}

\section{Luís Fernando Martins Carlos Júnior}

Orientador: Prof. Dr. João Luís Garcia Rosa

Dissertação apresentada ao Instituto de Ciências Matemáticas e de Computação - ICMC-USP, como parte dos requisitos para obtenção do título de Mestre em Ciências - Ciências de Computação e Matemática Computacional. VERSÃO REVISADA 
Ficha catalográfica elaborada pela Biblioteca Prof. Achille Bassi e Seção Técnica de Informática, ICMC/USP, com os dados fornecidos pelo(a) autor(a)

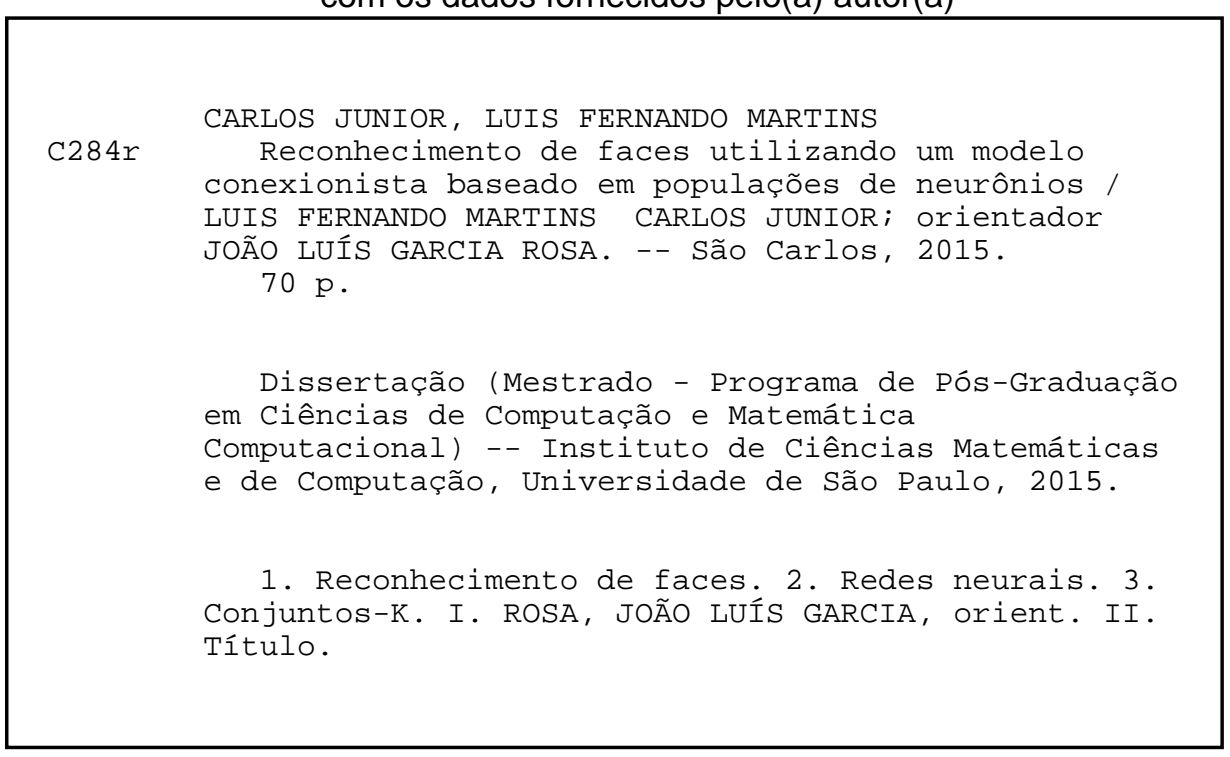


O começo de todas as ciências é o espanto de as coisas serem o que são.

Aristóteles 

Este trabalho é dedicado aos meus pais, Maria e Luís, que estiveram presentes durante toda minha trajetória, me ajudando, apoiando e incentivando. 



\section{Agradecimentos}

Ao professor Dr. João Luís Garcia Rosa, pela orientação ao longo desse projeto. Aos amigos Denis e Raphael pela ajuda, apoio e discussões durante o projeto. À CAPES pelo apoio financeiro para a realização desta pesquisa. 

Reconhecimento de faces consiste em, a partir de uma imagem, identificar ou verificar um ou mais indivíduos através de um banco de dados de faces. O reconhecimento de faces é uma tarefa de grande interesse, principalmente pelo grande número de possíveis aplicações. Dessa forma, existem diversos métodos para lidar com o problema. No entanto, apesar da maioria dos métodos conseguirem bons resultados em ambientes controlados, quando há variações de iluminação, pose ou expressão facial, esse desempenho é reduzido. Buscando lidar com as dificuldades existentes, este trabalho propõe um método para o reconhecimento de faces utilizando os conjuntos-K. Os conjuntos-K são modelos conexionistas baseados em populações de neurônios, concebidos através de estudos e análises do sistema olfativo animal. Estes modelos apresentam estrutura e comportamento biologicamente mais plausíveis que os modelos tradicionais de redes neurais. Os conjuntos-K vêm sendo usados em diversas tarefas de aprendizado de máquina, apresentando bons resultados principalmente na resolução de problemas complexos ou com ruídos. Devido ao grande potencial dos conjuntos-K para reconhecimento de padrões em ambientes complexos e ruidosos, é levantada a hipótese de que um método baseado nos conjuntos-K alcance um melhor desempenho que os métodos existentes na literatura. $\mathrm{O}$ método proposto foi avaliado utilizando dois bancos de dados, AT\&T e Yale $\mathrm{B}$, o primeiro com pequenas variações em relação a pose e expressão facial e o segundo com grandes variações de iluminação fornecendo um cenário mais complexo. Os resultados mostraram que o método proposto consegue um desempenho equivalente ou um pouco inferior que os outros métodos avaliados para o primeiro banco de dados. Porém, para o segundo banco de dados, que fornece o cenário mais complexo, o método proposto supera os demais métodos. 

Ace recognition consists of, from a picture, identifying or checking one or more individuals through a face database. Face recognition is an interesting task mainly because of the large number of possible applications. This way, there are various methods to deal with the problem. However, although most methods achieve good results in controlled environments, when there are lighting, pose or facial expression variations, this performance is reduced. Seeking to deal with the existing difficulties, this work proposes a method for recognizing faces using K-sets. The K-sets are connectionist models based on neuron populations, designed from studies and analyses of the animal olfactory system. These models present more biologically plausible structure and behavior than traditional neural network models. K-sets have been used in various machine learning tasks with good results, mainly in the resolution of complex or noisy problems. Due to the great potential of K-sets for pattern recognition in complex and noisy environments, a hypothesis is raised that a method based on K-sets achieves a better performance than existing methods. The proposed method was evaluated using two databases, AT\&T and Yale B, the first with small variations of pose and facial expressions and the second with large variations in illumination providing a more complex scenario. The results show that the proposed method achieve an equivalent or slightly lower performance than the other methods evaluated for the first database. However, for the second database, which provides the more complex scenario, the proposed method outperforms the other methods. 

Resumo

$\begin{array}{lll}\text { Abstract } & \text { iii }\end{array}$

1 Introdução $\quad 1$

1.1 Organização do Texto . . . . . . . . . . . . . . . . 3

2 Reconhecimento de Faces 5

2.1 Visão Geral do Problema . . . . . . . . . . . . . . . . . . . . . 5

2.2 Detecção Facial . . . . . . . . . . . . . . . . . . . . . 6

2.2.1 Framework de detecção de objetos Viola-Jones . . . . . . . . . . . . . . 7

2.3 Extração de características . . . . . . . . . . . . . . . . . . . . 9

2.3.1 Métodos Holísticos . . . . . . . . . . . . . . . . . . . . . . . . . . . . . .

2.3.2 Métodos Locais . . . . . . . . . . . . . . . . . . . . . . . . . . . . . . . . . . . . . . . .

2.3.3 Métodos Híbridos . . . . . . . . . . . . . . . . . . . . 14

2.4 Redes Neurais Aplicadas ao Reconhecimento Facial . . . . . . . . . . . . . . . . . 15

2.5 Bancos de Dados . . . . . . . . . . . . . . . . . . . . . 17

2.6 Avaliação . . . . . . . . . . . . . . . . . . . . . . . . . . . . . . . . . . . .

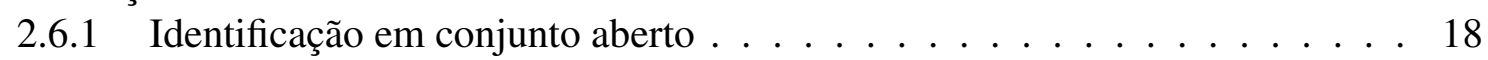

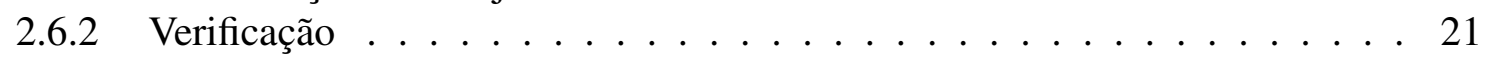

2.6.3 Identificação em conjunto fechado . . . . . . . . . . . . . . . . . . 22

2.7 O problema em mensurar os resultados . . . . . . . . . . . . . . . 23

2.8 Direções para Pesquisas Futuras . . . . . . . . . . . . . . . . . . . . 24

2.9 Considerações finais . . . . . . . . . . . . . . . 25

3 Modelos K de Freeman $\quad 27$

3.1 Visão Geral dos Conjuntos K . . . . . . . . . . . . . . . . . . . . . . 27

3.2 Sistemas Dinâmicos . . . . . . . . . . . . . . . . . . . . . 28

3.3 Conjuntos KO, KI e KII . . . . . . . . . . . . . . . . . . . . . . . 30

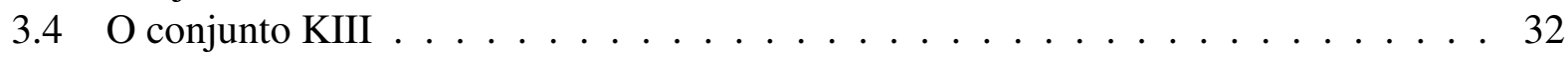

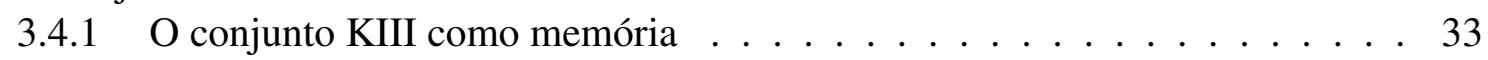

3.4 .2 Aprendizado no KIII . . . . . . . . . . . . . . . . . . 34

3.4.3 Reconhecimento de Faces utilizando o conjunto KIII . . . . . . . . . . . . 35

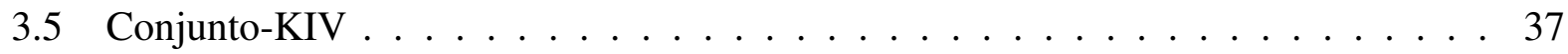

3.6 Considerações Finais . . . . . . . . . . . . . . . . . . 38 
4 Metodologia e Resultados $\quad 39$

4.1 Visão Geral do Método Proposto . . . . . . . . . . . . . . . . . . . . . . . . 39

4.1.1 Filtragem de Dados Utilizando o conjunto-KIII . . . . . . . . . . . . . . 41

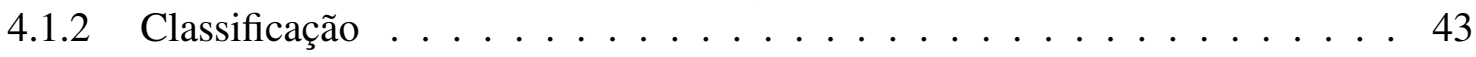

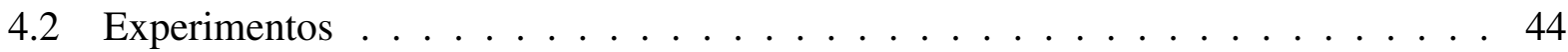

4.2.1 Conjuntos de dados a serem utilizados . . . . . . . . . . . . . . . . . . . 44

4.2.2 Definição dos Subespaços PCA e LDA . . . . . . . . . . . . . . . 45

4.2.3 Aplicação do Método e Resultados . . . . . . . . . . . . . . . . . . . . . . . . . . . . . 48

4.3 Considerações Finais . . . . . . . . . . . . . . . . . . 57

5 Conclusões $\quad 59$ 


\section{Lista de Figuras}

2.1 Diagrama de sistema de reconhecimento facial genérico. . . . . . . . . . . . 6

2.2 Os quatro tipos de características utilizadas na abordagem original do detector de objetos Viola-Jones. Adaptado de Viola e Jones (2001) . . . . . . . . . . . . . . . . 8

2.3 Cascata de classificadores utilizada no Viola-Jones. Em cada estágio da cascata, as amostras classificadas negativamente $(\mathrm{N})$ são rejeitadas, enquanto as classificadas positivamente $(\mathrm{P})$ são passadas ao estágio seguinte. Adaptado de Viola e Jones

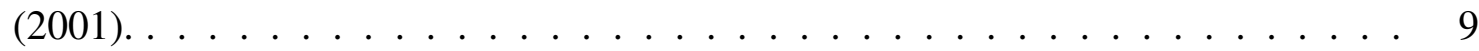

2.4 Desempenho de um sistema na identificação de conjunto aberto, reportado em uma curva ROC. . . . . . . . . . . . . . . . . . . . . . 20

2.5 Desempenho de um sistema na identificação de conjunto fechado, reportado em uma curva CMC . . . . . . . . . . . . . . . . . 23

3.1 Diagrama dos conjuntos KO, KI e KII, e sua resposta a um impulso. . . . . . . . . 31

3.2 Estrutura genérica de um conjunto KIII de três entradas. Adaptado de Beliaev et al. (2005) . . . . . . . . . . . . . . . . . . . 32

3.3 Diagrama genérico dos métodos que utilizaram KIII no reconhecimento de faces. Adaptado de (Zhang et al., 2006). . . . . . . . . . . . . . . . . . 35

3.4 Particionamento da imagem. Adaptado de Zhang et al. (2006). . . . . . . . . . . . 36

3.5 Estrutura de um conjunto KIV para a aplicação de navegação em robôs. Adaptado de Kozma e Freeman (2003) . . . . . . . . . . . . . . . . . . . . . . . 37

4.1 Diagrama de blocos do método proposto. . . . . . . . . . . . . . . . 40

4.2 Diagrama de fluxo da fase de treinamento. . . . . . . . . . . . . . . . 40

4.3 Diagrama de fluxo da fase de teste. . . . . . . . . . . . . . . . . 41

4.4 Amostra do Banco de Dados Olivetti AT\&T (ORL) (Samaria e Harter, 1994) . . . 45

4.5 Exemplos de imagens de um único indivíduo do "Yale Face Database B" na pose frontal, mostrando as variações de iluminação. A imagens foram divididas em 4 sub-conjuntos de acordo com o ângulo que a fonte da luz faz com o eixo da câmera, sub-conjunto $1\left(12^{\circ}\right)$, sub-conjunto $2\left(25^{\circ}\right)$, sub-conjunto $3\left(50^{\circ}\right)$, e sub-conjunto

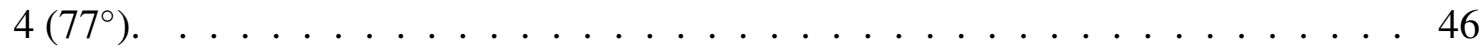

4.6 Variância cumulativa dos autovetores PCA referente às amostras de treinamento para o Banco de dados AT\&T. . . . . . . . . . . . . . . . . . . . 47

4.7 Variância cumulativa dos autovetores PCA referente às amostras de treinamento para o Banco de dados Yale B. . . . . . . . . . . . . . . . . . . . . 48

4.8 CMC para distância euclidiana. . . . . . . . . . . . . . . . . 50 
4.9 CMC para distância de Mahalanobis. . . . . . . . . . . . . . . . . . . . . 51

4.10 CMC para distância de Manhattan. . . . . . . . . . . . . . . . . . . 52

4.11 CMC para distância euclidiana. . . . . . . . . . . . . . . . . . . . . . . . . . . . . . . . . .

4.12 CMC para distância de Mahalanobis. . . . . . . . . . . . . . . . . . 55

4.13 CMC para distância de Manhattan. . . . . . . . . . . . . . . . . . . . 56 


\section{Lista de Tabelas}

2.1 Comparação entre características locais e holísticas sensíveis a variações. Adaptado de Tan et al. (2006). . . . . . . . . . . . . . . . . . . . . 15

2.2 Principais bancos de dados de faces. . . . . . . . . . . . . . . . . 18

3.1 Hierarquia dos modelos K. Adaptado de Kozma e Freeman (2003). . . . . . . . . . . 28

3.2 Taxa de Identificação obtida pelos métodos SVD, DCT e WPT (Li et al., 2006), para 8,16, 32, 64 e 80 características extraídas (sub-imagens) por imagem. . . . . 36

3.3 Comparação dos métodos com KIII, com os métodos MLP (Rod et al., 2000), HMM(Samaria, 1994), PCA(Samaria, 1994) para banco de dados AT\&T. . . . . . 37

4.1 Pesos utilizados nos conjuntos-KII em cada camada do conjunto-KIII. . . . . . . . 42

4.2 Pesos utilizados nos conjuntos-KII em cada camada do conjunto-KIII. . . . . . . . 42

4.3 Pesos utilizados nos conjuntos-KII em cada camada do conjunto-KIII. . . . . . . . 42

4.4 Taxa de identificação e desvio padrão obtidos pelos métodos avaliados para o rank 1. Utilizando o Banco de Dados AT\&T. . . . . . . . . . . . . . . . . . . . . 49

4.5 Taxa de identificação obtida pelos métodos avaliados para o rank 1 . . . . . . . . 53 
O reconhecimento de faces é considerado um dos métodos biométricos mais importantes e possui algumas vantagens sobre os demais métodos biométricos, por ser natural e passivo, não necessitando da cooperação de indivíduos como acontece em outros métodos, como o de reconhecimento de íris (Zhang e Gao, 2009). Esta característica do reconhecimento facial o torna atraente para aplicações na área de segurança, em que é necessário realizar o reconhecimento através de câmeras de segurança sem a cooperação do indivíduo.

O reconhecimento de faces também pode ser aplicado em diversas outras tarefas relacionadas com identificação ou verificação como por exemplo: na identificação de indivíduos para acesso a um setor restrito de uma determinada empresa, como substituto para senhas no acesso a computadores ou outros recursos (Zhao et al., 2003) e na organização de álbuns de fotos (Facebook, Google's Picasa, e iPhoto) (Chellappa et al., 2010).

O reconhecimento de faces vem se mostrando uma área de pesquisa bastante atrativa para muitos pesquisadores, principalmente por dois motivos: o grande número de aplicações possíveis e os desafios encontrados na área. Dentre os desafios encontrados na área, os principais são: ruídos na imagem, variações na iluminação, variação de pose, expressão facial, variação de idade, óculos, barba, bigode. (Zhang e Gao, 2009).

Muitos pesquisadores têm trabalhado com o objetivo de desenvolver um método robusto o bastante para lidar com as dificuldades encontradas na área, surgindo assim diversas técnicas diferentes para lidar com o problema. Dentre as técnicas existentes, as principais são os métodos baseados em projeções lineares como: principal component analysis (PCA) (Kirby e Sirovich, 1990; Turk e Pentland, 1991b), linear discriminant analysis (LDA) (Zhao et al., 1998) e indepen- 
dent component analysis (ICA) (Bartlett et al., 1998). Também vale citar os métodos baseados em support vector machines (Phillips, 1999) e redes neurais (Lawrence et al., 1997; Er et al., 2002).

Apesar dos vários anos de pesquisas e quantidade de abordagens distintas para o reconhecimento facial, a maioria dos métodos ainda encontra dificuldades para lidar com os problemas da área (Abate et al., 2007). Em Phillips et al. (2003), é apresentada uma avaliação dos principais métodos de reconhecimento facial, sendo observado que a maioria dos métodos consegue uma taxa de identificação maior que $90 \%$ em condições de iluminação controlada. No entanto, esse desempenho é reduzido quando há variações de iluminação, pose ou expressão facial.

Devido aos desafios da área e às deficiências encontradas nos modelos atuais, este projeto propõe a investigação e desenvolvimento de um método para o reconhecimento facial baseado nos conjuntos-K de Freeman. Os conjuntos-K são modelos pertencentes à quarta geração do conexionismo (Kozma et al., 2007), e são baseados em populações de neurônios, com uma estrutura e comportamento biologicamente mais plausíveis (Li e Kozma, 2003). Os conjuntos-K foram concebidos através de estudos e observações do neurocientista Walter J. Freeman sobre o sistema olfatório de animais a partir de eletroencefalogramas (Freeman, 1975; Erwin e Freeman, 2008).

Utilizado com sucesso em diversas tarefas, os conjuntos-K produzem melhores resultados em problemas complexos, ruidosos ou com poucos exemplos, onde outras técnicas normalmente não conseguem bons resultados. Os conjuntos- $\mathrm{K}$ já foram utilizados para predição de séries temporais (Li e Kozma, 2003), reconhecimento de caracteres (Wang et al., 2005), reconhecimento de padrões complexos (Xiaomin et al., 2010) e reconhecimento facial (Zhang et al., 2005, 2006; Li et al., 2006).

Dentre as características apresentadas pelos conjuntos-K, destacam-se algumas que podem trazer benefícios à tarefa de reconhecimento facial, tais como (i) comportamento dinâmico que permite uma melhor generalização e tolerância a erros (Li e Kozma, 2003), (ii) capacidade de generalizar em ambientes complexos, ruidosos e com poucos exemplos (Kozma et al., 2007; Li e Kozma, 2003), (iii) necessidade de apenas um passo para convergir no aprendizado, que em certos casos faz com que os conjuntos-K sejam mais rápidos que outros modelos, apesar do custo computacional por passo ser maior (Zhang et al., 2005).

Alguns trabalhos (Zhang et al., 2005, 2006; Li et al., 2006) aplicaram os conjuntos-K no reconhecimento facial e conseguiram resultados significativos, entre $89 \%$ e $91.5 \%$ de taxa de identificação. Nestes trabalhos o primeiro passo realizado foi a extração de características, onde foram utilizadas transformadas matemáticas como transformada discreta de cosseno (DCT) e transformada wavelet packet (WPT - Wavelet Packet Transform). Em seguida, os dados foram processados pelos conjuntos-K, que são utilizados como um filtro de dados no sentido em que agem convertendo os dados de entrada para um espaço de oscilações espaço-temporais, simulando o aprendizado realizado no cérebro. Por fim, a saída do conjunto-K é classificada utilizando o algoritmo k-vizinhos mais próximos (k-NN). Esses métodos baseados nos conjuntos-K foram aplicados para a tarefa de identificação de faces sobre o banco de faces AT\&T. Este banco de faces é considerado simples, 
pois possui apenas pequenas variações nas imagens, como sutis variações na pose e expressão facial. No entanto, o sucesso dos conjuntos-K nesse banco de faces motiva a aplicação de métodos baseados nos conjuntos-K em bancos de faces mais complexos.

Outro ponto a ser observado é a técnica de extração de características utilizada, visto que esta pode influenciar muito os resultados (Yambor et al., 2000; Delac et al., 2005). Dentre as várias técnicas existentes para a extração de características, a combinação PCA mais LDA (Belhumeur et al., 1997; Yang e yu Yang, 2003) chama a atenção por sua simplicidade e eficiência. Desta forma, este trabalho propõe a criação de um método para o reconhecimento de faces baseado nos conjuntos-K, em que a extração de características é realizada através da combinação dos métodos PCA e LDA. O intuito é que o método proposto possa alcançar bons resultados tanto em situações simples, quanto em situações mais complexas. A avaliação do método proposto será realizada utilizando dois bancos de faces, o banco AT\&T (Samaria e Young, 1994), simulando um cenário mais simples, e o banco Yale B (Georghiades et al., 2000) simulando um cenário mais complexo.

\subsection{Organização do Texto}

Os Capítulos 2 e 3 abordam a revisão bibliográfica. No Capítulo 2, são apresentados alguns pontos relevantes ao reconhecimento facial. Primeiramente, é apresentada uma visão geral sobre o problema e, a seguir, são apresentados e discutidos os métodos. Na sequência, é abordado o uso de redes neurais na resolução do problema, e por fim, é discutida a avaliação dos métodos de reconhecimento de faces apresentando os bancos de dados e protocolos de avaliação mais utilizados. No Capítulo 3, são apresentados os conjuntos-K, onde é mostrada uma visão geral dos modelos. Também é apresentada a hierarquia dos modelos e são discutidos cada um de seus elementos. Ao final, são abordadas as aplicações dos modelos, bem como seu uso na resolução do problema de reconhecimento de faces.

No Capítulo 4, é apresentado o método proposto, em que é mostrada uma visão geral sobre o método e explicado seu funcionamento nas fases de treinamento e teste. Este capítulo também apresenta uma descrição das técnicas, algoritmos e parâmetros utilizados no método proposto. O Capítulo 5 trata dos experimentos e resultados. Primeiramente, são apresentados os conjuntos de dados utilizados e, a seguir, são definidos os parâmetros dependentes dos dados de entrada. Por fim, são apresentados os experimentos e resultados obtidos. O Capítulo 6 apresenta as conclusões sobre o trabalho e sugestões para trabalhos futuros. 



\section{Reconhecimento de Faces}

Neste Capítulo, é apresentada uma visão geral sobre o problema. A seguir, são apresentadas as etapas do reconhecimento de faces: detecção facial, extração de características e classificação, descrevendo e dando exemplos de técnicas utilizadas em cada etapa. Na sequência, é abordado o uso de redes neurais na resolução do problema. Por fim, é feita uma revisão sobre os bancos de dados de faces e os tipos de avaliação.

\subsection{Visão Geral do Problema}

O reconhecimento facial, seja ele a partir de imagens estáticas ou imagens de vídeos, é considerado uma área de pesquisa bem promissora, abrangendo diversas disciplinas como processamento de imagem, reconhecimento de padrões e visão computacional (Chellappa et al., 1995). Existem diversas aplicações em que a identificação humana é necessária e o reconhecimento facial possui algumas vantagens sobre as demais tecnologias biométricas (Abate et al., 2007):

1. Não intrusiva: não necessita da cooperação do indivíduo que será reconhecido;

2. Fácil utilização: é possível utilizá-lo através de uma simples câmera, não sendo necessário nenhum equipamento específico, como no reconhecimento de impressão digital ou íris;

3. Baixo custo de implementação comparado com outros sistemas biométricos, como reconhecimento de íris.

Existem diversas técnicas para o reconhecimento de faces, mas de um modo geral pode-se dividir os métodos de reconhecimento de faces em três módulos: detecção de faces, extração de 
características e classificação. A Figura 2.1 mostra um diagrama de um método de reconhecimento de faces genérico. Na detecção facial, a região da face é identificada e isolada do restante da imagem. Em seguida, é realizada a extração de características sobre a região da face detectada. $\mathrm{Na}$ extração de características são extraídas as informações úteis para distinguir os indivíduos. Por fim, é realizada a classificação, onde as características extraídas são comparadas e classificadas. Nessa fase, ocorre identificação ou verificação, de acordo com o tipo de aplicação desejada.

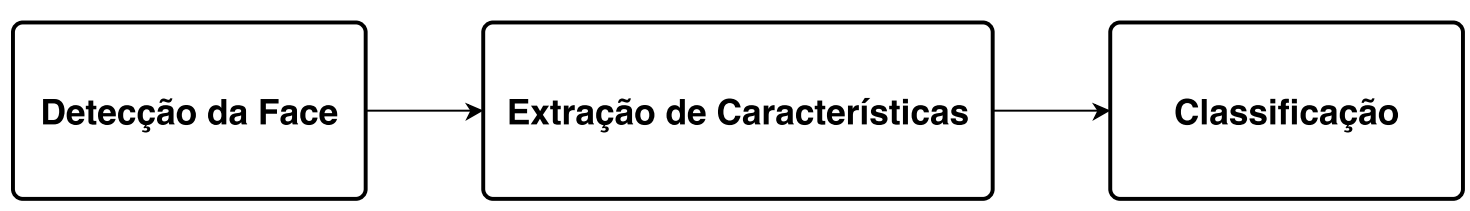

Figura 2.1: Diagrama de sistema de reconhecimento facial genérico.

O reconhecimento facial é utilizado em diversas aplicações, sejam elas na área comercial, militar ou de segurança pública. De maneira geral o reconhecimento facial pode ser utilizado na resolução das três tarefas básicas apontadas a seguir (Chellappa et al., 2010):

- Verificação: o sistema determina se a imagem da face corresponde à identidade desejada. Como exemplos de aplicações citam-se acesso a instalações seguras, e-commerce e segurança de computadores.

- Lista de assistidos: o sistema determina se o indivíduo da imagem buscada está presente na lista, e, se estiver, o identifica. Como exemplos de aplicações citam-se sistemas de segurança em aeroportos e fronteiras internacionais.

- Identificação: o sistema determina a identidade de um indivíduo a partir da imagem da face. Pode ser utilizado em aplicações como busca de suspeitos pelas forças policiais e verificação de antecedentes civis.

\subsection{Detecção Facial}

A detecção facial ou segmentação é o primeiro passo a ser realizado em um sistema de reconhecimento facial, e consiste em identificar e isolar a área referente à face em uma imagem. A detecção facial pode ser realizada com base em vários estímulos: cor de pele, formato do rosto ou cabeça, aparência da face, ou a combinação destes. A maior parte dos algoritmos de sucesso de detecção facial são os baseados em aparência, sem usar outros estímulos (Li e Jain, 2005).

No problema de detecção, duas estatísticas são importantes: verdadeiros positivos e falsos positivos. Um sistema confiável deve ter altas taxas de verdadeiros positivos e baixas taxas de falsos positivos. Levando em conta essas duas estatísticas, os melhores resultados encontrados foram apresentados em Sung e Poggio (1998); Rowley et al. (1998); Schneiderman e Kanade (2000); Roth et al. (2000); Amit et al. (1997). O framework de detecção de objetos Viola-Jones (Viola 
e Jones, 2001) conseguiu alcançar um resultado equivalente a esses métodos com a vantagem de detectar as faces de forma extremamente rápida.

$\mathrm{Na}$ detecção facial a região da face é detectada e separada do restante da imagem. Após a região da face ser extraída, ela é redimensionada para o tamanho de 56x56 pixels. Então esta imagem resultante é transformada em um vetor de 3136 elementos, em que cada pixel da imagem representa um elemento do vetor. Este vetor de elementos serve de entrada para a próxima etapa do sistema, a extração de características. Para detectar a face na imagem foi utilizado o Framework de detecção de objetos Viola-Jones, que é apresentado com detalhes a seguir.

\subsubsection{Framework de detecção de objetos Viola-Jones}

O framework de detecção de objetos Viola-Jones (Viola e Jones, 2001) pode ser treinado para detectar uma variedade de classes de objetos, no entanto sua criação foi motivada pelo problema de detecção de faces. O framework é composto de três partes. A primeira delas é a representação da imagem em um espaço de características baseadas nos filtros de Haar (Papageorgiou et al., 1998). Isto é feito com o auxílio da "imagem integral". A segunda é um algoritmo de aprendizado baseado em Boosting capaz de selecionar as características mais relevantes (Freund e Schapire, 1997). Por fim é feita uma combinação em cascata de classificadores garantindo bom desempenho e velocidade de processamento. No Viola-Jones, a representação dos dados de treinamento no espaço de características é obtida através da "imagem integral" $I(m, n)$, definida por:

$$
I(m, n)=\sum_{m^{\prime} \leq m, n^{\prime} \leq n} g\left(m^{\prime}, n^{\prime}\right),
$$

onde $g(m, n)$ é uma imagem de tamanho $m \times n, 1 \leq m, m^{\prime} \leq m$ e $1 \leq n, n^{\prime} \leq m$. A principal vantagem desta representação é que ela possibilita calcular a soma dos elementos de qualquer retângulo contido na imagem com apenas quatro pontos de $I(m, n)$. Além disso é possível obtê-la com apenas uma varredura na imagem (Viola e Jones, 2001).

Um conjunto de características, dado pela diferença entre a soma dos pixels de regiões retangulares, é facilmente obtido através da imagem integral. Este tipo de característica é semelhante ao produto interno com as wavelets de Haar e por isso são também conhecidas como Haar-like features. $\mathrm{Na}$ abordagem original de Viola-Jones foram utilizados quatro tipos de características, como ilustrado na Figura 2.2, onde o valor de uma dada característica é a diferença entre a soma dos pixels da região branca e a soma dos pixels da região cinza.

O conjunto de treinamento do Viola-Jones é formado por amostras do tipo $\left(x_{n}, y_{n}\right)$ com $N$ amostras, onde $x_{n}$ é uma imagem de dimensão $24 \times 24$ e $y_{n}=\{0,1\}$ é o rótulo de classe. Neste caso $y_{n}=1$ corresponde a uma imagem de face e $y_{n}=0$ a uma imagem de não-face. A dimensão das amostras faz com que o número total de características seja maior que 180.000. Isto torna necessária a seleção das características mais relevantes. Para tal é utilizada uma versão do AdaBoost conhecida como Gentle Adaboost (Friedman et al., 2000). 

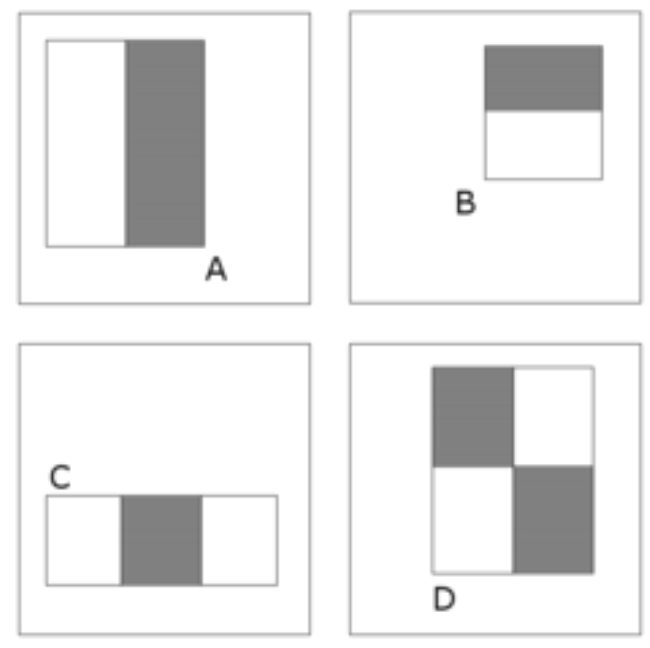

Figura 2.2: Os quatro tipos de características utilizadas na abordagem original do detector de objetos Viola-Jones. Adaptado de Viola e Jones (2001).

Em cada iteração do AdaBoost, um conjunto de classificadores fracos $h_{j}$ é ajustado para minimizar o erro de classificação. Cada um destes classificadores corresponde a uma característica $f_{j}\left(x_{n}\right)$, onde $j=1, \ldots, J$ e $J$ é o total de características. Dado um limiar $\theta_{j}$ e uma paridade $p_{j}$, a regra de classificação pode ser dada por:

$$
h_{j}\left(x_{n}\right)=\left\{\begin{array}{l}
1, \text { se } p_{j} f_{j}\left(x_{n}\right)>p_{j} \theta_{j} \\
0, \text { caso contrário }
\end{array}\right.
$$

onde a paridade $p_{j}$ indica a direção da desigualdade.

Em problemas práticos as taxas alcançadas por esta abordagem não são satisfatórias. Por isso é feita uma combinação de classificadores na forma de uma árvore degenerada, também conhecida como cascata de classificadores. Nesta combinação, cada nó (ou estágio) é invocado sequencialmente e corresponde a um classificador AdaBoost ajustado para obter uma taxa de falso negativo próxima a zero. Para reduzir o tempo de processamento o número de características selecionadas em cada estágio é menor que no estágio seguinte. Isto faz com que os estágios sejam sequencialmente mais complexos e o número de amostras diminua rapidamente à medida que eles são invocados (Amit et al., 1997). A Figura 2.3 ilustra a classificação em cascata feita pelo ViolaJones.

Na detecção, como não se sabe a posição nem o tamanho da face na imagem de teste, as características selecionadas no treinamento são escalonadas do tamanho mínimo até o tamanho da imagem, nos respectivos estágios da cascata. Estas versões escalonadas são aplicadas em todas as sub-janelas possíveis dentro da imagem de teste. A maioria das sub-janelas são rejeitadas nos primeiros estágios enquanto os últimos são responsáveis por classificar as sub-janelas mais difíceis.

Neste trabalho o Viola-Jones foi utilizado através do método CascadeObjectDetector do pacote vision do MATLAB (The Math Works, 2014). 


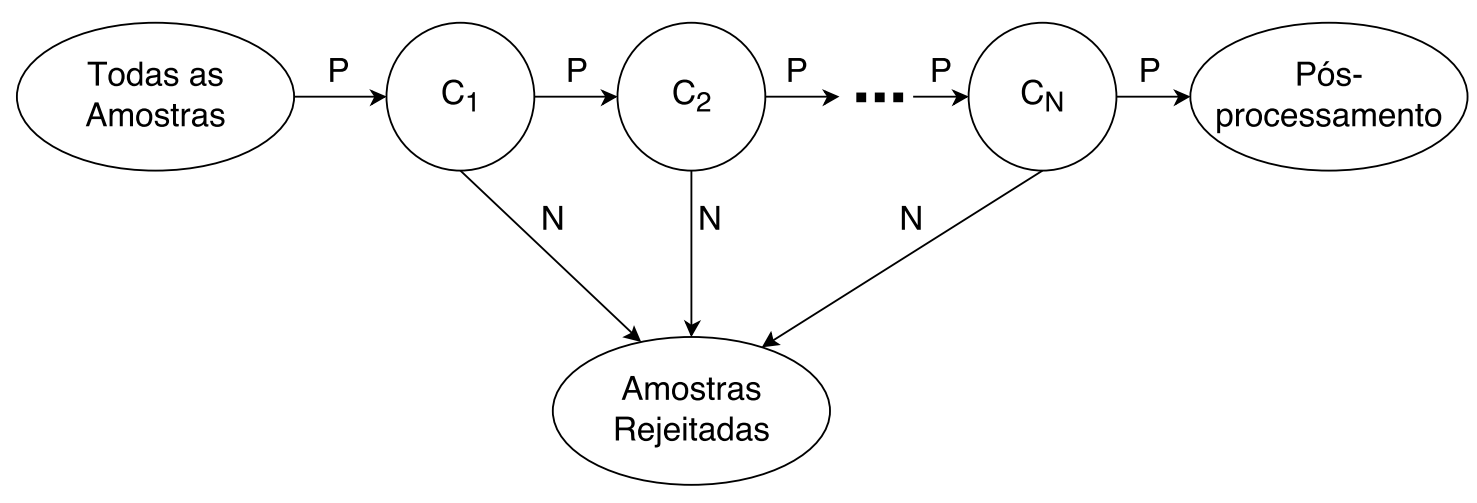

Figura 2.3: Cascata de classificadores utilizada no Viola-Jones. Em cada estágio da cascata, as amostras classificadas negativamente $(\mathrm{N})$ são rejeitadas, enquanto as classificadas positivamente (P) são passadas ao estágio seguinte. Adaptado de Viola e Jones (2001).

\subsection{Extração de características}

Para que o reconhecimento seja realizado, antes deve ser realizada a extração de características a partir das imagens de face. A extração das características pode ser feita de duas formas: de maneira holística, ou seja, toda a região da face serve como entrada para o sistema, ou de maneira local, onde a face é representada por características individuais (olhos, nariz, boca, etc.). Desta forma, os métodos de reconhecimento facial podem ser classificados de acordo com a forma com que analisam a face, podendo ser divididos nos três tipos: holísticos, locais e híbridos (Zhao et al., 2003).

\subsubsection{Métodos Holísticos}

Nestes métodos, cada face é representada como um único vetor de alta dimensionalidade formado pela concatenação dos valores de cinza de todos os pixels da imagem da face. Este tipo de representação possui duas vantagens: preserva implicitamente todas as informações de textura e formas que são muito úteis para distinguir as faces, e pode capturar mais aspectos globais da face do que descrições baseadas em características locais (Tan et al., 2006). Contudo este vetor pode ser considerado demasiadamente grande, tornando o processo de reconhecimento dispendioso. Devido ao grande espaço dimensional do vetor de características, é interessante a utilização de alguma técnica de redução de dimensionalidade. Observando as redundâncias na imagem, é possível caracterizá-la em um espaço dimensional menor, onde apenas as informações mais relevantes para o reconhecimento estão presentes. O intuito dessas técnicas é diminuir significativamente o espaço de entrada selecionando as características mais relevantes, visando melhorar tanto o desempenho computacional quanto a taxa de reconhecimento.

Dentre os métodos utilizados para a redução de dimensionalidade os mais relevantes são Análise de Componentes Principais (PCA) (Kirby e Sirovich, 1990; Turk e Pentland, 1991b), Análise de Componente Independentes (ICA) (Bartlett et al., 1998), e Análise Discriminante Linear (LDA) 
(Belhumeur et al., 1997; Zhao et al., 1998). Os três métodos baseiam-se em análises estatísticas dos vetores da face e em transformações lineares e não lineares dos sistemas de coordenadas onde se encontram estes vetores. Cada uma dessas técnicas possui um mecanismo próprio para realizar a redução de dimensionalidade baseado em conceitos estatísticos diferentes. Ao final do processo, é obtido um novo vetor como representação das características de cada imagem de face. O reconhecimento é realizado através de um classificador, que analisa os vetores de face de treinamento comparando-os com os de teste, e define se a face está no banco de treinamento ou não. A classificação pode ser realizada de várias formas. Dentre as mais utilizadas cita-se o uso de medidas de distâncias entre vetores, como por exemplo distância euclidiana, do cosseno, e de Mahalanobis. (Perlibakas, 2004; Delac et al., 2005).

\section{Análise de Componentes Principais (PCA)}

A técnica de Análise de Componentes Principais (PCA) é um procedimento matemático que utiliza uma transformação ortogonal para converter um conjunto de observações de variáveis possivelmente correlacionadas a um conjunto de valores de variáveis linearmente não correlacionadas, chamadas componentes principais (Hotelling, 1933). Dependendo da área de aplicação, o PCA é também conhecido por transformada Karhunen-Loève (KLT) discreta, transformada de Hotelling ou decomposição ortogonal própria (POD). Quando aplicado ao reconhecimento de faces, recebe o nome de Eigenfaces (Turk e Pentland, 1991b).

O PCA é um método baseado em projeções lineares, os métodos baseados em projeções lineares podem ser descritos da seguinte forma: considere $X$ como o conjunto de todas as faces de treinamento, ou seja, $X=\left(x_{1}, x_{2}, \ldots, x_{N}\right)$ uma matriz $p t \times N$, onde cada $x_{i}$ é um vetor face de dimensão $p t$ (linearização da imagem $m \times n=p t$ ), pt é o número total de pixels na imagem de face, e $N$ a quantidade de faces do conjunto de treinamento. A transformação linear que mapeia o espaço original da imagem em um espaço de características de menor dimensão é dada pela seguinte equação:

$$
Y=W^{T} \cdot X
$$

onde $Y$ é a matriz com a representação dos vetores originais no novo espaço vetorial $(d \times N)$, $X(p t \times N)$ são os vetores do espaço original, e $W(p t \times d)$ é a matriz de transformação. Note que $d$ é a dimensão do espaço $Y$ e $p t$ o tamanho dos vetores, ressaltando que $d$ sempre é menor que a dimensão original representada por $p t$.

Para realizar o reconhecimento de faces utilizando o PCA, deve-se encontrar a matriz de projeção $W$ presente na Equação 2.3. Para tal, considere o conjunto de $N$ amostras de treinamento $X=\left(x_{1}, x_{2}, \ldots, x_{N}\right)$. Primeiramente, é computada a face média $\mu$ dada por:

$$
\mu=\frac{1}{N} \sum_{i=1}^{N} x_{i}
$$


Em seguida, é computada a matriz de dispersão total definida por:

$$
S_{T}=\sum_{i=1}^{N}\left(x_{i}-\mu\right) \cdot\left(x_{i}-\mu\right)^{T} .
$$

A matriz de projeção $W$ é composta pelos $m$ autovetores correspondentes aos $m$ autovalores mais significativos da matriz de dispersão $S_{T}$. No PCA, a projeção $W_{\text {otima }}$ é escolhida para maximizar o determinante do total de dispersão da matriz das amostras projetadas,

$$
W_{\text {otima }}=\arg \max _{W}\left|W^{T} S_{T} W\right|=\left[\begin{array}{llll}
\mathbf{w}_{1} & \mathbf{w}_{2} & \ldots & \mathbf{w}_{m}
\end{array}\right]
$$

onde $\left\{\mathbf{w}_{i} \mid i=1,2, \ldots, m\right\}$ é o conjunto de autovetores n-dimensional de $S_{T}$ correspondente aos $m$ maiores autovalores. Desde que esses autovetores tenham a mesma dimensão que as imagens originais, eles são chamados de Eigenpictures ou Eigenfaces (Belhumeur et al., 1997).

Quando uma nova imagem é consultada, ela é projetada no espaço de faces através da operação, $y_{k}=W^{T}\left(x_{k}-\mu\right)$ para $k=1, \ldots, N$. O vetor obtido é comparado com os das amostras de treinamento (também projetadas no espaço de faces), utilizando uma medida de distância (usualmente euclidiana). A classe da face consultada é dada pela classe da imagem que obtiver a menor distância, se essa distância for maior que um limiar previamente estabelecido. Caso contrário, a face é dada como desconhecida. Como o PCA é realizado apenas para o treinamento do sistema, este método é muito rápido, quando testado em novas imagens.

O PCA reduz a dimensionalidade dos dados maximizando a dispersão de todos os exemplos. Uma desvantagem desta abordagem é que a dispersão maximizada não é apenas a dispersão entre as classes, mas também a dispersão dentro da mesma classe, o que é prejudicial para a classificação. A maior parte das variações entre uma imagem e outra é dada por mudanças na iluminação. Assim, se forem apresentadas ao PCA imagens de faces com variações de iluminação, a matriz de projeção conterá os componentes principais que retêm variações de iluminação no espaço de características projetados. Consequentemente, os pontos projetados no espaço não serão bem agrupados, e pior, classes diferentes podem ser colocadas juntas (Adini et al., 1997).

Uma possível, solução seria descartar os três principais componentes mais significativos, assim a variação devido à iluminação seria reduzida (Adini et al., 1997). A esperança é que se os primeiros componentes principais capturam as variações referente a iluminação, então um melhor agrupamento das amostras projetadas será alcançado ignorando-os. No entanto, é pouco provável que os três primeiros de vários componentes principais correspondam somente a variação de iluminação. Consequentemente, informações úteis para a discriminação das classes podem ser perdidas (Belhumeur et al., 1997). 


\section{Análise Discriminante Linear LDA}

O método Análise Discriminante Linear (LDA - Linear Discriminant Analysis) conhecido também como Discriminante Linear de Fisher (FLD - Fisher's linear discriminant) é um método utilizado para achar uma combinação linear de características que caracteriza ou separa duas ou mais classes de objetos ou eventos. Este método pode ser usado como um classificador linear ou como uma técnica de redução de dimensionalidade.

No reconhecimento de faces as amostras de treinamento são rotuladas. Portanto, faz sentido usar essa informação a fim de construir um método de extração de características mais confiável (Belhumeur et al., 1997). O LDA é um método que utiliza essas informações, realizando a redução do espaço de forma que sejam selecionadas as características mais discriminantes entre as classes em vez de selecionar as características que melhor descrevem os dados. Este método seleciona a matriz de projeção $W$ de tal modo que a razão entre a dispersão entre as classes e a dispersão dentro da classe seja maximizada. A matriz de dispersão entre classes é definida pela Equação 2.7.

$$
S_{B}=\sum_{i=1}^{c} N_{i}\left(\mu_{i}-\mu\right)\left(\mu_{i}-\mu\right)^{T}
$$

e a matriz de dispersão dentro da classe (intra-classe) é defina pela Equação 2.8.

$$
S_{W}=\sum_{i=1}^{c} \sum_{x_{k} \in X_{i}}\left(x_{k}-\mu_{i}\right)\left(x_{k}-\mu_{i}\right)^{T}
$$

onde $\mu$ é a média de todo o conjunto, $\mu_{i}$ é a média das imagens da classe $X_{i}$, e $N_{i}$ é o número

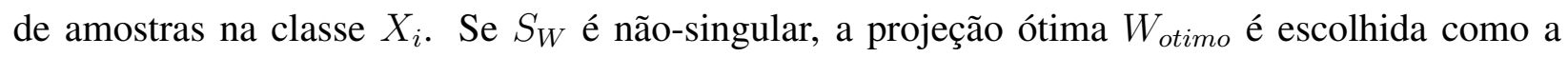
matriz com colunas ortonormais que maximiza a razão do determinante da matriz de dispersão entre-classes das amostras projetadas para o determinante da matriz de dispersão intra-classe das amostras projetadas. A projeção $W_{\text {otimo }}$ é definida pela Equação 2.9.

$$
W_{\text {otimo }}=\arg \max _{W} \frac{\left|W^{T} S_{B} W\right|}{\left|W^{T} S_{W} W\right|}=\left[\begin{array}{llll}
\mathbf{w}_{1} & \mathbf{w}_{2} & \ldots & \mathbf{w}_{m}
\end{array}\right]
$$

onde $\left\{\mathbf{w}_{i} \mid i=1,2, \ldots, m\right\}$ é o conjunto de autovetores generalizados de $S_{B}$ e $S_{W}$ correspondente aos $m$ maiores autovalores generalizados $\{\lambda \mid i=1,2, \ldots, m\}$, dado pela Equação 2.10.

$$
S_{B} \mathbf{w}_{i}=\lambda_{i} S_{W} \mathbf{w}_{i}, \quad i=1,2, \ldots, m
$$

Note que existem no máximo $c-1$ autovalores generalizados diferentes de zero, e assim um limite superior $m$ é $c-1$, onde $c$ é o número de classes.

No problema de reconhecimento de faces, há a dificuldade de que a matriz de dispersão dentro da classe $S_{W} \in \mathbb{R}^{n \times n}$ seja sempre singular. Isto ocorre devido ao fato de que o grau de $S_{W}$ é no máximo $N-c$, e geralmente o número de imagens no conjunto de aprendizado $N$ é muito menor 
que o número de pixels em cada imagem $n$. Isto significa que é possível escolher a matriz $W$ tal que a matriz de dispersão intra-classe das amostras projetadas possa ser exatamente zero.

Com o objetivo de resolver o problema de $S_{W}$ singular, Swets e Weng (1996a,b) e Belhumeur et al. (1997) propuseram o uso do PCA como espaço intermediário. Primeiramente a imagem $n$ dimensional é projetada em um espaço $s$-dimensional utilizando o PCA e depois é projetada para um espaço $m$-dimensional utilizando o LDA. Considerando $N$ amostras de treinamento e $c$ classes, $s$ deve ser escolhido tal que $s+c \leq N$, para que $S_{W}$ não seja singular (Swets e Weng, 1996a). Por outro lado, $s$ não pode ser menor que o número de classes $c$, assim $c<s \leq N-c$. Formalmente o $W_{\text {otimo }}$ é dado por

$$
W_{\text {otimo }}^{T}=W_{l d a}^{T} W_{p c a}^{T}
$$

onde

$$
\begin{aligned}
& W_{p c a}=\arg \max _{W}\left|W^{T} S_{T} W\right| \\
& W_{l d a}=\arg \max _{W} \frac{\left|W^{T} W_{p c a}^{T} S_{B} W_{p c a} W\right|}{\left|W^{T} W_{p c a}^{T} S_{W} W_{p c a} W\right|}
\end{aligned}
$$

Combinando PCA e LDA, é obtida uma projeção linear que mapeia o vetor de entrada $X$ em um sub-espaço de face $Y$, e em seguida em um espaço de classificação $Z$ :

$$
\begin{gathered}
Y=W_{p c a}(x-\mu) \\
Z=W_{l d a} Y \\
Z=W_{\text {otimo }}(x-\mu)
\end{gathered}
$$

Assim como ocorre em outros métodos de projeção linear, quando uma nova imagem é consultada, ela é projetada no espaço de faces através da operação, $y_{k}=W_{\text {otimo }}^{T}\left(x_{k}-\mu\right)$ para $k=1, \ldots, N$. E o vetor obtido é comparado com os das amostras de treinamento (também projetadas no espaço de faces). A utilização do LDA no reconhecimento de faces surgiu com a necessidade de se encontrar um método que oferecesse uma alternativa ao PCA, superando suas deficiências. O métodos Fisherfaces (Belhumeur et al., 1997) e subespaço LDA (Zhao et al., 1999), que realizam o reconhecimento através de uma projeção linear que combina PCA e LDA, mostraram-se bem sucedidos nesse sentido.

\subsubsection{Métodos Locais}

Como visto na seção anterior, nos métodos holísticos as decisões de reconhecimento facial são feitas considerando a imagem inteira. Em contraste, as abordagens locais consideram apenas, ou 
principalmente, um conjunto de pontos isolados ou regiões nas imagens de face e os padrões de classificação são extraídos de uma região limitada na imagem. A maioria dos primeiros métodos pertence à categoria de métodos de correspondência estrutural (structural matching), utilizando a largura da cabeça, distância entre os olhos, e dos olhos para a boca, etc. (Kelly, 1971), ou as distâncias e ângulos entre os cantos dos olhos, extremos da boca, narina e queixo (Kanade, 1973). Um outro método desta categoria, um pouco mais recente (Cox et al., 1996), apresentou uma abordagem baseada em mistura de distâncias, onde cada face é representada por 30 distâncias extraídas manualmente.

Template matching foi uma das primeiras tentativas de reconhecer faces considerando regiões locais representadas em templates, em que os pixels da imagem de entrada são selecionados através de um template e comparados utilizando uma métrica adequada, tal como a distância euclidiana. Brunelli e Poggio (1993) selecionaram automaticamente um conjunto de 4 templates de características, isto é, olhos, nariz, boca e a face toda, para todas as faces disponíveis. Dentro de cada template, a região da imagem de entrada é comparada com cada imagem do banco de dados na mesma região através da correlação cruzada normalizada ${ }^{1}$. A decisão do reconhecimento é feita usando a soma das pontuações de correspondência. Um problema do template matching reside na descrição desses templates. Uma vez que o sistema de reconhecimento tem que ser tolerante a certas discrepâncias entre a as imagens de treinamento e as imagens de teste.

Sem descobrir os locais exatos das características faciais, métodos baseados em Modelo Oculto de Markov (HMM - Hidden Markov Model) usam tiras de pixels que cobrem a testa, olhos, nariz, boca e queixo (Samaria e Young, 1994; Nefian e Hayes, 1998). Nefian e Hayes (1998) reportaram um desempenho melhor que Samaria e Young (1994), utilizando coeficientes 2D-DCT (Transformada Discreta de Cosseno - 2D) em vez de tiras de pixels brutos.

Um dos métodos locais mais bem sucedidos é o Elastic Bunch Graph Matching (EBGM) (Wiskott et al., 1997; Okada et al., 1998), que é baseado em Dynamic Link Architecture (DLA) (Buhmann et al., 1990; Lades et al., 1993). Neste método, as faces humanas são descritas usando Gabor wavelets nos componentes faciais (por exemplo: olhos, nariz e boca) (Wiskott et al., 1997). Uma representação de características locais típica consiste de coeficientes wavelet para diferentes escalas e rotações baseados em bases wavelet fixas (chamados jets em Okada et al. (1998)). Esses coeficientes wavelet estimados localmente são robustos para alterações na iluminação, translação, distorção, rotação e escala.

\subsubsection{Métodos Híbridos}

Os métodos híbridos são aqueles que combinam os métodos holísticos e os locais, utilizando tanto as características holísticas quanto as características locais da face. Os fatores chave que influenciam o desempenho dos métodos híbridos incluem, determinar como os métodos devem ser

\footnotetext{
${ }^{1}$ Correlação cruzada é uma medida de similaridade entre dois sinais em função de um atraso aplicado a um deles (Lewis, 1995).
} 
combinados, de modo a preservar as vantagens e evitar as desvantagens individuais de cada um dos métodos. Estes problemas têm estreita relação com os sistemas de classificação múltipla (MCS Multiple Classifier System) (Kittler et al., 1998), e ensemble learning (Zhou et al., 2002) no campo de aprendizado de máquina. Infelizmente, mesmo nestes campos, esses problemas continuam sem solução. Apesar disso, os inúmeros esforços feitos nesta área nos fornecem algumas ideias sobre a resolução destes problemas, que podem ser usadas como diretrizes na concepção de um sistema de reconhecimento facial híbrido (Tan et al., 2006).

As características locais e globais possuem propriedades muito diferentes e são sensíveis a diferentes tipos de variações, como pode ser visto na Tabela 2.1. Desta forma espera-se que elas possam oferecer informações complementares, resultando em melhorias na classificação. Por exemplo, mudanças de iluminação têm mais influência em características locais, enquanto que as mudanças de expressão têm mais impacto sobre as características holísticas. A partir destas observações, conclui-se que métodos híbridos que utilizam tanto características holísticas quanto locais podem ser uma forma eficaz de reduzir a complexidade de classificadores e melhorar a sua capacidade de generalização (Tan et al., 2006).

Tabela 2.1: Comparação entre características locais e holísticas sensíveis a variações. Adaptado de Tan et al. (2006).

\begin{tabular}{ccc}
\hline Fatores de Variação & Características Locais & Características Holísticas \\
\hline Iluminação & Muito sensivel & Sensível \\
Expressão Facial & Pouco sensivel & Sensivel \\
Pose & Sensivel & Muito sensivel \\
Ruídos & Muito sensivel & Sensível \\
Oclusão & Pouco sensivel & Muito sensível \\
\hline
\end{tabular}

Um exemplo de método híbrido é a abordagem modular eigenfaces (Pentland et al., 1994) que utiliza ambas as características: globais (eigenfaces) e locais (eigenfeatures). Em Pentland et al. (1994), foram realizadas melhorias na capacidade do sistema proposto anteriormente (Turk e Pentland, 1991b), onde o conceito de eigenfaces (PCA) pôde ser aplicado para eingenfeatures através da aplicação do PCA em características isoladas da face como, olhos, nariz, boca, etc. $\mathrm{O}$ método foi avaliado utilizando um conjunto limitado de imagens (45 indivíduos, duas imagens por indivíduo, com expressão facial diferente, neutro vs. sorrindo), o desempenho foi medido para eigenfaces, eigenfeatures e para a combinação das duas representações. O eigenfeatures mostrouse melhor que o eigenfaces, enquanto que a combinação dos dois mostrou apenas uma pequena melhora em relação ao eigenfeatures.

\subsection{Redes Neurais Aplicadas ao Reconhecimento Facial}

Uma solução não linear para o problema do reconhecimento facial é dada pelas redes neurais, extensamente utilizadas em problemas de reconhecimento de padrões e readaptada para o reco- 
nhecimento de faces. A ideia básica seria dimensionar a rede com uma entrada para cada pixel da imagem. Contudo, devido às dimensões do modelo, as redes não são treinadas diretamente com as imagens como entrada, pois isto tornaria a rede muito complexa e difícil de treinar. Ao invés disso, a rede recebe como entrada dados processados por alguma técnica de redução de dimensionalidade (Abate et al., 2007).

Uma abordagem para o problema foi proposta por Cottrell e Fleming (1990) utilizando duas redes perceptron de múltiplas camadas (MLP - Multilayer perceptron) com o algoritmo backpropagation, onde a primeira trabalha em modo auto-associativo, extraindo características para a segunda, que realiza a classificação. Embora as redes neurais possam ser usadas para problemas envolvendo muitas imagens, neste trabalho é mostrado que mesmo em "condições favoráveis" a solução proposta por eles não consegue um resultado melhor que o PCA.

Um método totalmente automático de detecção/reconhecimento de faces foi proposto por Lin et al. (1997). Este método utiliza uma rede neural baseada em decisão probabilística (PDBNN Probabilistic Decision-Based Neural Network) e consiste de três módulos: detector de faces, detector de olhos e um reconhecedor de faces. Diferentemente da maioria dos métodos, este método utiliza para o reconhecimento a região da face que contém as sobrancelhas, os olhos e nariz, mas não a boca. A boca não é considerada, pois ela muda muito quando há variações na expressão facial. Desta forma, ela foi desconsiderada com o objetivo de conseguir um método que fosse robusto a variações na expressão. As PDBNNs possuem uma característica única, que é sua estrutura modular. Isto é, para cada classe a ser reconhecida, a PDBNN dedica uma de suas sub-redes para a representação dessa classe. Comparada com a maioria dos sistemas de reconhecimento de multi-classe que usam uma função de discriminação entre quaisquer duas classes, PDBNN tem uma taxa menor de alarmes falsos/rejeição, porque suas funções discriminantes obedecem uma restrição probabilística.

Outros tipos de redes também têm sido utilizados em trabalhos na área, buscando explorar propriedades particulares de cada rede. Por exemplo, a rede neural mapa auto-organizável (SOM - Self-organizing map) é invariante a pequenas alterações na imagem de amostra, enquanto que a rede neural de convolução (CNN - Convolutional Neural Network) fornece invariância parcial com respeito a rotações, translações e escala. Lawrence et al. (2002) apresentaram um sistema que combina uma amostragem local da imagem, uma rede neural SOM e uma rede neural de convolução. Enquanto a rede SOM fornece uma redução de dimensionalidade e invariância a pequenas mudanças nas amostras, a rede neural de convolução providencia invariância parcial a rotações, translações e escala.

Outro trabalho importante foi uma análise com redes MLP realizada por Rizk e Taha (2002), utilizando o algoritmo de treinamento back-propagation, rede neural de Função Base Radial (RBF - Radial Basis Function), e rede neural de Cluster Multicamadas (MCNN - Multilayer Cluster Neural Networks) aplicadas no reconhecimento de faces. As redes neurais foram alimentadas com um vetor característico extraído das imagens através de vários métodos de extração e compressão de dados: transformada discreta de Wavelet (DWT - Discrete Wavelet Transform), transformada 
discreta de Radon (DRT - Discrete Radon Transform), transformada discreta de cosseno (DCT Discrete Cosine Transform) e PCA.

Er et al. (2002) apresentaram um método holístico para o reconhecimento facial, onde as características mais discriminantes são extraídas com PCA e usadas como entrada para uma rede neural RBF. As redes RBF têm bom desempenho para problemas de reconhecimento facial, possuem topologia compacta e o aprendizado é rápido. Além das tarefas tradicionais do reconhecimento facial (identificação e verificação de identidade) as redes neurais já foram utilizadas para diversas outras tarefas como: identificação de gênero (Tamura et al., 1996) e reconhecimento de expressões faciais (Franco e Treves, 2001).

\subsection{Bancos de Dados}

A área de reconhecimento facial é bastante ativa e possui uma grande quantidade de abordagens distintas para a resolução do problema. Desta forma, a avaliação dos métodos propostos é considerada uma tarefa de grande importância (Zhao et al., 2003). Isto motivou muitos pesquisadores a gerar bancos de dados de faces que forneçam as variações necessárias para avaliar os métodos com eficiência (Abate et al., 2007). A Tabela 2.2 apresenta os principais bancos de dados de faces, onde consta o nome do banco, sistema de cor, resolução da imagem, número de pessoas, quantidade de fotos por pessoa e as variações existentes em cada banco.

\subsection{Avaliação}

No reconhecimento de faces e biometria, o desempenho é reportado sobre três tarefas padrões: verificação, identificação em conjunto aberto e identificação em conjunto fechado. Cada tarefa tem sua própria medida de desempenho. Todas as três tarefas estão intimamente relacionadas, com a identificação em conjunto aberto sendo o caso geral.

Para computar o desempenho, são necessários três conjuntos de imagens. O primeiro é a galeria $G$, que contém as amostras conhecidas pelo sistema. Os outros dois são conjuntos de prova, que são amostras apresentadas ao sistema para o reconhecimento. O primeiro conjunto de prova é $P_{G}$, que contém amostras de pessoas que estão na galeria. $\mathrm{O}$ outro conjunto de prova é $P_{N}$, que contém amostras de pessoas que não estão na galeria.

A identificação em conjunto fechado é a medida de desempenho clássica utilizada pela comunidade de reconhecimento de faces, onde é conhecida como identificação; nesse caso a questão básica a ser respondida é: de quem é esse rosto? Esta questão tem sentido para a identificação em conjunto fechado, já que uma amostra do conjunto de prova sempre é alguém na galeria.

$\mathrm{Na}$ identificação em conjunto aberto, a pessoa no conjunto de prova não está necessariamente presente na galeria. A questão básica a ser respondida é: sabe-se de quem é esse rosto? $\mathrm{Na}$ identificação em conjunto aberto, o sistema decide se a pessoa da prova está ou não na galeria. 
Tabela 2.2: Principais bancos de dados de faces.

\begin{tabular}{|c|c|c|c|c|c|}
\hline Nome & RGB/Cinza & Resolução & $\begin{array}{l}\text { Número } \\
\text { de pessoas }\end{array}$ & $\begin{array}{l}\text { Fotos por } \\
\text { pessoa }\end{array}$ & Variações \\
\hline Ar Face Database (Martinez, 2002) & RGB & $576 \times 768$ & 126 & 26 & $\mathrm{i}, \mathrm{e}, \mathrm{o}, \mathrm{t}$ \\
\hline CVL Database (Solina et al., 2003) & RGB & $640 \times 480$ & 114 & 7 & $\mathrm{p}, \mathrm{e}$ \\
\hline $\begin{array}{l}\text { The Yale Face Database B } \\
\text { (Georghiades et al., 2000) }\end{array}$ & Cinza & $640 \times 480$ & 10 & 576 & $\mathrm{p}, \mathrm{i}$ \\
\hline $\begin{array}{l}\text { The Yale Face Database } \\
\text { (Belhumeur et al., 1997) }\end{array}$ & Cinza & $320 \times 243$ & 15 & 11 & $\mathrm{i}, \mathrm{e}$ \\
\hline PIE Database (Sim et al., 2003) & RGB & $640 \times 486$ & 68 & 608 & $\mathrm{p}, \mathrm{i}, \mathrm{e}$ \\
\hline $\begin{array}{l}\text { Olivetti ORL - AT\&T } \\
\text { (Samaria e Harter, 1994) }\end{array}$ & Cinza & $92 \times 112$ & 40 & 10 & \\
\hline $\begin{array}{l}\text { (JAFFE) Database } \\
\text { (Lyons et al., 1998) }\end{array}$ & Cinza & $256 \times 256$ & 10 & 7 & $\mathrm{e}$ \\
\hline $\begin{array}{l}\text { The Human Scan Database } \\
\text { (Jesorsky et al., 2001) }\end{array}$ & Cinza & $384 \times 286$ & 23 & 66 & \\
\hline $\begin{array}{l}\text { The University of Oulu } \\
\text { Physics Based Face Database } \\
\text { (Marszalec et al., 2000) }\end{array}$ & Cinza & $428 \times 569$ & 125 & 16 & $\mathrm{i}$ \\
\hline XM2VTSDB (Messer et al., 1999) & RGB & $576 \times 720$ & 295 & 5 & $\mathrm{p}$ \\
\hline FERET (Phillips et al., 2000) & Cinza e RGB & $256 \times 284$ & 1199 & 12 & $\mathrm{p}, \mathrm{i}, \mathrm{e}, \mathrm{i} / \mathrm{o}, \mathrm{t}$ \\
\hline
\end{tabular}

Variações nas imagens indicadas por: (i) iluminação, (p) pose, (e) expressão, (o) oclusão, (i/o) indoor (ambiente fechado)/outdoor (ao ar livre) e (t) tempo.

Se sim reporta a identidade da pessoa. Quando a galeria é pequena a identificação em conjunto aberto pode ser referida como uma tarefa de lista de assistidos (watch list). A identificação em conjunto aberto ou em conjunto fechado algumas vezes também é chamada de correspondência 1 para muitos, ou 1:N.

Na tarefa de verificação, uma pessoa apresenta uma amostra de dados biométricos a um sistema e reivindica uma identidade. $\mathrm{O}$ sistema tem que decidir se a amostra pertence à identidade reivindicada. Na verificação, a questão básica a ser respondida é: essa pessoa é quem ela diz ser? A verificação também é chamada de autenticação ou correspondência 1 para 1 (Phillips et al., 2011).

\subsubsection{Identificação em conjunto aberto}

$\mathrm{Na}$ identificação em conjunto aberto, um sistema determina se a prova $p_{j}$ corresponde a uma pessoa na galeria $G$. Se é determinado que a prova está na galeria, então o algoritmo identifica a pessoa da prova. 
A galeria $G$ consiste de um conjunto de amostras biométricas $\left\{g_{1}, \ldots, g_{G}\right\}$. Quando uma prova $p_{j}$ é apresentada para o sistema, ela é comparada com todas as amostras da galeria. A comparação entre a prova $p_{j}$ e cada amostra da galeria produz um escore de similaridade $s_{i j}$. Grandes escores de similaridade indicam que duas amostras são mais similares. A distância entre as amostras pode ser convertida para um escore de similaridade pelo complemento da distância. Um escore de similaridade $s_{i j}$ é um escore de correspondência (match score) se $g_{i}$ e $p_{j}$ são amostras da mesma pessoa e um escore de não correspondência (nonmatch score) se são de pessoas diferentes (Phillips et al., 2011).

Se $p_{j}$ é uma amostra de uma pessoa na galeria, então considere $g^{*}$ sua única correspondência na galeria. $\mathrm{O}$ escore de similaridade entre $p_{j}$ e $g^{*}$ é denotado por $s_{* j}$. A função $i d()$ retorna a identidade da amostra, com $i d\left(p_{j}\right)=i d\left(g^{*}\right)$. Para identificação, todos os escores de similaridade entre a prova $p_{j}$ e uma galeria são examinados e ordenados. A prova $p_{j}$ tem rank $n$ se $s_{* j}$ é o $n$-ésimo maior escore de correspondência. Isto é denotado por $\operatorname{rank}\left(p_{j}\right)=n$. $\mathrm{O}$ rank 1 algumas vezes é chamado de correspondência do topo (top match) (Phillips et al., 2011).

O desempenho para a identificação em conjunto aberto é caracterizado por duas estatísticas de desempenho: taxa de identificação e taxa de alarme falso. Primeiramente, será abordado o caso em que a identidade da prova é alguém na galeria, isto é, $p_{j} \in P_{G}$. Uma prova é identificada se sua correspondência está correta e o escore de correspondência está acima de um limiar operacional $\tau$. Estas condições formalmente correspondem a:

- $\operatorname{rank}\left(p_{j}\right)=1 \mathrm{e}$

- $s_{* j} \geq \tau$ onde $i d\left(p_{j}\right)=i d\left(g^{*}\right)$,

para o limiar operacional $\tau$. A taxa de identificação é a fração das provas em $P_{G}$ que são corretamente identificadas. A taxa de identificação no limiar $\tau$ é (Phillips et al., 2011)

$$
P_{D I}(\tau, 1)=\frac{\mid\left\{p_{j}: p_{j} \in P_{G}, \operatorname{rank}\left(p_{j}\right)=1, \text { e } s_{* j} \geq \tau\right\} \mid}{\left|P_{G}\right|} .
$$

A segunda estatística de desempenho é a taxa de alarme falso. A taxa de alarme falso fornece uma estatística de desempenho quando uma prova não é alguém na galeria, isto é, $p_{j} \in P_{N}$. Este tipo de prova também é referenciada como impostor. Um alarme falso ocorre quando o escore de correspondência do topo para um impostor está acima de um limiar operacional. Formalmente, um alarme falso ocorre quando

$$
\max _{i} s_{i j} \geq \tau
$$

A taxa de alarme falso é a fração de provas em $p_{j} \in P_{N}$ que são alarmes. Isto é computado por

$$
P_{F A}(\tau)=\frac{\left|\left\{p_{j}: p_{j} \in P_{N}, \max _{i} s_{i j} \geq \tau\right\}\right|}{\left|P_{N}\right|}
$$


O sistema ideal deve ter uma taxa de identificação de 1.0 e uma taxa de alarme falso de 0.0 , ou seja, todas as pessoas na prova são identificadas e não existem alarmes falsos. Entretanto, nos sistemas do mundo real há uma relação de compromisso entre a taxas de identificação e alarme falso. Alterando o limiar operacional, as taxas de desempenho também mudam. Aumentando o limiar de ambas as taxas, identificação e alarme falso diminuem. As duas taxas não podem ser otimizadas simultaneamente, pois existe uma relação de compromisso entre elas. Essa relação é mostrada por uma curva ROC (Receiver Operating Characteristic) (Phillips et al., 2003). Um exemplo de uma curva ROC é mostrado na Figura 2.4, em que o eixo horizontal é a taxa de alarmes falsos e o eixo vertical é a taxa de identificação.

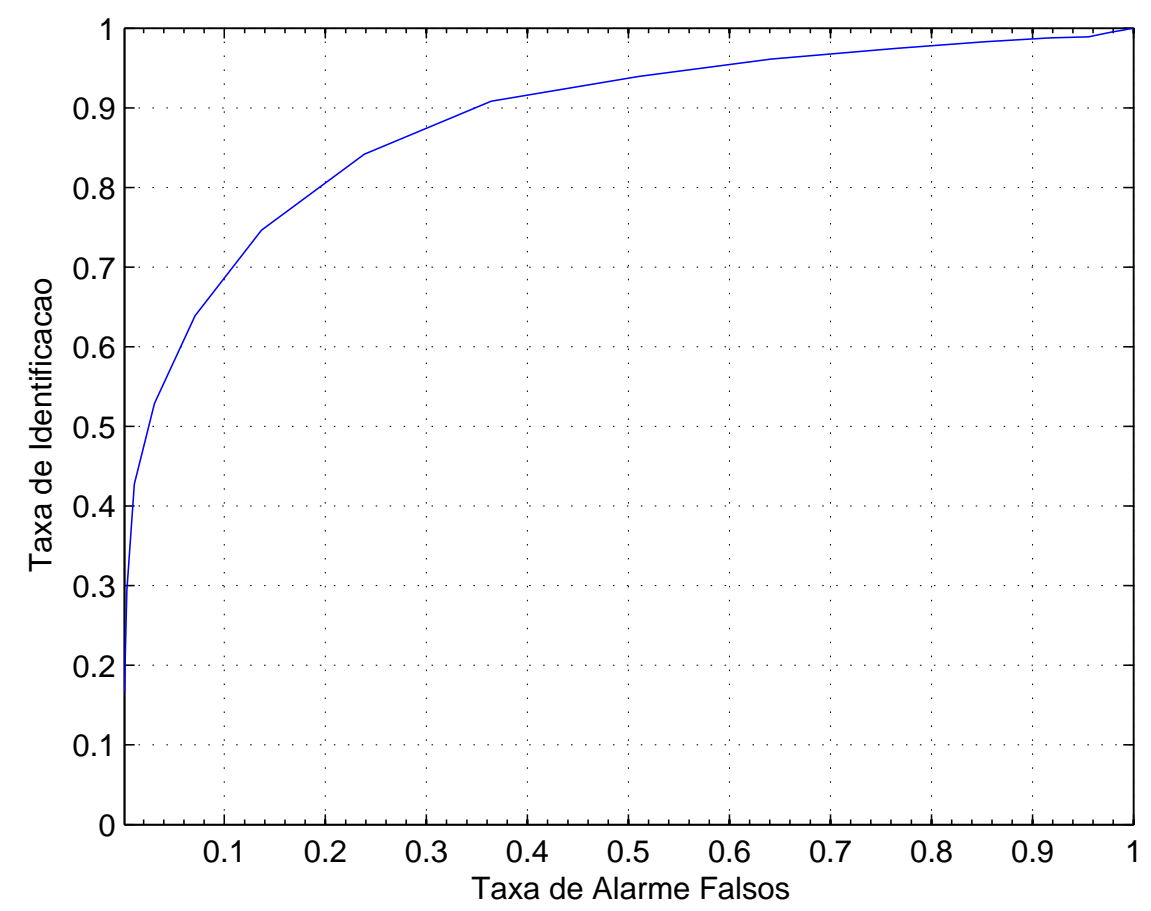

Figura 2.4: Desempenho de um sistema na identificação de conjunto aberto, reportado em uma curva ROC.

Em um caso geral de identificação em conjunto aberto, um sistema examina as $n$ primeiras correspondências entre uma prova e uma galeria. Uma prova de uma pessoa na galeria é identificada no rank $n$ se a prova é do rank $n$ ou menor e a correspondência correta está acima do limiar operacional. Esta condição formalmente corresponde a:

- $\operatorname{rank}\left(p_{j}\right) \leq n \mathrm{e}$

- $s_{* j} \geq \tau$ onde $i d\left(p_{j}\right)=i d\left(g^{*}\right)$.

A taxa de identificação no rank $n$ é a fração das provas em $P_{G}$ que são corretamente identificadas no rank $n$. A taxa de identificação no rank $n$ e limiar $\tau$ é 


$$
P_{D I}(\tau, n)=\frac{\mid\left\{p_{j}: p_{j} \in P_{G}, \operatorname{rank}\left(p_{j}\right) \leq n, \text { e } s_{* j} \geq \tau\right\} \mid}{\left|P_{G}\right|}
$$

A computação da $P_{F A}(\tau)$ no rank $n$ é a mesma do rank 1 .

O desempenho geral da identificação em conjunto aberto pode ser plotado em três eixos: identificação, alarme falso e rank. A performance do sistema é representada como uma superfície neste espaço de parâmetros tri-dimensional. No entanto, em vez de plotar o desempenho completo como uma superfície, usualmente o desempenho é plotado como porções bi-dimensionais (Phillips et al., 2011). Um exemplo é a Figura 2.4 que considera o rank igual a 1, e a relação de compromisso entre as taxas de identificação e alarme falso é mostrada.

\subsubsection{Verificação}

O processo de verificação ocorre da seguinte forma: uma pessoa apresenta sua amostra biométrica para o sistema e reivindica ser uma pessoa na galeria. A amostra biométrica apresentada é uma prova. O sistema então compara a prova com a amostra biométrica da pessoa na galeria, e esta comparação produz um escore de similaridade. O sistema aceita a identidade reivindicada se o escore de similaridade for maior que o limiar operacional do sistema. Caso contrário o sistema rejeita a identidade reivindicada. O limiar operacional é determinado pela aplicação, e aplicações diferentes devem ter limiares operacionais diferentes (Phillips et al., 2011).

Existem dois protocolos padrão para computar o desempenho de verificação. O primeiro é o método round robin. No protocolo round robin, ambos os conjuntos de prova $P_{G}$ e $P_{N}$ são o mesmo conjunto e serão referenciados como conjunto de prova $P$. Todos os escores entre a galeria e o conjunto de prova são computados. Todos os escores de correspondência entre a galeria e o conjunto de prova são usados para computar a taxa de verificação, e todos os escores de não correspondência são usados para computar a taxa de alarmes falsos. Formalmente, para o método round robin, a taxa de verificação é computada por

$$
P_{V}(\tau)=\frac{\left|\left\{p_{j}: s_{i j} \geq \tau, i d\left(g_{i}\right)=i d\left(p_{j}\right)\right\}\right|}{|P|}
$$

e a taxa de alarme falso é computada por

$$
P_{F A}(\tau)=\frac{\left|\left\{s_{i j}: s_{i j} \geq \tau, i d\left(g_{i}\right) \neq i d\left(p_{j}\right)\right\}\right|}{(|P|-1)|G|}
$$

Uma queixa com o protocolo round robin é que as provas são usadas para gerar ambas as taxas, verificação e alarme falsos. Há uma preocupação de que isso não modele adequadamente a situação em que as reivindicações de identidade falsas são geradas por pessoas que não estão na galeria. O protocolo "impostor verdadeiro" resolve esta preocupação. No protocolo impostor verdadeiro, o desempenho é computado a partir dos conjuntos de prova, $P_{G}$ e $P_{N}$. A taxa de verificação é computada a partir dos escores de correspondência entre a galeria e $P_{G}$. A taxa de 
alarme falso é computada a partir de todos escores de não correspondência entre a galeria e $P_{N}$. Estes escores de não correspondência são chamados de impostores verdadeiros, porque as pessoas em $P_{N}$ não estão na galeria. O número de escores de não correspondência é $\left|P_{N}\right||G|$ (Phillips et al., 2011). Formalmente, para o método impostor verdadeiro, a taxa de verificação é computada por

$$
P_{V}(\tau)=\frac{\left|\left\{p_{j}: p_{j} \in P_{G}, s_{i j} \geq \tau, i d\left(g_{i}\right)=i d\left(p_{j}\right)\right\}\right|}{\left|P_{G}\right|}
$$

e a taxa de alarme falso é computada por

$$
P_{F A}(\tau)=\frac{\left|\left\{s_{i j}: p_{j} \in P_{N}, s_{i j} \geq \tau\right\}\right|}{\left|P_{N}\right||G|} .
$$

\subsubsection{Identificação em conjunto fechado}

O desempenho da identificação em conjunto fechado é uma medida de desempenho clássica em trabalhos de reconhecimento de faces. Na identificação em conjunto fechado, a questão não é sempre "a primeira correspondência está correta?", mas sim "alguma das $n$ primeiras correspondências está correta?".

O primeiro passo na computação do desempenho em conjunto fechado é ordenar os escores de similaridades entre $p_{j}$ e a galeria $G$, e computar o $\operatorname{rank}\left(p_{j}\right)$. A taxa de identificação para o rank $n$, $P_{1}(n)$, é a fração das provas no rank $n$ ou menor. Para o rank $n$, considere

$$
C(n)=\left|\left\{p_{j}: \operatorname{rank}\left(p_{j}\right) \leq n\right\}\right|,
$$

sendo a contagem cumulativa de números de provas de rank $n$ ou menor. A taxa de identificação no rank $n$ é

$$
P_{1}(n)=\frac{|C(n)|}{\left|P_{G}\right|}
$$

As funções $C(n)$ e $P_{1}(n)$ são não decrescentes em $n$. A taxa de identificação no rank 1 , $P_{1}(n)$, é também chamada de taxa de identificação correta, ou taxa de correspondência do topo. $\mathrm{O}$ desempenho da identificação em conjunto fechado é reportado em um CMC (Cumulative Match Characteristic). Um CMC plota $P_{1}(n)$ como uma função de rank $n$ (Phillips et al., 2003). A Figura 2.5, mostra um CMC. O eixo horizontal é o rank e o eixo vertical é $P_{1}(n)$.

O desempenho da identificação em conjunto fechado é na maioria das vezes resumido com o desempenho para o rank 1 . Outros pontos também são comumente usados, como os ranks 5, 10 ou 20.

A identificação em conjunto fechado é um caso especial da identificação em conjunto aberto onde o conjunto de prova $P_{N}$ está vazio e o limiar operacional $\tau=-\infty$. Um limiar operacional 


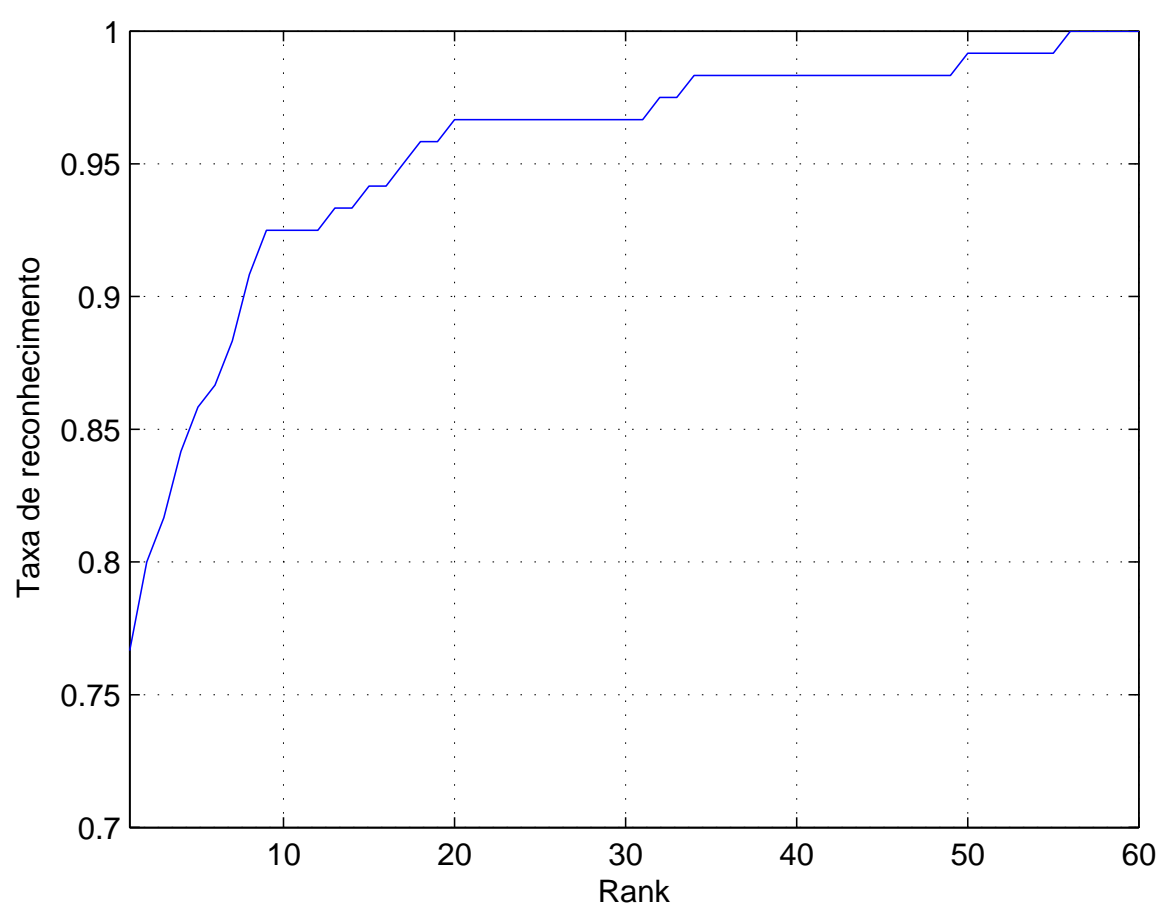

Figura 2.5: Desempenho de um sistema na identificação de conjunto fechado, reportado em uma curva CMC.

de $\tau=-\infty$ corresponde a uma taxa de alarme falso de 1.0. Isto significa que $s_{* j} \geq \tau$ para todos escores de correspondência e todos escores são reportados como alarmes. Assim, para qualquer $n$, $P_{D I}(-\infty, n)=P_{I}(n)$ (Phillips et al., 2011).

\subsection{O problema em mensurar os resultados}

No reconhecimento de faces, assim como em outras tarefas, definir o estado da arte não é algo trivial. Durante todos os anos de pesquisas sobre o tema houve grandes avanços na área e muitas pesquisas mostram resultados significativos. O problema está em mensurar estes resultados e comparar os métodos, sendo que não há um padrão oficial amplamente adotado para as avaliações. Em Phillips et al. (1998), este problema foi levantado, e com o objetivo de avaliar de forma eficiente os métodos é proposta uma metodologia de avaliação que consiste de duas partes, um banco de dados de faces e um programa de testes. Esse projeto, além da metodologia em si, realiza a avaliação de diversos métodos, em que os melhores resultados foram alcançados por algoritmos baseados em Análise Probabilística de Subespaço, LDA e EGM.

Apesar do trabalho realizado em Phillips et al. (1998) ter grande valor, ainda assim esta metodologia de avaliação não foi adotada como método de avaliação padrão para área. Um dos possíveis motivos seriam as limitações existentes, tanto no banco de dados de faces, quanto na metodologia de avaliação. $\mathrm{O}$ banco possui limitações em relação às variações e cenários disponíveis, sendo que no reconhecimento de faces há uma grande quantidade de cenários possíveis e seria praticamente 
impossível um banco de dados atender a todos. Outra limitação é em relação ao protolo de avaliação proposto, que limita o uso de apenas uma imagem por pessoa para o treinamento dos métodos. Isto limita alguns métodos, em que o funcionamento depende, ou é otimizado, com o uso de várias imagens por classe para o treinamento.

Para contornar a dificuldade em comparar métodos de reconhecimento de faces, a maioria dos pesquisadores realizam as avaliações de seus métodos replicando os mesmos testes para outros métodos de reconhecimentos de faces. Na grande maioria das vezes, são utilizados os métodos Eigenfaces (baseado em PCA) e Fisherfaces (baseado em LDA), pois estes métodos são pioneiros, de fácil implementação, e geralmente alcançam bons resultados. Contudo, ainda há uma grande dificuldade em identificar o estado da arte, pois devido ao grande número de cenários possíveis é difícil definir um método como melhor, sendo que cada método pode se comportar melhor em um determinado cenário.

\subsection{Direções para Pesquisas Futuras}

Atualmente, existem diversas aplicações bem sucedidas de reconhecimento de faces. No entanto, ainda há muito a ser explorado. Abaixo são listados alguns segmentos do reconhecimento de faces ainda pouco explorados:

- Reconhecimento de faces a longas distâncias - A maioria dos algoritmos e sistemas de reconhecimento de faces existentes são efetivos apenas quando as imagens dos rostos estão a uma pequena distância (algumas dezenas de metros no máximo) da câmera. Estendendo a distância em que o reconhecimento de faces pode ser eficaz daria um novo impulso a aplicações em sistemas de segurança (Chellappa et al., 2010).

- Reconhecimento de faces baseado em vídeo - Esta aplicação é particularmente útil em cenários de vigilância em que não seja possível capturar um único bom frame, necessário na maioria dos métodos de reconhecimento de faces baseados em imagens fixas. Neste tipo de reconhecimento, é necessário abordagens robustas que explorem as sequências de vídeos. Nesse sentido, existem ainda alguns problemas a serem resolvidos como Tracking em tempo real, normalização de pose em faces em movimento, normalização de iluminação e compensação para imagens de baixa resolução (Chellappa et al., 2009).

- Reconhecimento de faces em redes multicâmera - Redes multicâmera são uma solução cada vez mais comuns para problemas de vigilância em áreas amplas. Ter várias câmeras adquirindo várias imagens de uma face, pode ajudar a construir uma representação de faces mais robusta. Entretanto, para utilizar as informações de vários pontos de vista, é necessário estimar a posição da cabeça do indivíduo. Porém solucionar este problema pode ser difícil principalmente quando a resolução da imagem é baixa ou o indivíduo está muito longe da 
câmera. Existem também outros problemas como multiview tracking ${ }^{2}$, criar uma representação apropriada para as imagens de faces de vários pontos de vista e reconhecimento de faces a partir de vários pontos de vista (Taj e Cavallaro, 2010; Zervos, 2013).

- Reconhecimento de faces na web 2.0 - Nos últimos anos, módulos de reconhecimento de faces vêm sendo utilizados em várias aplicações, como Facebook, Google's Picasa e iPhoto. Estes modulos são programados para reconhecer pessoas nos albuns de fotos dos usuários. Eles também permitem que o usuário corrija possíveis erros de classificação. $\mathrm{O}$ feedback pode ser utilizado para melhorar o algoritmo, pois aponta rapidamente os pontos onde há falhas para que possam ser melhorados. Uma outra forma de usar o feedback dos usuários é em algoritmos que aprendem por reforço. Assim, o usuário se torna um tipo de supervisor que contribui para o aprendizado do algoritmo. Os problemas encontrados nesse tipo de aplicação em geral são os mesmo que acontecem no reconhecimento de faces com multicâmeras, além de alguns aspectos únicos, como o problema de possíveis erros de usuários ao rotularem uma foto (Chellappa et al., 2010; Choi et al., 2011).

- Reconhecimento de faces utilizando contexto - Alguns métodos de reconhecimento de faces estão utilizando, além das informação da imagem da face, informações de contexto que possam ser úteis para aumentar o taxa de acerto. Em Davis et al. (2005), foram utilizadas informações de contexto para o reconhecimento de faces em fotos tiradas do celular. Dentre as informações utilizadas, estão a localização, horário e dia da semana. Outro exemplo são as informações de contextos disponíveis pelas redes sociais, como o Facebook e GooglePlus (Stone et al., 2010).

\subsection{Considerações finais}

Neste capítulo foi revisada a importância do reconhecimento facial como método biométrico e suas vantagens sobre os demais métodos. Foram apresentados os passos do reconhecimento facial: detecção facial, extração de características e classificação e as técnicas utilizadas em cada passo. Também foram abordados os principais bancos de faces utilizados, mostrando informações importantes sobre cada um deles. Na sequência foi abordado a avaliação dos métodos, em que o desempenho é reportado sobre três tarefas padrão: identificação em conjunto aberto, identificação em conjunto fechado e verificação, e foi descrita como é feita a avaliação para cada uma das três tarefas. Por fim, foi discutido o estado da arte e as direções para pesquisas futuras.

\footnotetext{
${ }^{2}$ Multiview tracking combina dados de diferentes câmeras para estimar a evolução temporal de objetos em uma área monitorada (Taj e Cavallaro, 2010).
} 

Este capítulo apresenta uma visão geral dos conjuntos K. É apresentada a hierarquia dos conjuntos, detalhando a estrutura e funcionalidades de cada elemento. Também é discutida a utilização do conjunto KIII como memória, os tipos de aprendizados utilizados e a aplicação no reconhecimento de faces.

\subsection{Visão Geral dos Conjuntos K}

Os conjuntos K de Freeman são uma família de componentes de complexidade crescente, que possuem estrutura e comportamento fortemente inspirados em modelos neurais biológicos. São modelos mesoscópicos que representam um nível intermediário entre os neurônios microscópicos e as estruturas macroscópicas do cérebro (Kozma, 2008; Erwin e Freeman, 2008). Os conjuntos foram introduzidos pelo neurocientista Walter J. Freeman na década de 1970 (Freeman, 1975) e ganharam destaque desde a virada do século (Chang et al., 1998; Freeman et al., 2001; Kozma e Freeman, 2001; Li et al., 2005). Foram concebidos a partir de observações sobre o sistema olfatório de animais através de eletroencefalogramas (EEG) (Freeman, 1975; Erwin e Freeman, 2008). $\mathrm{O}$ nome dos conjuntos (K) foi escolhido como homenagem ao físico Aharon Katzir-Katchalsky, pioneiro em neurodinâmica, cujas pesquisas tiveram grande influência no trabalho de Freeman (Erwin e Freeman, 2008).

Os conjuntos $\mathrm{K}$ fazem parte da quarta geração do conexionismo, de acordo com a categorização proposta em Clark (2001) e estendida em Kozma et al. (2007). A quarta geração do conexionismo é uma abordagem dinâmica para a inteligência, que engloba modelos mais complexos de compor- 
tamento caótico e dinâmico, concebidos graças aos avanços em análises de EEG (Kozma et al., 2007; Kozma, 2008).

Os conjuntos $\mathrm{K}$ possuem comportamento dinâmico que permite uma melhor generalização e tolerância a erros (Li e Kozma, 2003), além da capacidade de generalizar em ambientes complexos, ruidosos e com poucos exemplos (Kozma et al., 2007; Li e Kozma, 2003). Outras vantagens dos conjuntos $\mathrm{K}$ em relação às redes neurais tradicionais são o pequeno número de exemplos necessários para o treinamento e a convergência em um único passo (Erwin e Freeman, 2008). A principal desvantagem apresentada pelos conjuntos-K é o desempenho computacional, porém existem algumas pesquisas (Chang et al., 1998; Principe et al., 2001), que propõem algumas soluções interessantes para esse problema.

Devido ao seu comportamento dinâmico, os conjuntos K costumam produzir melhores resultados em ambientes caóticos, complexos, ruidosos ou com poucos exemplos, onde outras técnicas normalmente não conseguem bons resultados. Os conjuntos $\mathrm{K}$ têm sido utilizados com sucesso em diversas aplicações, como predição de séries temporais (Li e Kozma, 2003), reconhecimento de caracteres (Wang et al., 2005), reconhecimento de padrões complexos (Xiaomin et al., 2010) e reconhecimento de faces (Zhang et al., 2005, 2006; Carlos Jr. e Rosa, 2014).

A família dos conjuntos $\mathrm{K}$ é composta pelos conjuntos KO, KI, KII, KIII, KIV, KV e KVI. Cada um deles tem por objetivo modelar uma parte do cérebro (Li e Kozma, 2003). A Tabela 3.1 mostra os quatro primeiros elementos dos conjuntos $\mathrm{K}$ e suas respectivas funcionalidades.

Tabela 3.1: Hierarquia dos modelos K. Adaptado de Kozma e Freeman (2003).

\begin{tabular}{|c|c|c|c|}
\hline Elemento & Estrutura & Dinâmicas inerentes & Exemplos no cérebro* \\
\hline $\mathrm{KO}$ & Unidade única & Função de entrada/saída não linear & Compõe todos os níveis superiores \\
\hline $\mathrm{KI}$ & $\begin{array}{l}\text { Populações de unidades } \\
\text { excitatórias ou inibitória }\end{array}$ & $\begin{array}{l}\text { Convergência para um ponto fixo } \\
\text { zero ou não zero }\end{array}$ & PG, DG, BG, BS \\
\hline KII & $\begin{array}{l}\text { Interação de populações de } \\
\text { unidades Excitatórias ou inibitórias }\end{array}$ & Periódico, oscilações de ciclo limite & $\begin{array}{l}\text { OB, AON, PC, CA1, CA2, CA3, HT, BG, } \\
\text { BS, Amígdala }\end{array}$ \\
\hline KIII & Interação de modelos KII & Aperiódico, oscilações caóticas & Córtex, Hipocampo, Prosencéfalo medial \\
\hline KIV & Interação de modelos KIII & $\begin{array}{l}\text { Dinâmicas espaço-temporais } \\
\text { com transições de fase global } \\
\text { (itinerância) }\end{array}$ & $\begin{array}{l}\text { Cooperação hemisférica do Córtex, } \\
\text { Hipocampo, Prosencéfalo medial, } \\
\text { coordenados pela Amígdala }\end{array}$ \\
\hline
\end{tabular}

*Siglas: PG - Periglomerular; OB - Bulbo Olfatório; AON - Núcleo Olfatório Anterior; PC - Córtex pré-piriforme; DG - giro dentado; CA1, CA2, CA3 - Cornu Ammonis; BG - Gânglios Basais; HT - Hipotálamo; DB - Banda Diagonal de Broca; SP - Septo;

As dinâmicas inerentes dos conjuntos-K estão estritamente relacionadas à teoria dos sistemas dinâmicos. Dessa forma, para um melhor entendimento dos conjuntos-K, a próxima seção mostra uma breve revisão sobre sistemas dinâmicos.

\subsection{Sistemas Dinâmicos}

Um sistema dinâmico consiste de um conjunto de estados possíveis e uma regra da evolução desses estados em relação ao tempo (Alligood et al., 1997). Todos os possíveis estados de um 
sistema são caracterizados por pontos de um conjunto $X$, sendo que este conjunto é chamado de espaço de estados do sistema. A especificação de um ponto $x \in X$ além de descrever a posição atual do sistema deve ser suficiente para determinar a evolução do mesmo. A evolução de um sistema dinâmico significa uma alteração no estado do sistema com $t \in T$, onde $T$ é um conjunto numérico. Se o conjunto de tempo $T=\mathbb{R}^{1}$ o sistema é dito de tempo-contínuo e se $T=\mathbb{Z}$ é um sistema de tempo-discreto.

O principal componente de um sistema dinâmico é a regra que determina o estado $x_{t}$ do sistema no tempo $t$, desde que se conheça o estado inicial $x_{0}$. O modo mais genérico de especificar a evolução é assumir que para dado $t \in T$ um mapa $\varphi^{t}$ é definido no espaço de estados $X$,

$$
\varphi^{t}: X \rightarrow X
$$

que transforma o estado inicial $x_{0} \in X$ em algum estado $x_{t} \in X$ no tempo $t$ :

$$
x_{t}=\varphi^{t} x_{0}
$$

O mapa $\varphi^{t}$ é frequentemente chamado de operador evolutivo. Finalmente, tem-se a definição formal de um sistema dinâmico dado pela tríplice $\left\{T, X, \varphi^{t}\right\}$, onde $T$ é o conjunto de tempo, $X$ é o espaço de estados e $\varphi^{t}: X \rightarrow X$ é uma família de operadores evolutivos parametrizados por $t \in T$ (Kuznetsov, 1998).

A maneira mais comum para descrever um sistema dinâmico de tempo contínuo é por meio de uma equação diferencial. Considere que $x_{1}(t), x_{2}(t), \ldots, x_{N}(t)$ descrevam as variáveis de estados de um sistema dinâmico não linear, onde o tempo contínuo $t$ é uma variável independente e $N$ é a ordem do sistema. As dinâmicas do sistema dinâmico podem ser convertidas na forma de um sistema de equações diferenciais de primeira ordem, descritas da seguinte forma:

$$
\frac{d}{d t} x_{j}(t)=f_{j}\left(x_{j}(t)\right), j=1,2, \ldots, N
$$

onde a função $f_{j}($.) geralmente é uma função não linear de seus argumentos. Um sistema dinâmico em que a função $f$ não dependa explicitamente de $t$ é dito autônomo, e chamado de não autônomo caso contrário. Independente da forma da função $f$, o estado $x(t)$ deve variar com o tempo $t$, de outra forma este seria constante, descaracterizando-o como sistema dinâmico (Haykin, 1999).

Para facilitar o entendimento de um sistema dinâmico, este pode ser observado de um ponto de vista geométrico. Por exemplo, um estado observado no instante $t$ pode ser representado como um ponto no espaço de estados $X$. Enquanto que mudanças no estado com o tempo $t$ são representadas por uma curva no espaço de estados. Esta curva é chamada de órbita ou trajetória (Kuznetsov, 1998; Haykin, 1999).

Um sistema dinâmico pode ter um ou mais pontos fixos, um ponto $p$ é considerado um ponto fixo se $f(p)=p$. Se todos os pontos suficientemente pertos de $p$ são atraídos para ele, $p$ recebe o nome de sumidouro ou atrator de ponto fixo. Por outro lado, se todos os pontos suficientemente 
próximos de $p$ são repelidos, $p$ é chamado de fonte ou repelente de ponto fixo (Alligood et al., 1997; Haykin, 1999).

É comum um sistema dinâmico apresentar um comportamento cíclico, em que uma órbita retorne a um ponto $p$ depois de passar por $k$ pontos. Quando isto ocorre, ou seja $f^{k}(p)=p$, este ponto $p$ é chamado de ponto de período $\mathrm{k}$ e a órbita de $k$ pontos com o ponto inicial $p$ é chamada de órbita de período k. Se $p$ for um sumidouro, a órbita é chamada sumidouro periódico ou atrator de ciclo limite, e é chamada de fonte periódica caso $p$ seja fonte (Alligood et al., 1997).

Além dos atratores de ponto fixo e ciclo limite, existem os atratores de toro e os atratores estranhos. Os atratores de toro possuem uma dinâmica quase-periódica, formada por ciclos quase periódicos, que aproximam-se da órbita mas nunca a repetem exatamente. Estes atratores são constituídos por um círculo em espiral, e sua forma é similar a uma rosquinha (Kuznetsov, 1998). Os atratores estranhos são aqueles que possuem uma estrutura fractal. Estes atratores apresentam a característica de extrema sensibilidade às condições iniciais, gerando uma instabilidade que os torna imprevisíveis a longo prazo. Esta dinâmica é chamada de caos determinístico, um tipo de dinâmica determinística com aparência de aleatória (Leiber, 1997; Werndl, 2009).

\subsection{Conjuntos KO, KI e KII}

$\mathrm{O}$ conjunto $\mathrm{KO}$ é a estrutura mais simples na hierarquia dos conjuntos $\mathrm{K}$ e o elemento básico necessário para a construção de todos os outros níveis superiores (Principe et al., 2001). O KO representa uma coleção de neurônios que não interagem entre si e possuem entradas e saídas comuns. Cada KO representa uma população com cerca de 10.000 neurônios (Freeman, 1975; Erwin e Freeman, 2008). Apesar de cada KO representar vários neurônios, uma unidade KO tem apenas uma entrada e uma saída. Desta forma, um KO é análogo a um único neurônio em uma rede neural artificial tradicional como a multilayer perceptron (MLP). A dinâmica do KO é descrita pela seguinte equação diferencial ordinária de segunda ordem (ODE):

$$
\frac{1}{a b}\left[\frac{d^{2} x_{i}(t)}{d^{2} t}+(a+b) \frac{d x_{i}(t)}{d t}+a b x_{i}(t)\right]=f(t)
$$

onde $a=0.22$ e $b=0.72$, são constantes de tempo biologicamente determinadas e $x_{i}$ é a ativação da $i$-ésima população de neurônios. A entrada do KO é dada por:

$$
f(t)=\sum_{j \neq i}^{N}\left[W_{i j} \times Q\left(x_{j}(t), q\right)\right]+I_{i}(t)
$$

onde $\mathrm{N}$ é o número de populações, $\mathrm{W}$ é o vetor de pesos representando a conexão entre as populações $i$ e $j, t$ é o tempo, $I$ é estímulo externo. $Q(x(t), q)$ é a função sigmoide que modela a transformação entre ondas e pulsos nas ativações dos neurônios e é dada por: 


$$
Q(x(t), q)= \begin{cases}q\left(1-e^{-\left(e^{x(t)}-1\right) / q}\right), & x(t)>x_{0} \\ -1, & x(t)<x_{0}\end{cases}
$$

$$
x_{0}=\ln (1-q \ln (1+1 / q))
$$

onde $q$ é uma constante, usualmente $q=5$. Esse parâmetro especifica a inclinação e a assíntota máxima da curva. Esta função sigmoide foi modelada a partir de experimentos sobre a ativação neural biológica (Freeman, 1975).

O conjunto KI é formado por pelo menos dois $\mathrm{KO}$ conectados através de conexões excitatórias ou inibitórias. Ele representa a interação entre populações de neurônios com a mesma polaridade. Possui feedback positivo, sendo capaz de segurar um impulso de entrada por mais tempo. A dinâmica do KI é descrita como a convergência para um ponto fixo diferente de zero (Kozma et al., 2007).

O conjunto KII é formado por pelo menos dois KIs ou quatro KOs interconectados, e possui quatro tipos de interações: excitatória-excitatória, inibitória-inibitória, excitatória-inibitória e inibitória-excitatória (Kozma et al., 2007). O KII modela a interação entre populações de neurônios de polaridades opostas através de feedback negativo, formando osciladores. As oscilações geradas pelos KII são governadas por um atrator ciclo limite (Erwin e Freeman, 2008). A Figura 3.1 mostra os conjuntos KO, KI e KII e sua resposta a uma pequena pertubação.

a) $\mathrm{KO}$
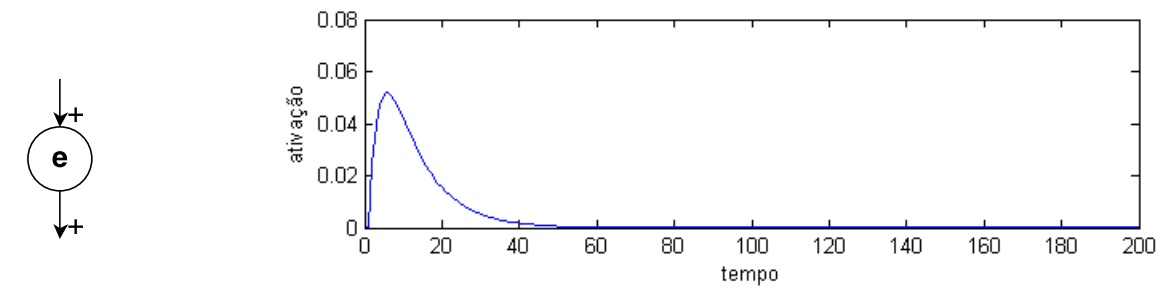

b) $\mathrm{KI}$
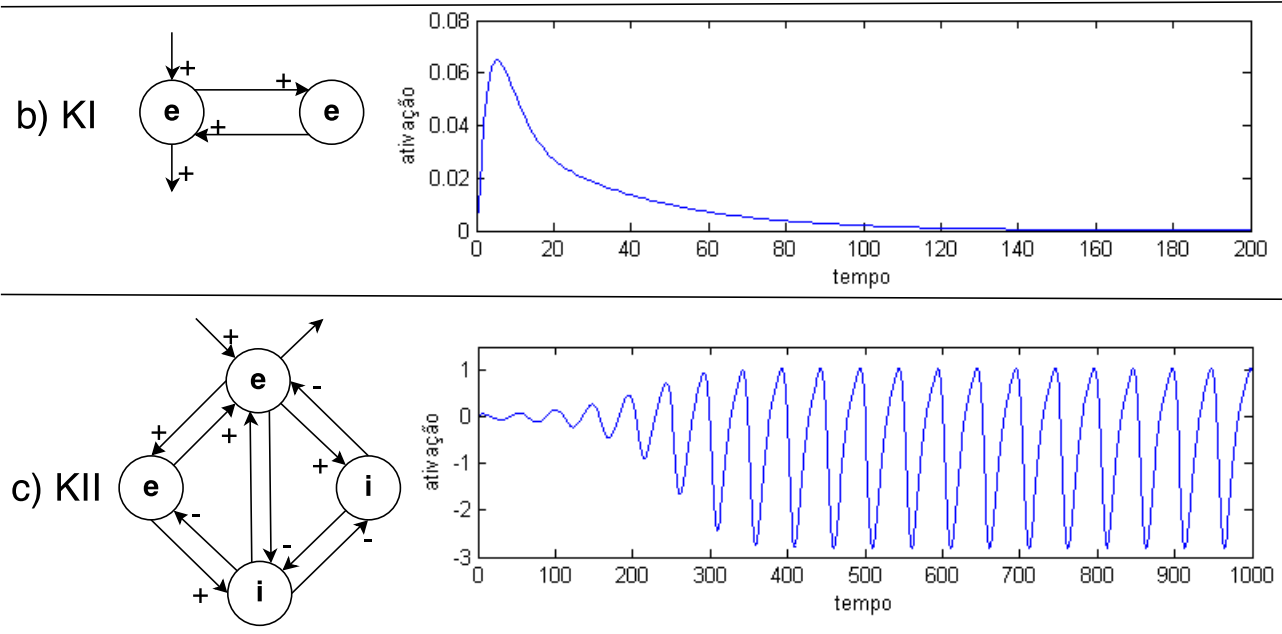

Figura 3.1: Diagrama dos conjuntos KO, KI e KII, e sua resposta a um impulso. 


\subsection{O conjunto KIII}

O conjunto KIII é composto por três camadas de KII, e descreve um determinado sistema sensorial do cérebro como olfatório, visual, auditivo e somatossensorial. A primeira camada representa o bulbo olfatório (OB), que é modelado por uma rede de KII de tamanho $N$, onde $N$ é a dimensão de entrada da rede. A segunda e terceira camadas também são formadas por redes de KII de mesmo tamanho, onde a segunda camada representa o núcleo olfatório anterior (AON) e a terceira o córtex pré-piriforme (PC). As três camadas compartilham conexões entre si, conforme pode ser observado na Figura 3.2.

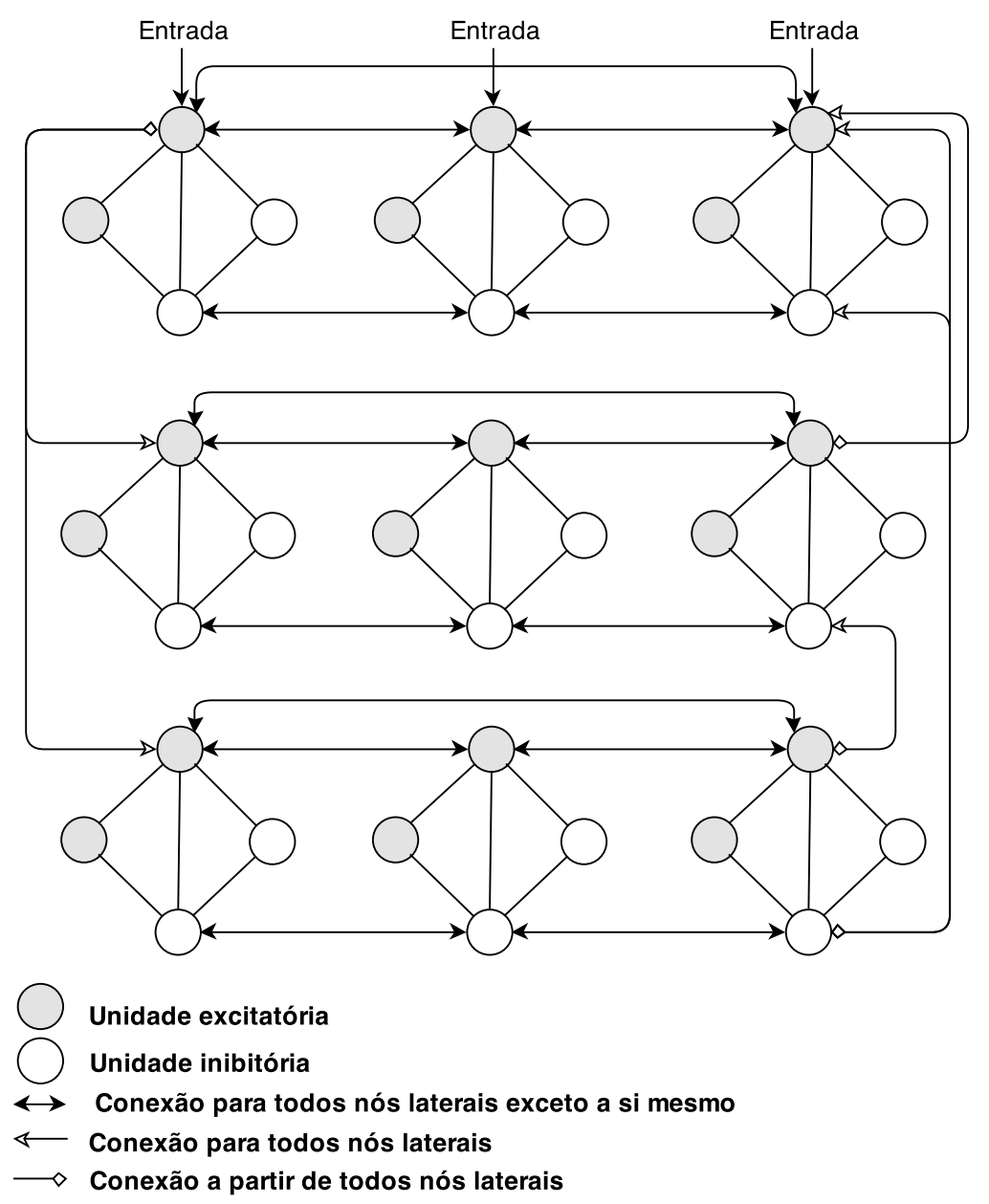

Figura 3.2: Estrutura genérica de um conjunto KIII de três entradas. Adaptado de Beliaev et al. (2005).

O KIII pode apresentar a propriedade de alternar entre múltiplos atratores, indicando a presença de itinerância caótica. Essa dinâmica só surge quando os parâmetros internos estão devidamente ajustados. Os atratores resultantes podem ser alterados e podem aparecer novos atratores no processo de modificação de certos pesos de conexão. Desta forma, o KIII é uma rede neural recorrente que opera em regime não convergente usando algoritmo de aprendizado não-supervisionado, podendo ser utilizado como uma memória associativa que codifica os dados de entrada em padrões 
de oscilações espaço-temporais não convergentes (Chang e Freeman, 1996; Kozma e Freeman, 2001). Comparada com as redes recorrentes convergentes, as memórias caóticas do KIII possuem as seguintes vantagens (Kozma et al., 2007; Kozma, 2008):

1. Produzem memórias robustas baseadas em relativamente poucos exemplos de aprendizagem, mesmo em ambientes ruidosos;

2. A capacidade de codificação de uma rede KIII com um dado número de nós é exponencialmente maior do que uma rede convergente;

3. Recuperam dados armazenados rapidamente, tal como os seres humanos e os animais podem reconhecer um padrão aprendido dentro de uma fração de segundo.

\subsubsection{O conjunto KIII como memória}

Os conjuntos $\mathrm{K}$ foram criados com o objetivo de simular as dinâmicas presentes no cérebro. No entanto, foi demonstrado que eles também podem ser utilizados em tarefas práticas como classificação de padrões (Xiaomin et al., 2010), predição de séries temporais (Beliaev et al., 2005) e agrupamento (Kozma et al., 2013). Nesta seção, será apresentada uma configuração do conjunto KIII adaptado para a tarefa de classificação de padrões.

Considere dois conjuntos de padrões, um de treinamento e um de testes. A aplicação do KIII na classificação de padrões consiste de três etapas: treinamento, rotulação e teste. Na etapa de treinamento, os padrões de treinamento são apresentados um a um. Cada padrão é apresentado sobre um período de tempo chamado período ativo, que geralmente é escolhido entre 50 e 150 milissegundos de tempo simulado. Durante a segunda parte do período ativo, as séries temporais das ativações de cada unidade da camada de saída são registradas e seu desvio padrão é calculado. Portanto, a saída da rede é um vetor de desvios padrão. Este vetor torna-se disponível logo após o final da fase ativa. O sistema entra no período de relaxamento que dura entre 150 e 300 milissegundos. Durante esse período, são realizadas alterações nos pesos das conexões laterais das camadas do KIII através do aprendizado hebbiano. A apresentação repetida dos padrões de treinamento contribui para a formação de padrões de modulação de amplitude complexos.

Na rotulação, os padrões de treinamento são apresentados novamente ao KIII. O vetor de saída obtido é armazenado em uma tabela de referência juntamente com o rótulo da classe correspondente. Assim, a associação entre os padrões de amplitude e as classes é registrada.

$\mathrm{Na}$ fase de testes, um novo padrão é apresentado para o sistema. O vetor de saída é lido e comparado com os vetores armazenados na tabela de referência. Para isto, usualmente é utilizado o algoritmo $k$-vizinhos mais próximos $(k-\mathrm{NN})$. 


\subsubsection{Aprendizado no KIII}

Como visto anteriormente, o funcionamento do KIII é dividido em duas fases: período ativo e período de relaxamento. O aprendizado no KIII ocorre logo após o período ativo e é alcançado através de modificações nos pesos laterais da terceira camada, através do aprendizado hebbiano combinado com habituação (Kozma e Freeman, 2001; Zhang et al., 2006). O aprendizado hebbiano reforça os padrões de estímulos desejados enquanto a habituação diminui o impacto de ruídos de fundo e estímulos que não são relevantes.

Ao apresentar um padrão para o KIII obtem-se na saída o vetor $\vec{\sigma}$, que representa o padrão de modulação de amplitude correspondente a entrada. $\mathrm{O}$ vetor $\vec{\sigma}$ é obtido calculando o $\sigma_{i}$ de todos os nós da terceira camada. Cada nó da terceira camada produz uma série temporal discreta $y_{i j}$, onde $i$ é o índice do nó e $j$ é o índice do passo da simulação. $\mathrm{O} \sigma_{i}$ é o desvio padrão calculado sobre a segunda metade do período ativo da série temporal gerada pelo nó $i$, dado pela seguinte equação (Ilin, 2008):

$$
\sigma_{i}=\sqrt{\frac{1}{T_{2}-T_{1}} \sum_{j=T_{1}}^{T_{2}}\left(y_{i j}-\bar{y}_{i}\right)^{2}}
$$

onde $T_{1}$ e $T_{2}$ são os índices de início e fim da segunda metade do período ativo, e $i$ é executado para todos nós da terceira camada.

$\mathrm{O}$ aprendizado hebbiano utiliza o vetor $\vec{\sigma}$ para realizar os ajustes nos pesos. Considere a conexão entre os nós $p$ e $q$, cujo peso entre os nós é indicado por $W_{p q}$. Este peso é fortalecido se ambos $\sigma_{p}$ e $\sigma_{q}$ estão acima da média, de acordo com a seguinte regra (Ilin, 2008):

$$
\Delta W_{p q}=\left\{\begin{array}{l}
\alpha\left(\sigma_{p}-\bar{\sigma}\right)\left(\sigma_{q}-\bar{\sigma}\right), \quad \text { se } \sigma_{p}>\bar{\sigma} \text { e } \sigma_{q}>\bar{\sigma} \\
0, \text { caso contrário }
\end{array}\right.
$$

onde $\Delta W_{p q}$ é alteração de peso entre os nós $p$ e $q, \alpha$ é a taxa de aprendizagem (que influencia a velocidade do aprendizado) e $\bar{\sigma}$ é modulação de amplitude média, dada por:

$$
\bar{\sigma}=\frac{1}{N} \sum_{i=1}^{N} \sigma_{i}
$$

onde $N$ é número de nós da última camada e $\sigma_{i}$ corresponde a modulação de amplitude para o nó $i$.

A habituação é um processo automático em cada área sensorial primária que serve para evitar estímulos que são irrelevantes, confusos, ambíguos ou indesejados. Ela constitui um filtro adaptativo para reduzir o impacto do ruído do ambiente que é contínuo e não informativo (Kozma e Freeman, 2001). Ela consiste da diminuição lenta dos pesos das conexões, em que a taxa de diminuição é escolhida para ser menor que a taxa de aprendizagem hebbiana, para permitir o cres- 
cimento das conexões afetadas pela regra hebbiana, enquanto que as conexões não afetadas pela regra hebbiana diminuem. A fórmula para a habituação é a seguinte (Ilin, 2008):

$$
\Delta W_{p q}=-W_{p q}(1-H)
$$

onde $H$ é a taxa de habituação, $0 \leq H \leq 1$.

Este é o processo de aprendizagem mais comum utilizado no conjunto KIII. Porém já foram utilizadas outras formas de aprendizagem, como a utilizada em Kozma e Freeman (2001) que propõe o uso de uma terceira etapa, chamada de normalização, após realizado o aprendizado hebbiano e a habituação, ou como o aprendizado hebbiano associativo sem habituação utilizado em Li e Kozma (2003).

\subsubsection{Reconhecimento de Faces utilizando o conjunto KIII}

O conjunto KIII já foi aplicado com sucesso em diversas tarefas como classificação (Chang et al., 1998), reconhecimento de imagens (Li et al., 2005) e predição de séries temporais (Kozma e Beliaev, 2004). Foi demonstrado que o KIII consegue bons resultados principalmente em ambientes complexos, ruidosos ou com poucos exemplos (Kozma et al., 2007). Porém existem poucos trabalhos utilizando os conjuntos K para o reconhecimento de faces (Zhang et al., 2005, 2006; Li et al., 2006). Nestes trabalhos a abordagem utilizada é bem semelhante, sendo que a única diferença entre eles é a técnica de extração de características. A Figura 3.3 mostra um diagrama genérico do método utilizado.

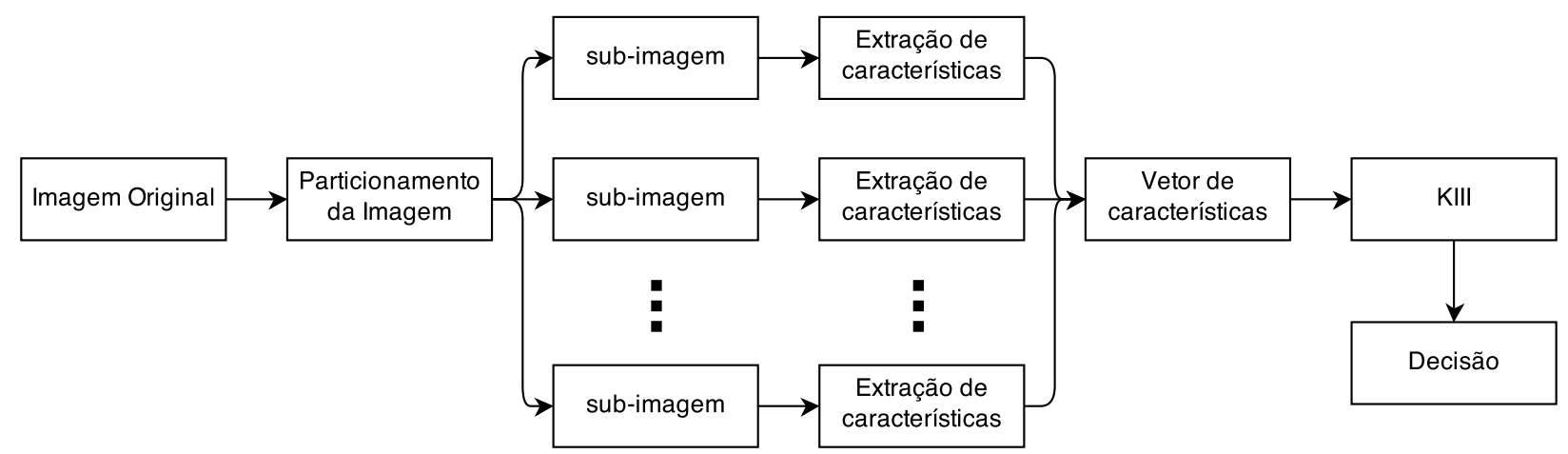

Figura 3.3: Diagrama genérico dos métodos que utilizaram KIII no reconhecimento de faces. Adaptado de (Zhang et al., 2006).

Primeiramente, a imagem original é particionada em várias sub-imagens de mesmo tamanho, como na Figura 3.4. Nas simulações realizadas, as imagens foram divididas individualmente em 8, 16, 32, 64 e 80 sub-imagens. Em seguida, é realizada a extração de características, em que apenas uma característica é extraída de cada sub-imagem. Essas características são combinadas em um vetor que servirá de entrada para a rede. Para a extração de característica, foi utiliza transformada discreta de cosseno (DCT - Discrete Cosine Transform), decomposição em valores 
singulares (SVD - Singular Value Decomposition) ou transformada wavelet packet (WPT - Wavelet Packet Transform), separadamente.

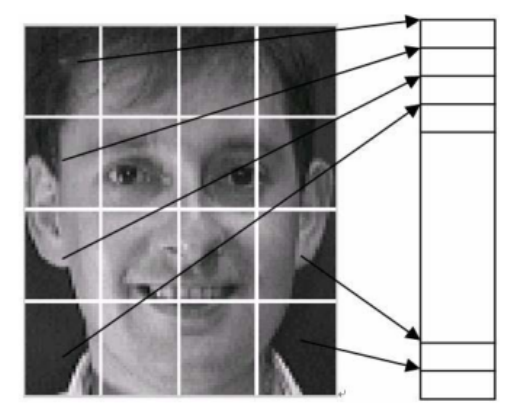

Figura 3.4: Particionamento da imagem. Adaptado de Zhang et al. (2006).

Para a avaliação dos métodos, foi utilizado o banco de dados de faces AT\&T (antigo ORL) (Samaria e Harter, 1994), composto de 400 imagens, sendo 40 indivíduos e 10 imagens de cada um. Foram utilizadas 5 imagens por pessoa para treinamento e as outras 5 para teste. Na fase de treinamento, os vetores de características correspondentes às imagens de treinamento são aprendidos pelo KIII e, em seguida, codificados em padrões de amplitudes do KIII e armazenados. Na fase de testes, os vetores de características correspondentes às imagens de teste são codificados pelo KIII e é calculada a distância euclidiana entre estes padrões e os padrões de treinamento armazenados. O algoritmo k-vizinhos mais próximos (k-NN $k$-nearest neighbours) é utilizado para classificá-los. Os resultados obtidos pelos métodos para os diferentes números de características utilizadas podem ser observados na Tabela 3.2.

Tabela 3.2: Taxa de Identificação obtida pelos métodos SVD, DCT e WPT (Li et al., 2006), para $8,16,32,64$ e 80 características extraídas (sub-imagens) por imagem.

\begin{tabular}{ccccccc}
\hline \multicolumn{7}{c}{ Taxa de Identificação } \\
\hline \multirow{2}{*}{ Método Número de características } \\
\cline { 2 - 7 } & 8 & 16 & 32 & 48 & 64 & 80 \\
\hline SVD & $69,30 \%$ & $81,50 \%$ & $88,30 \%$ & $90,00 \%$ & $90,80 \%$ & $91,00 \%$ \\
DCT & $67,00 \%$ & $82,00 \%$ & $88,50 \%$ & $90,00 \%$ & $91,50 \%$ & $91,00 \%$ \\
WPT & $69,50 \%$ & $81,80 \%$ & $87,30 \%$ & $89,80 \%$ & $90,80 \%$ & $89,80 \%$ \\
\hline
\end{tabular}

De acordo com a Tabela 3.2 observa-se que quanto maior é o vetor de características utilizado melhor é o resultado. E que o método com DCT alcança uma taxa de identificação um pouco melhor que os outros dois. Na Tabela 3.3 é apresentada uma comparação dos métodos utilizando o KIII com alguns dos métodos mais populares de reconhecimento de faces, e os métodos com o KIII alcançaram uma taxa de identificação melhor do que todos os outros. 
Tabela 3.3: Comparação dos métodos com KIII, com os métodos MLP (Rod et al., 2000), HMM(Samaria, 1994), PCA(Samaria, 1994) para banco de dados AT\&T.

\begin{tabular}{c|cccccc}
\hline Método & MLP & HMM & PCA & WPT+KIII & SVD+KIII & DCT+KIII \\
\hline Taxa de Identificação & $84,00 \%$ & $87,00 \%$ & $90,00 \%$ & $90,80 \%$ & $91,00 \%$ & $91,50 \%$ \\
\hline
\end{tabular}

\subsection{Conjunto-KIV}

As neurodinâmicas do KIV foram modeladas através de dados obtidos por análises de EEG registrados simultaneamente de múltiplos eletrodos nas estruturas sensoriais e límbica. O KIV fornece a neuro-arquitetura necessária para modelar as interações das principais populações neurais no encéfalo frontal, responsável pelo comportamento cognitivo associado com aprendizado (Kozma et al., 2003).

O conjunto KIV é composto por quatro componentes principais, três deles são KIII e descrevem o córtex sensorial, o hipocampo e o prosencéfalo medial. O outro componente é um KII que representa a amígdala e conecta os KIIIs ao tronco do cérebro (BS). A Figura 3.5 ilustra as conexões entre os componentes do KIV (Kozma e Freeman, 2003).

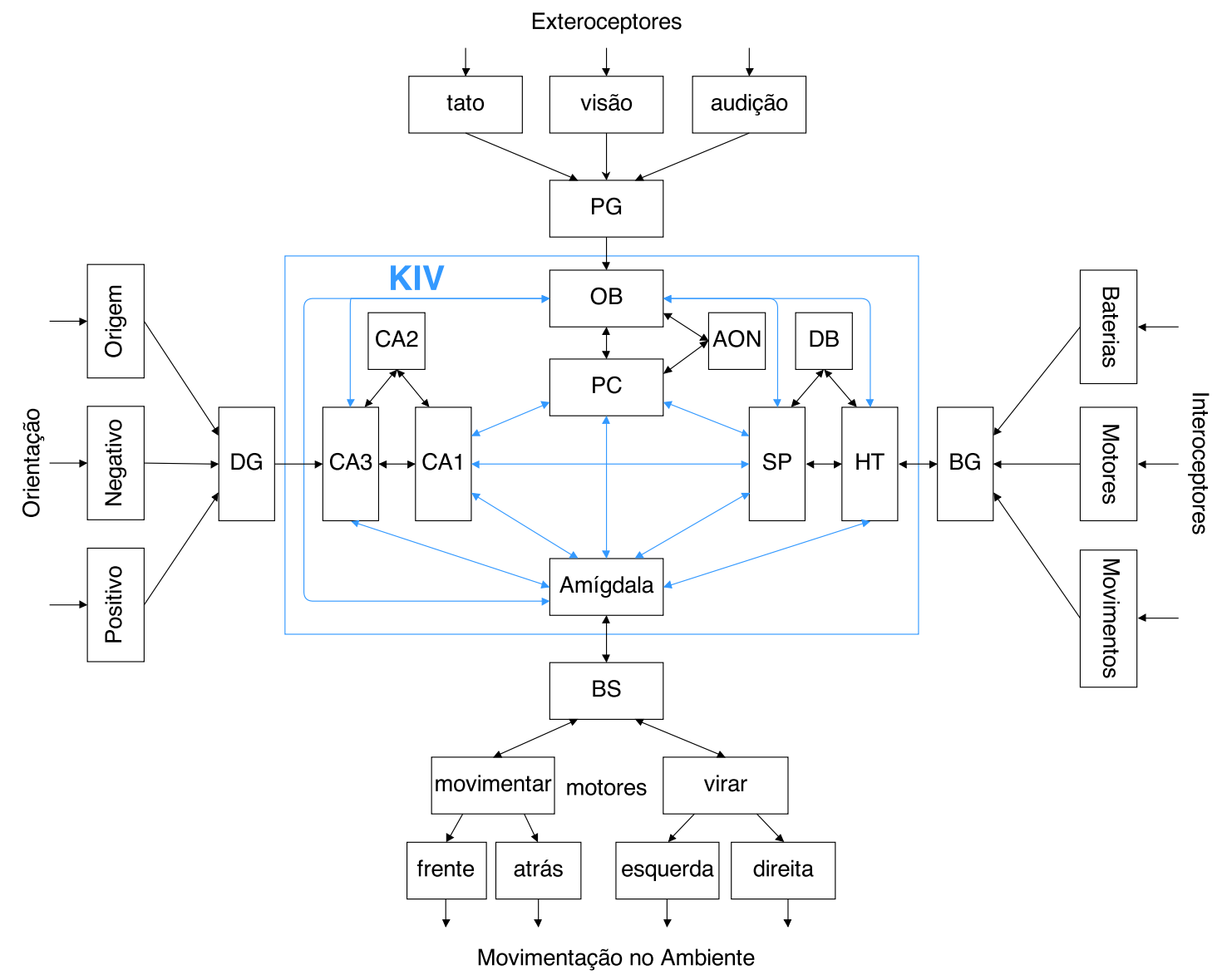

Figura 3.5: Estrutura de um conjunto KIV para a aplicação de navegação em robôs. Adaptado de Kozma e Freeman (2003). 
Este conjunto KIV foi proposto por Kozma e Freeman (2003) e foi aplicado ao problema da navegação autônoma de robôs. No entanto, existem outras variações como o conjunto KIV simplificado proposto por Kozma e Muthu (2004), que possui o hipocampo, o córtex e a amígdala, entretanto o prosencéfalo medial é omitido. Este KIV foi aplicado ao controle do agente autônomo Sony AIBO robot ERS-220A. Outra variação do KIV é apresentada por Ilin e Kozma (2009) que é formado por dois conjuntos KIII, representando dois córtices, unidos por um KII que realiza a fusão de dados, e foi aplicado no reconhecimento de sequências de caracteres. A característica mais interessante do conjunto-KIV é sua capacidade de integração de diferentes dados para tomada de decisões. Com isso, é utilizado principalmente em tarefas que envolvem o processamento de dados vindo de fontes diferentes.

\subsection{Considerações Finais}

Este capítulo apresentou uma visão geral dos conjuntos $\mathrm{K}$, uma família de componentes que modelam elementos neurais, fortemente inspirados por estudos biológicos. Primeiramente foram abordados os conjuntos mais simples, KO, KI e KII, onde foi possível compreender melhor a estrutura, dinâmica e funcionalidade de cada elemento. Em seguida foi apresentado o conjunto KIII e discutido como ele pode ser utilizado como memória e também os tipos de aprendizados utilizados.

Também foi visto que o conjunto KIII já foi aplicado ao reconhecimento de faces, e obteve bons resultados em experimentos utilizando o banco de faces AT\&T. Este banco pode ser considerado simples, pois apresenta apenas pequenas variações na pose e expressão facial. Porém os bons resultados alcançados com este banco motivam a aplicação de métodos com KIII em bancos de faces mais complexos. Outros pontos a serem observados são as técnicas de extração de características e medida de distância utilizada, visto que estes dois pontos podem influenciar bastante os resultados. Desta forma, espera-se que a abordagem proposta neste trabalho consiga melhores resultados, tanto em problemas simples como em problemas mais complexos, como variações na iluminação.

Por fim, foi apresentado o conjunto KIV, onde estudou-se sua estrutura, dinâmica e exemplos de aplicações. Pode-se concluir que o KIV é um modelo eficiente para aplicações em tarefas complexas, como a navegação autônoma em robôs, que envolve tomadas de decisões através do processamento de vários dados de fontes diferentes. 
CAPÍtULO

4

\section{Metodologia e Resultados}

Este capítulo mostra a metodologia empregada no trabalho. Será abordada a visão geral sobre o método proposto, detalhando os passos da fases de treinamento e teste. Em seguida, é descrito o simulador dos conjuntos-KIII utilizado nos experimentos. São apresentados os bancos de dados utilizados nos experimentos. Por fim, apresenta-se a aplicação do método proposto e os resultados obtidos são discutidos.

\subsection{Visão Geral do Método Proposto}

Este trabalho propõe um método totalmente automático para reconhecimento de faces, englobando detecção e reconhecimento. O método proposto realiza o reconhecimento utilizando as características holísticas da imagem da face, pois estas mostraram-se mais eficazes quando aplicadas em bancos de faces grandes com variações na iluminação, rotação e escala das faces (Zhao et al., 2003).

Nos métodos holísticos o vetor de características compreende os pixels da região da face da imagem. Dessa forma, para evitar o problema da alta dimensionalidade, são utilizadas técnicas de extração de características/redução de dimensionalidade, como Análise de Componentes Principais (PCA), Análise Discriminante Linear (LDA), Análise de Componentes Independentes (ICA), Transformada discreta de cosseno (DCT), entre outras (Abate et al., 2007). Após a extração de características é realizada a classificação que pode ser feita de várias maneiras, geralmente utilizando sistemas estatísticos ou redes neurais.

O método proposto é composto de quatro módulos (veja Figura 4.1): detecção facial, extração de características, filtragem dos dados, e classificação. Para a detecção facial é utilizado o 
framework de detecção de objetos Viola-Jones (Viola e Jones, 2001), para a extração de características é utilizada a combinação dos métodos PCA e LDA (Zhao et al., 1999), em seguida os dados são filtrados utilizando o conjunto-KIII (Beliaev et al., 2005), por fim é realizada a classificação utilizando k-vizinhos mais próximo (k-NN - k-nearest neighbors) (Mitchell, 1997). O método proposto será descrito em duas fases, fase de treinamento e fase de testes. A fase de treinamento ocorre conforme o diagrama da Figura 4.2.

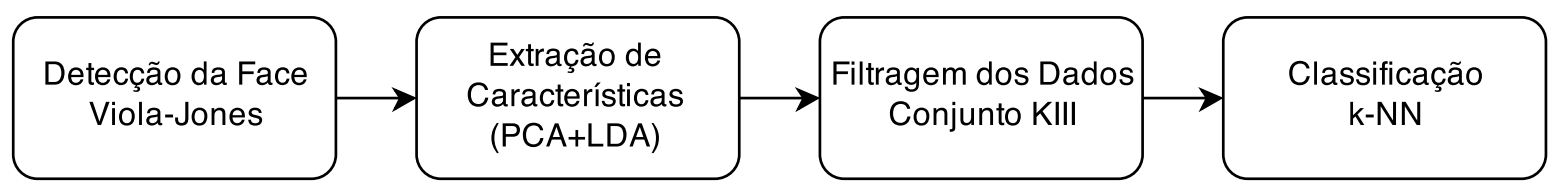

Figura 4.1: Diagrama de blocos do método proposto.

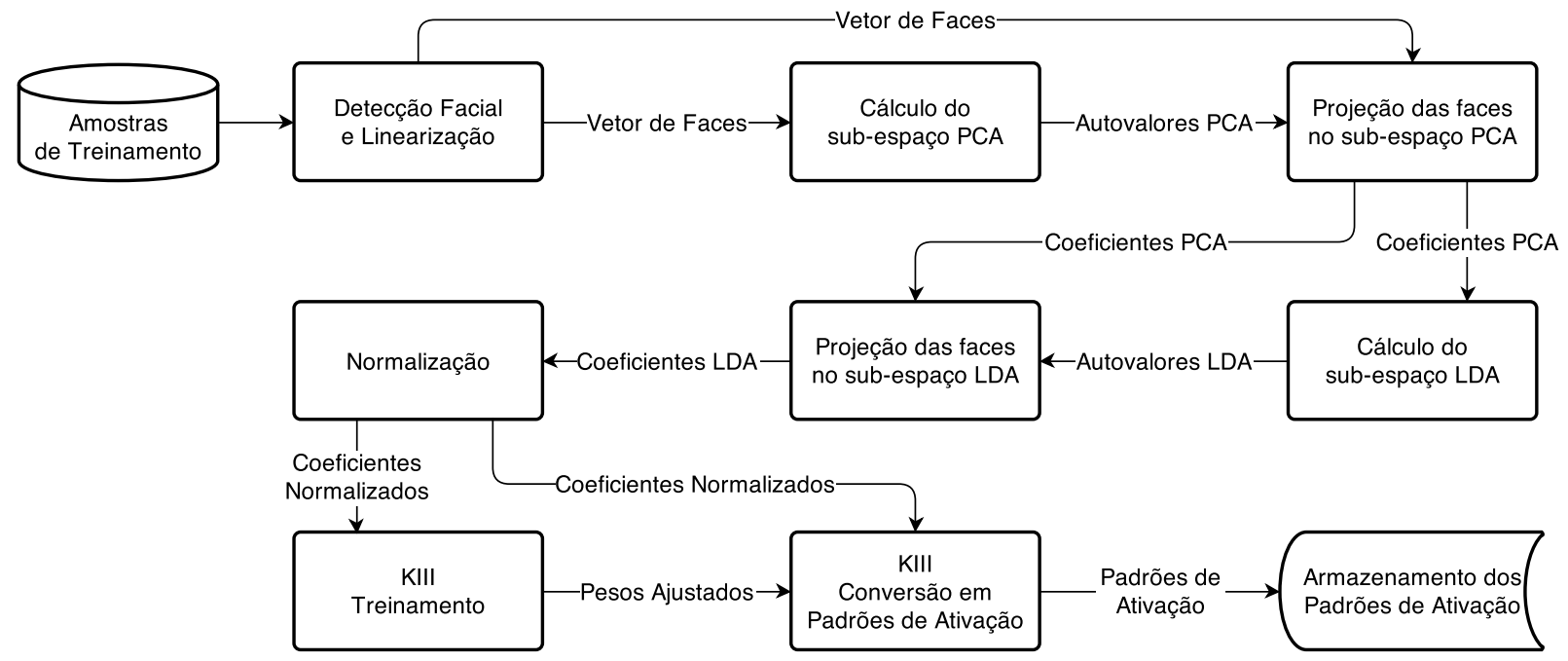

Figura 4.2: Diagrama de fluxo da fase de treinamento.

$\mathrm{Na}$ fase de treinamento, primeiramente as amostras de treinamento passam pela detecção facial. Após a região da face ser detectada e linearizada, é obtido o vetor de faces que é utilizado para calcular o sub-espaço PCA. A partir do cálculo do sub-espaço são obtidos os autovalores PCA que são utilizados para projetar o vetor de faces no sub-espaço PCA, assim obtêm-se os coeficientes PCA. A partir dos coeficientes PCA é calculado o sub-espaço LDA gerando os autovalores LDA que são utilizados para projetar os coeficientes PCA no sub-espaço LDA, obtendo-se os coeficientes LDA. Os coeficientes LDA são normalizados entre -1 e 1 e são apresentados ao conjunto-KIII. Nesta fase, ocorre o treinamento do KIII, em que os pesos de suas conexões são ajustados. Os coeficientes são novamente apresentados ao KIII, porém dessa vez não há treinamento, eles são apenas convertidos em padrões de ativação. Esses padrões de ativação são armazenados para serem utilizados posteriormente na fase de teste (Kozma e Beliaev, 2004). 
O diagrama do método proposto para a fase de testes é apresentado na Figura 4.3. Na fase de teste/reconhecimento, a face a ser reconhecida passa pela detecção facial, depois é projetada no sub-espaço PCA e em seguida projetada no sub-espaço LDA. Os coeficientes LDA obtidos pela última operação são normalizados e servem de entrada para a rede KIII. A rede KIII retorna os Padrões de Ativação referentes a essa consulta, que juntamente com os Padrões de Ativação de treinamento servem de entrada para o k-NN, que decide a classe representante.

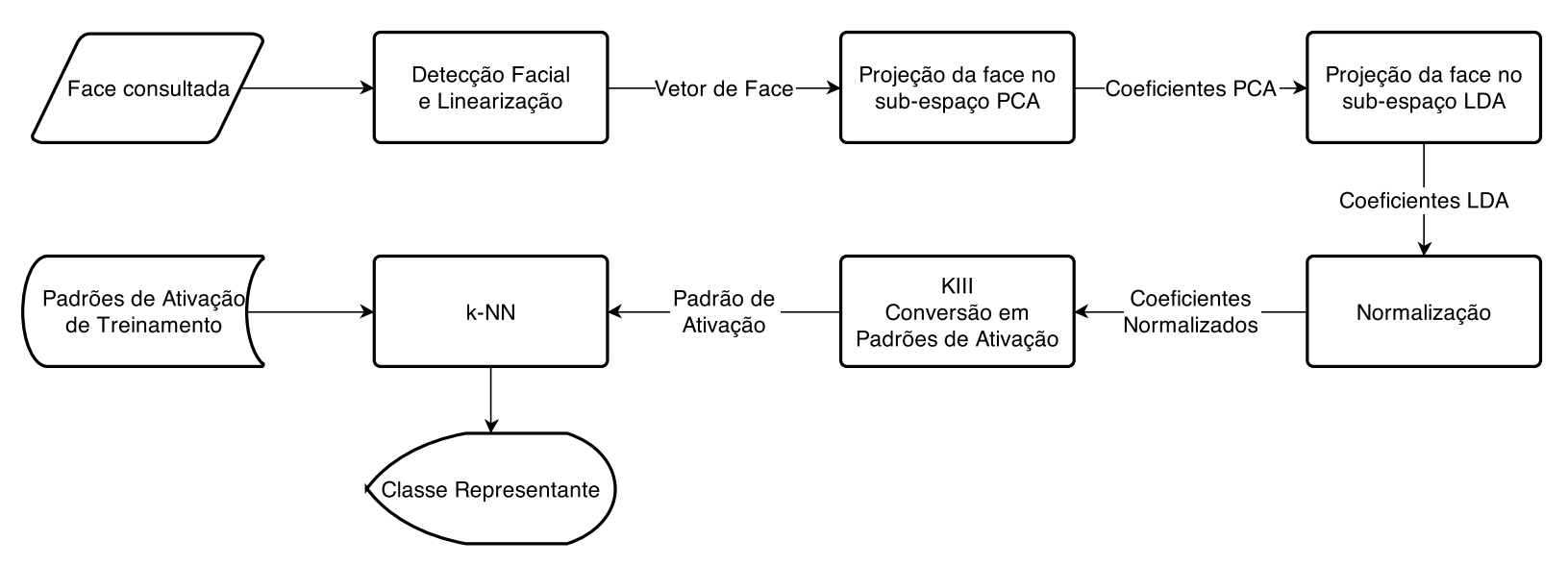

Figura 4.3: Diagrama de fluxo da fase de teste.

\subsubsection{Filtragem de Dados Utilizando o conjunto-KIII}

Os conjuntos-K são utilizados como um filtro de forma que transformam os exemplos apresentados à rede em um espaço formado por padrões de oscilação que possibilitam uma melhor separação dos dados.

Neste trabalho foi utilizado um simulador para os conjuntos-K de níveis KO até KIII, disponível em Piazentin e Carlos Jr. (2014). O simulador segue um padrão hierárquico em que os conjuntos-KI e KII são compostos pelas unidades básicas $\mathrm{KO}$ e as conexões entre elas. Cada conjunto-KO mantém um registro de todas as conexões que recebe e seus respectivos pesos e atrasos. Os conjuntos-KII são utilizados para compor camadas de KII, que por sua vez são utilizadas para formar o conjunto-KIII. A arquitetura modular do conjunto-KIII possibilita que o treinamento e captura da saída ocorra em qualquer uma das camadas.

O conjunto-KIII construído através do simulador possibilita larga parametrização de seus componentes. O número de entradas do conjunto-KIII, e a quantidade de conjuntos-KII em cada camada é definido pela dimensão dos dados de entrada. Neste trabalho, a dimensão de entrada do conjunto-KIII é definida pela dimensão de saída do passo anterior. Desta forma, o número de entradas do conjunto-KIII é igual a dimensão de saída do LDA. Devido à utilização de dois bancos de dados distintos nos experimentos, essa dimensão varia para cada um dos bancos e é definida na seção 4.2.2. Os demais parametros utilizados estão otimizados para a tarefa de classificação e foram obtidos através de buscas globais realizados por Chang e Freeman (1996) e Chang et al. (1998). 
O conjunto-KIII em questão é formado por 3 camadas de conjuntos-KII e os pesos utilizados em cada camada do conjunto-KIII são exibidos na Tabela 4.1.

Tabela 4.1: Pesos utilizados nos conjuntos-KII em cada camada do conjunto-KIII.

\begin{tabular}{|c|c|c|c|c|}
\hline \multicolumn{5}{|c|}{ Pesos dos conjuntos-KII } \\
\hline Camada & $w_{e} e$ & $w_{e} i$ & $w_{i} e$ & $w_{i} i$ \\
\hline $\mathbf{1}$ & 1.8 & 1.0 & -2.0 & -0.8 \\
\hline $\mathbf{2}$ & 1.6 & 1.6 & -1.5 & -2.0 \\
\hline $\mathbf{3}$ & 1.6 & 1.9 & -0.2 & -1.0 \\
\hline
\end{tabular}

Os pesos iniciais das conexões laterais entre os conjuntos-KII são definidos na Tabela 4.2. Estes são os valores utilizados para camadas com tamanho $n=1$, em camadas com tamanho $n>1$ é utilizado $\frac{w}{n-1}$, onde $w$ é o peso inibitório ou excitatório correspondente (Chang e Freeman, 1996; Chang et al., 1998).

Tabela 4.2: Pesos utilizados nos conjuntos-KII em cada camada do conjunto-KIII.

\begin{tabular}{|c|l|l|}
\hline \multicolumn{3}{|c|}{ Pesos laterais } \\
\hline Camada & excitatório & inibitório \\
\hline $\mathbf{1}$ & 0.15 & -0.10 \\
\hline $\mathbf{2}$ & 0.20 & -0.20 \\
\hline $\mathbf{3}$ & 0.15 & -0.10 \\
\hline
\end{tabular}

As conexões entre as três diferentes camadas de conjuntos-KII, além dos pesos, possuem atrasos temporais. Assim a saída de uma determinada conexão no tempo $t$ como atraso temporal $z$ retorna o valor de ativação do nó de origem no tempo $t-z$. Estas conexões entre as camadas ocorrem, a partir de nós excitatórios ou inibitórios para nós excitatórios ou inibitórios. Os pesos e atrasos definidos para essas conexões são apresentados na Tabela 4.3.

Tabela 4.3: Pesos utilizados nos conjuntos-KII em cada camada do conjunto-KIII.

\begin{tabular}{|c|c|c|c|c|}
\hline \multicolumn{5}{|c|}{ Conexões entre camadas } \\
\hline Camada de origem & Camada de destino & Tipo de conexão & Peso & Atraso \\
\hline 1 & 2 & excitatório para excitatório & 0.15 & 1 \\
\hline 1 & 3 & excitatório para excitatório & 0.60 & 1 \\
\hline 2 & 1 & excitatório para excitatório & 0.05 & 17 \\
\hline 2 & 1 & excitatório para inibitório & 0.25 & 25 \\
\hline 3 & 1 & inibitório para inibitório & -0.05 & 25 \\
\hline 3 & 2 & excitatório para inibitório & 0.20 & 25 \\
\hline
\end{tabular}

O treinamento do conjunto-KIII acontece através da adaptação dos pesos das conexões laterais. Durante o treinamento, cada uma das amostras é apresentada por 600 ciclos na fase ativa, seguido por 400 ciclos sem estímulo (fase de descanso). Os pesos das conexões são ajustados utilizando o aprendizado hebbiano na terceira camada, com a taxa de aprendizado $(\alpha) 0.005$. 


\subsubsection{Classificação}

A última fase de um sistema de reconhecimento de faces é a classificação, onde ocorre identificação ou verificação, dependendo da aplicação escolhida. A classificação é realizada utilizando os vetores de características do conjunto de treinamento e os vetores de características do conjunto de teste. Muitos métodos podem ser utilizados para esta tarefa. Dentre os mais utilizados temse, k-vizinhos mais próximos ( $k$-NN - k-nearest-neighbors), modelo oculto de Markov (HMM Hidden Markov Model) (Samaria e Harter, 1994), máquina de vetores de suporte (SVM - Support Vector Machine) (Phillips, 1999), métodos bayesianos (Moghaddam et al., 2000) e redes neurais (Lawrence et al., 1997; Er et al., 2002). Neste trabalho é utilizado o classificador k-vizinhos mais próximos principalmente por sua simplicidade e eficiência.

\section{K-Vizinhos Mais Próximos (k-NN)}

O k-NN é um algoritmo simples utilizado para classificação no qual um exemplo é classificado com base em seus k-vizinhos mais próximos. O k-NN assume que todos os exemplos correspondem a pontos num espaço de características $n$-dimensional. Um exemplo consultado é rotulado como pertencente a classe mais frequente entre os k exemplos de treinamento mais próximos àquele ponto consultado (Mitchell, 1997). A distância entre os pontos é definida de acordo com alguma métrica como distância euclidiana, de Manhattan ou de Mahalanobis. Geralmente, para dois vetores $p$ e $q$, as medidas de distâncias são dadas da seguinte forma:

$$
\begin{gathered}
d_{\text {Euclidiana }}(p, q)=\sqrt{\sum_{i=1}^{n}\left(p_{i}-q_{i}\right)^{2}} \\
d_{\text {Manhattan }}(p, q)=\sum_{i=1}^{n}\left|p_{i}-q_{i}\right| \\
d_{\text {Mahalanobis }}(p, q)=\sqrt{(p-q)^{t} S^{-1}(p-q)}
\end{gathered}
$$

onde S é a matriz de covariância.

A medida de distância mais comum e mais utilizada é a distância euclidiana. No entanto, alguns trabalhos realizam uma comparação entre as medidas de distância, buscando a que se adapte melhor ao problema. Em Yambor et al. (2000) foi realizado um estudo utilizando PCA e comparando quatro medidas de similaridade: distância de Manhattan (L1), distância euclidiana (L2), distância angular, distância de Mahalanobis e combinações dessas medidas. Foi demonstrado que Mahalanobis conseguiu um resultado significativamente melhor quando comparado como as outras três medidas. No entanto, uma combinação de medidas conseguiu uma pequena melhora em relação a Mahalanobis. 
Em Perlibakas (2004), foi apresentado um estudo comparando 14 medidas de similaridade e suas modificações para um método de reconhecimento de faces baseado em PCA, em que o melhor resultado de reconhecimento foi alcançado utilizando a distância de Mahalanobis simplificada. Outro estudo (Maheshkar et al., 2010) apresentou um método para o reconhecimento de faces baseado em DCT, e realizou uma comparação do método proposto utilizando duas medidas de similaridades: distância euclidiana e distância de Mahalanobis, em que Mahalanobis conseguiu um resultado melhor.

Neste trabalho, assim como na maioria dos trabalhos de reconhecimento de faces (Perlibakas, 2004; Delac et al., 2005), foi utilizado $k=1$, ou seja um exemplo consultado é rotulado como da mesma classe do exemplo de treinamento mais próximo no espaço de características. Em relação à medida de distância, foram utilizadas as três medidas de distâncias apresentadas, com o intuito de verificar qual delas se comporta melhor com o método proposto.

\subsection{Experimentos}

Neste trabalho serão realizados dois experimentos. O primeiro, reproduz o experimento realizado em Zhang et al. (2006), com o intuito de comparar o método proposto neste trabalho com o método de Zhang. Neste experimento é utilizado o banco de dados de faces AT\&T (antigo ORL), que possui pequenas variações incluindo pose, expressão facial e detalhes faciais (óculos, barba, etc). É interessante a comparação com o método proposto por Zhang (DCT+KIII), pois este método se assemelha muito ao método proposto neste trabalho, pois também faz uso da rede KIII após a extração de características.

Para o segundo experimento será utilizado o banco de dados de faces Yale B. O banco Yale B possui um vasta gama de variações na iluminação das imagens fornecendo um ambiente mais complexo para o reconhecimento de faces permitindo uma melhor avaliação dos métodos em condições complexas.

\subsubsection{Conjuntos de dados a serem utilizados}

Os bancos de faces utilizados nos experimentos foram: AT\&T e Yale B, que serão abordados detalhadamente a seguir.

\section{Banco de Dados AT\&T}

O banco de dados AT\&T (antigo ORL) foi produzido pelo Olivetti Research Laboratory na Universidade de Cambridge, UK (Samaria e Young, 1994). Este banco é gratuito/público e possui um total de 400 imagens sendo 40 indivíduos e 10 imagens diferentes para cada indivíduo. As imagens possuem variações na expressão facial (olhos abertos/fechados, sorrindo/sem sorrir), iluminação e detalhes faciais (com ou sem óculos). As imagens foram obtidas sob um fundo escuro e 
homogêneo, e estão em escala de cinza com uma resolução de 92x112 pixels. A Figura 4.4 fornece uma amostra deste banco de dados.
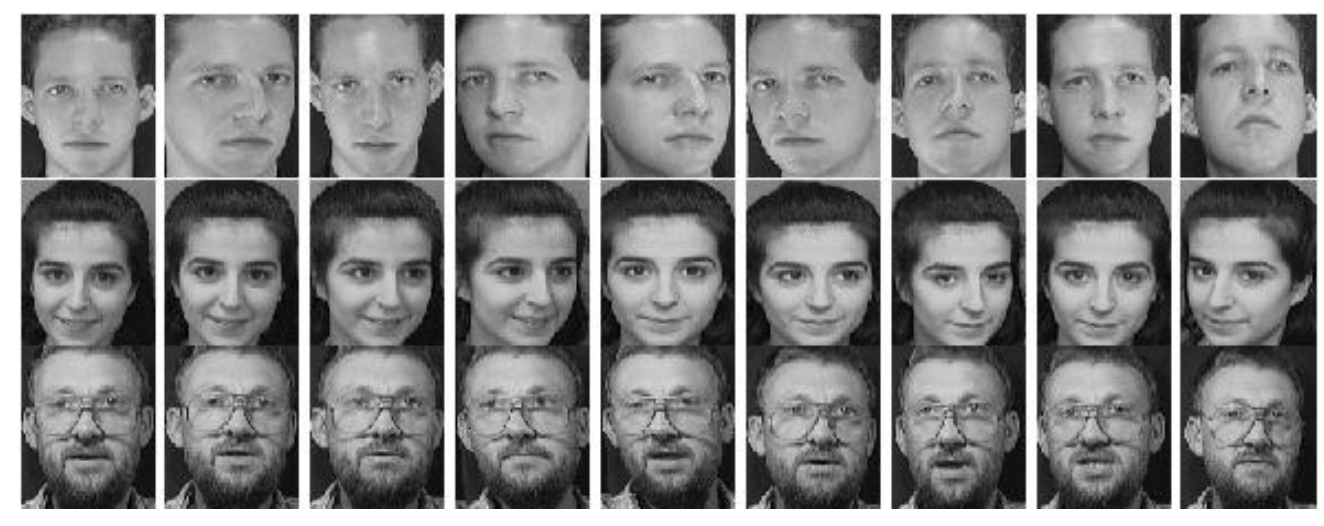

Figura 4.4: Amostra do Banco de Dados Olivetti AT\&T (ORL) (Samaria e Harter, 1994)

\section{Yale B}

O banco de dados de faces "Yale Face Database B" (Georghiades et al., 2000) foi desenvolvido para permitir testes sistemáticos de métodos de reconhecimentos de faces sob grandes variações na iluminação e pose. Para capturar as imagens desse banco de dados foi construída um equipamento de iluminação geodésica com 64 lampadas de xênon. O banco possui um total de 5760 imagens de $640 \times 480$ pixels, adquiridas de 10 indivíduos sob 64 condições de iluminação em nove poses (pose frontal, cinco poses com $12^{\circ}$ e três poses com $24^{\circ}$ a partir do eixo da câmera). As 64 imagens de uma determinada face foram adquiridas em cerca de 2 segundos. Portanto, estas imagens apresentam apenas uma alteração mínima na posição da cabeça e expressão facial.

Nos experimentos realizados, das 64 condições de iluminação apenas 45 foram utilizadas, pois as 19 condições restantes foram consideradas impróprias para o uso, pois ficaram muito escuras devido o posicionamento da fonte de luz utilizada (Georghiades et al., 2000). As imagens de cada pose foram divididas em 4 subconjuntos $\left(12^{\circ}, 25^{\circ}, 50^{\circ}\right.$ e $\left.77^{\circ}\right)$ de acordo com o ângulo da fonte de luz com o eixo da câmera (ver Figura 4.5). Os subconjuntos 1, 2, 3 e 4 possuem respectivamente 7, 12, 12 e 14 variações de iluminação para cada pose de cada indivíduo.

\subsubsection{Definição dos Subespaços PCA e LDA}

O PCA é um passo muito importante no método proposto, que é realizado logo após a detecção da face. Ele é utilizado para reduzir o espaço dos dados de entrada selecionando as características mais relevantes. Considerando $d$ a dimensão dos dados de entrada (número de pixels da região da face) e $M$ o total de amostras de treinamento, se $M<d$ existirão apenas $M-1$ autovetores significativos (Turk e Pentland, 1991a). Desta forma, a quantidade de autovetores a ser utilizada deverá ser escolhida entre 1 e $M-1$. 


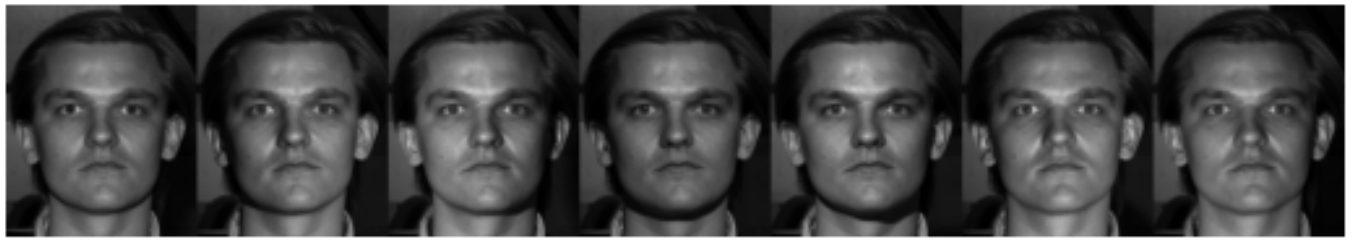

Subset 1 .

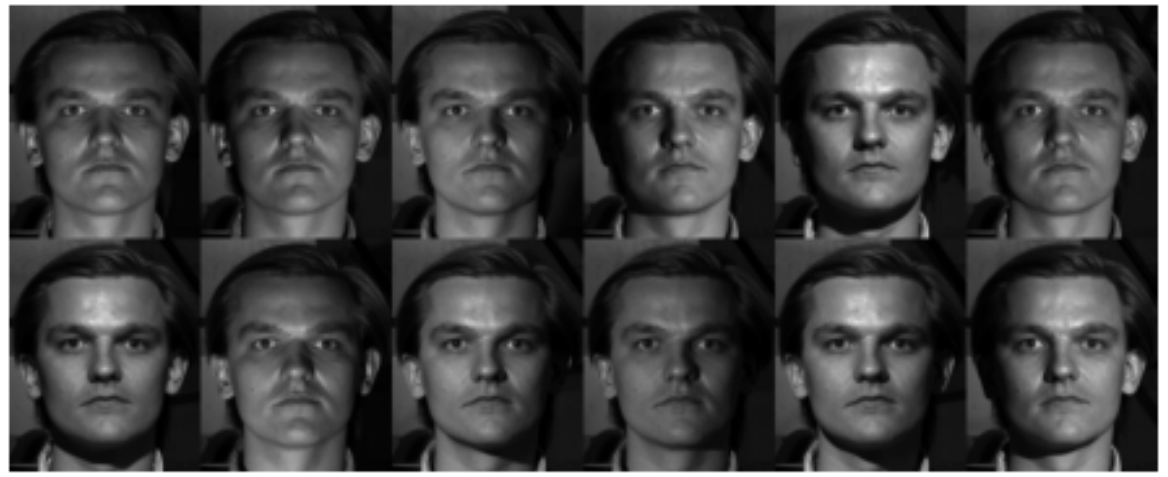

Subset 2 .

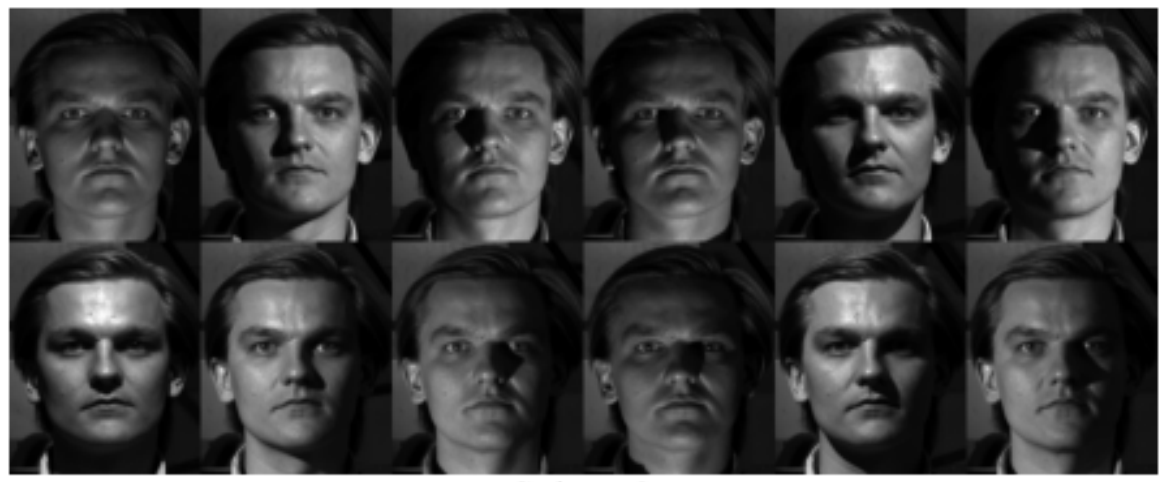

Subset 3 .

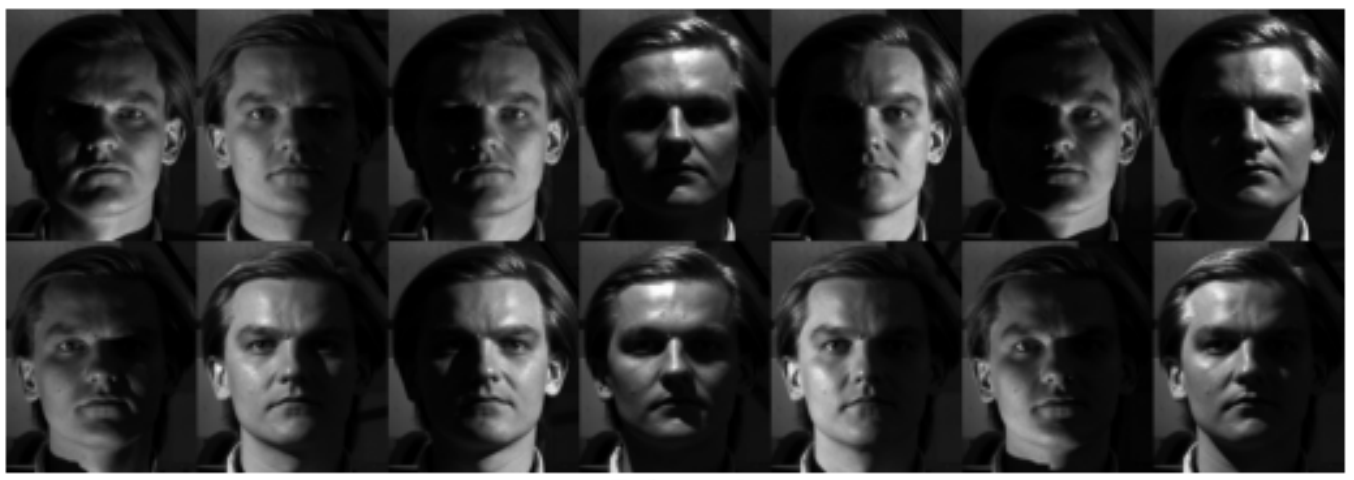

Subset 4 .

Figura 4.5: Exemplos de imagens de um único indivíduo do "Yale Face Database B" na pose frontal, mostrando as variações de iluminação. A imagens foram divididas em 4 sub-conjuntos de acordo com o ângulo que a fonte da luz faz com o eixo da câmera, sub-conjunto $1\left(12^{\circ}\right)$, sub-conjunto $2\left(25^{\circ}\right)$, sub-conjunto $3\left(50^{\circ}\right)$, e sub-conjunto $4\left(77^{\circ}\right)$.

Escolher o número ideal de autovetores é um problema crucial no PCA. Se forem selecionados autovetores demais, ruídos podem ser incluídos pelas flutuações nas amostras e se forem selecionados poucos, informações relevantes podem ser perdidas. Infelizmente, não existe ne- 
nhuma abordagem incontestável para a determinar o número ideal de autovetores. Porém, existem algumas regras que buscam alcançar o número ideal de autovetores, uma das mais utilizadas é o percentual da variância cumulativa. Nessa regra são selecionados autovetores suficientes para representar $x \%$ da variância total. De acordo com Swets e Weng (1996b) as melhores taxas de reconhecimento são alcançadas quando o número de autovetores selecionados correspondem cerca de $95 \%$ da variância total.

Logo após a etapa PCA é realizado o LDA, que gera um total de $c-1$ autovetores, onde $c$ é número de classes. No método proposto serão mantidos todos os autovetores LDA, como sugerido em Belhumeur et al. (1997) e Delac et al. (2005).

Para o banco de dados $A T \& T$ database, o treinamento será realizado utilizando 5 imagens por classe; como existem 40 classes, o treinamento é realizado utilizando 200 imagens. Desta forma, serão gerados no máximo 199 autovetores PCA. Seguindo a regra descrita anteriormente, é utilizada uma quantidade de autovetores que corresponda à $95 \%$ da variância total. Foi calculada a variância cumulativa para os todos autovetores PCA obtidos pelo conjunto de treinamento. A variância cumulativa é apresentada na Figura 4.6, onde é possível observar que $95 \%$ da variância cumulativa é alcançada quando se utiliza 115 autovetores. Assim a saída do PCA terá dimensão igual a 115 que será a entrada do LDA. Por sua vez o LDA reduzirá os dados para $c-1$, como o total de classes é igual a $10(c=40)$ a dimensão da saída do LDA será igual a 39.

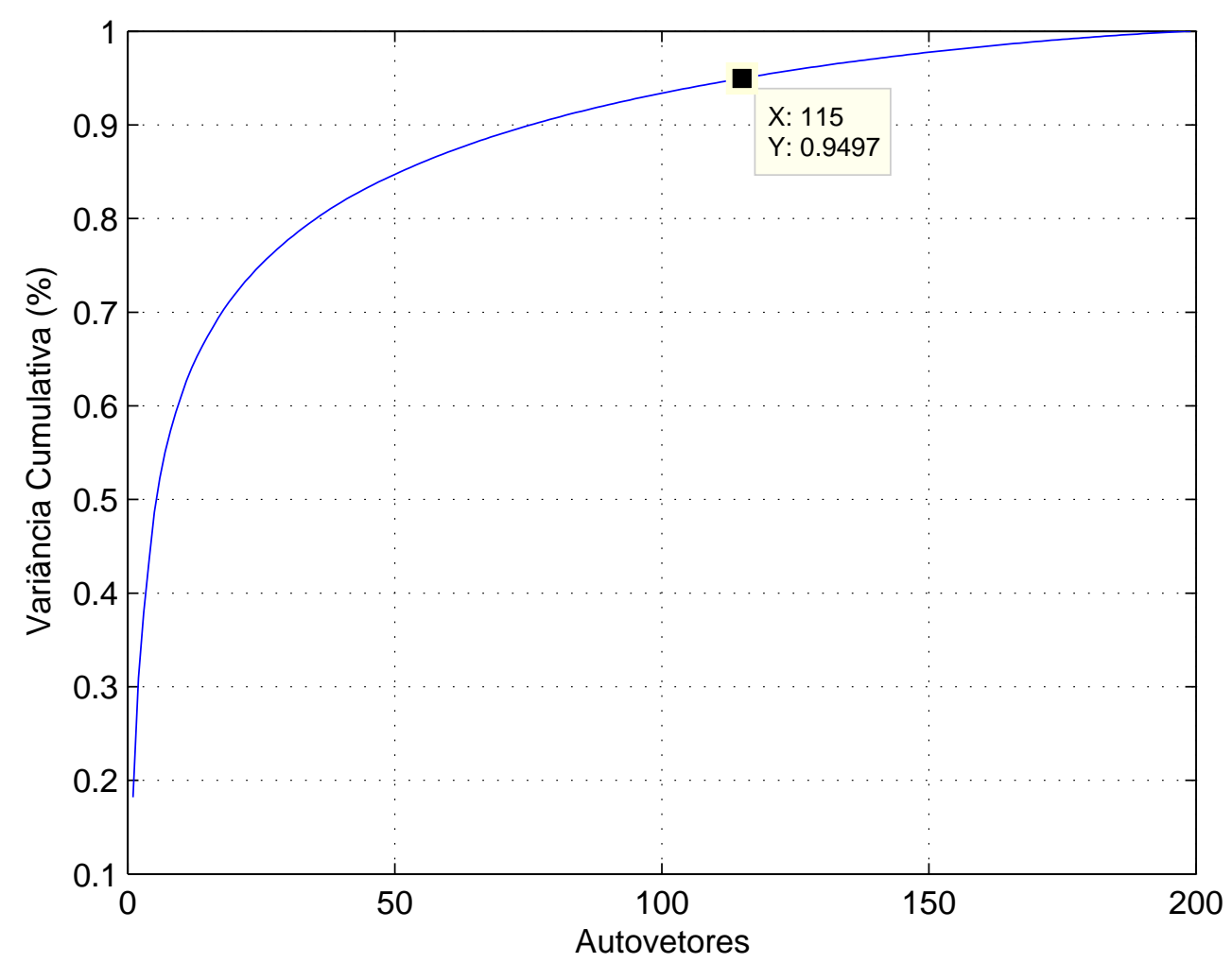

Figura 4.6: Variância cumulativa dos autovetores PCA referente às amostras de treinamento para o Banco de dados AT\&T. 
Para o banco de dados Yale B facedatabase, o treinamento será realizado utilizando as imagens frontais pertencentes ao sub-conjunto 1 . O sub-conjunto 1 possui 10 classes e 7 imagens por classe, um total de 70 imagens. Portanto, serão gerados no máximo 69 autovetores PCA. Conforme a regra descrita anteriormente, é utilizada uma quantidade de autovetores que corresponda à $95 \%$ da variância total. Foi calculada a variância cumulativa para os todos autovetores PCA obtidos pelo conjunto de treinamento, apresentada na Figura 4.7, onde é possível observar que 95\% da variância cumulativa é alcançada quando se utiliza 21 autovetores. Assim a saída do PCA terá dimensão igual a 21 que consequentemente é a entrada do LDA, que por sua vez o reduzirá os dados para $c-1$, como o total de classes é igual a $10(c=10)$ a dimensão da saída do LDA será igual a 9 .

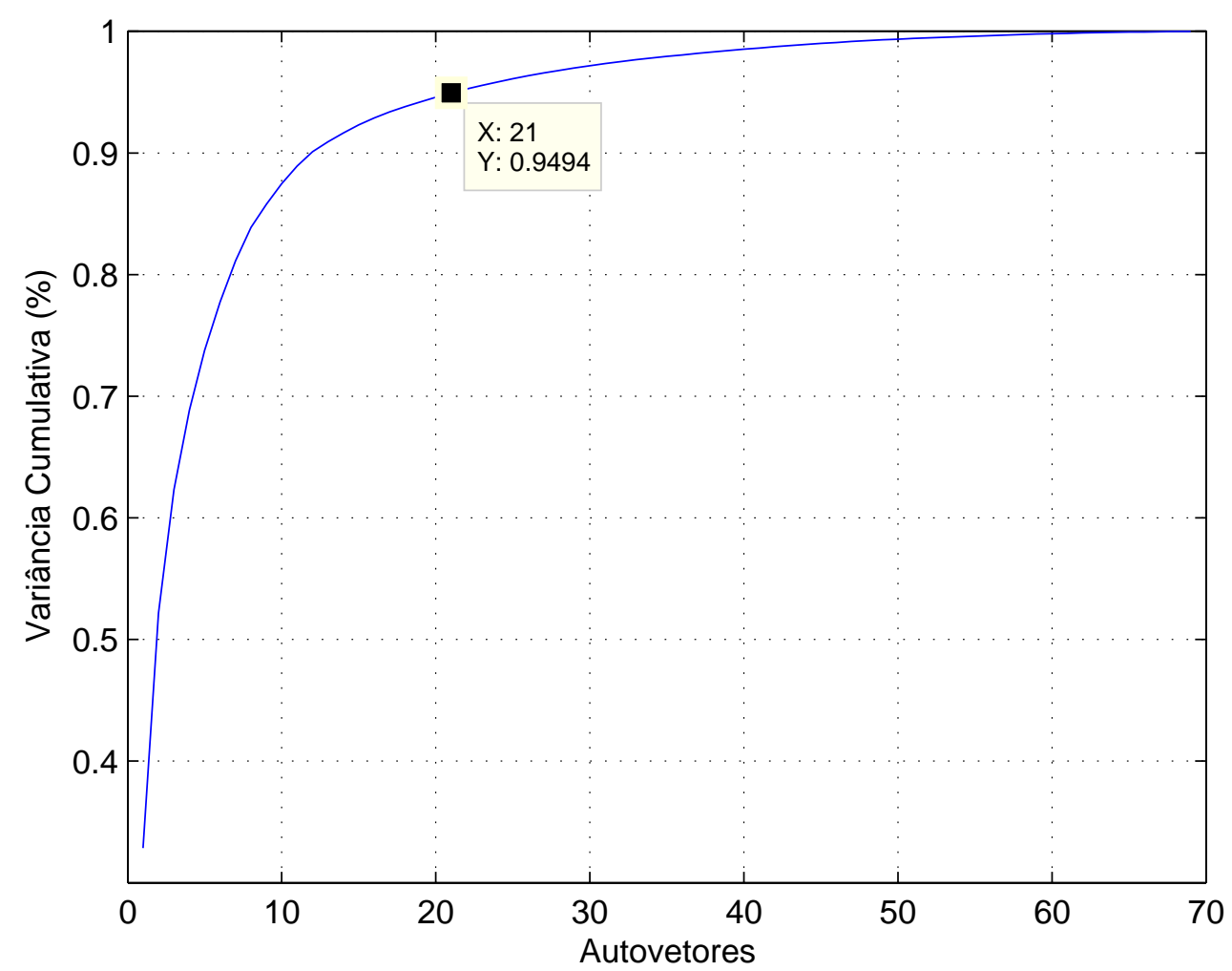

Figura 4.7: Variância cumulativa dos autovetores PCA referente às amostras de treinamento para o Banco de dados Yale B.

\subsubsection{Aplicação do Método e Resultados}

Abaixo são apresentadas as configurações selecionadas para a realização dos experimentos. Os parâmetros apresentados aqui foram escolhidos de acordo com a metodologia apresentada na seção anterior.

Para o primeiro experimento foi utilizada a seguinte configuração:

- Banco de Dados AT\&T; 
- 40 pessoas, 10 imagens por pessoa, total de 400 imagens;

- 5 imagens por pessoa para treino e 5 por pessoa para testes, total de 200 imagens para treino e 200 para teste;

- Dimensão das imagens utilizadas 92 x 112 pixels;

- Sub-espaço PCA com 115 autovetores;

- Sub-espaço LDA com 39 autovetores;

- Parâmetros do KIII:

- 3 camadas de KII, com 39 conjuntos KII em cada camada;

- demais parâmetros definidos na seção 4.1.1.

- Classificação da saída do KIII utilizando $k-N N$ com as seguintes medidas de distância:

- Euclidiana;

- De Mahalanobis;

- De Manhattan.

Para uma comparação do método proposto, o mesmo experimento foi realizado com o método proposto por Zhang et al. (2006) que usa o modelo KIII e a Transformada Discreta de Cosseno (DCT), além de dois dos métodos mais populares da área, PCA e Subespaço LDA (PCA + LDA). Os métodos são avaliados para a identificação em conjunto fechado conforme apresentado na seção 2.6.1, pois este é o modo de avaliação mais comum em trabalhos de reconhecimento de faces. Os resultados são apresentados de duas maneiras, através da Tabela 4.4 mostrando o taxa de identificação e o desvio padrão para o rank 1 e pelos gráficos CMC (Cumulative Match Characteristic) das Figuras 4.8, 4.9 e 4.10 mostrando o rank cumulativo, onde cada gráfico representa o resultado para uma das medidas de distância utilizadas.

Tabela 4.4: Taxa de identificação e desvio padrão obtidos pelos métodos avaliados para o rank 1 .

\begin{tabular}{lcccccc}
\multicolumn{7}{c}{ Utilizando o Banco de Dados AT\&T. } \\
\hline \multicolumn{7}{c}{ Resultados para o rank 1 } \\
\hline Método & Euclidiana & \multicolumn{3}{c}{ Mahalanobis } & \multicolumn{2}{c}{ Manhattan } \\
\hline PCA+LDA+KIII & 0,900 & 0,010 & $\mathbf{0 , 9 0 3}$ & 0,012 & 0,899 & 0,016 \\
PCA+LDA & 0,907 & 0,010 & $\mathbf{0 , 9 0 8}$ & 0,011 & 0,903 & 0,012 \\
PCA & 0,777 & 0,018 & 0,742 & 0,020 & $\mathbf{0 , 7 7 8}$ & 0,025 \\
DCT+KIII & 0,924 & 0,016 & 0,878 & 0,024 & $\mathbf{0 , 9 3 4}$ & 0,021 \\
DCT & 0,928 & 0,020 & 0,884 & 0,020 & $\mathbf{0 , 9 3 8}$ & 0,019 \\
\hline
\end{tabular}

De acordo com os resultados apresentados na Tabela 4.4, observa-se que o método que alcançou a maior taxa de reconhecimento foi o método baseado em DCT com 0,938 e em seguida o 


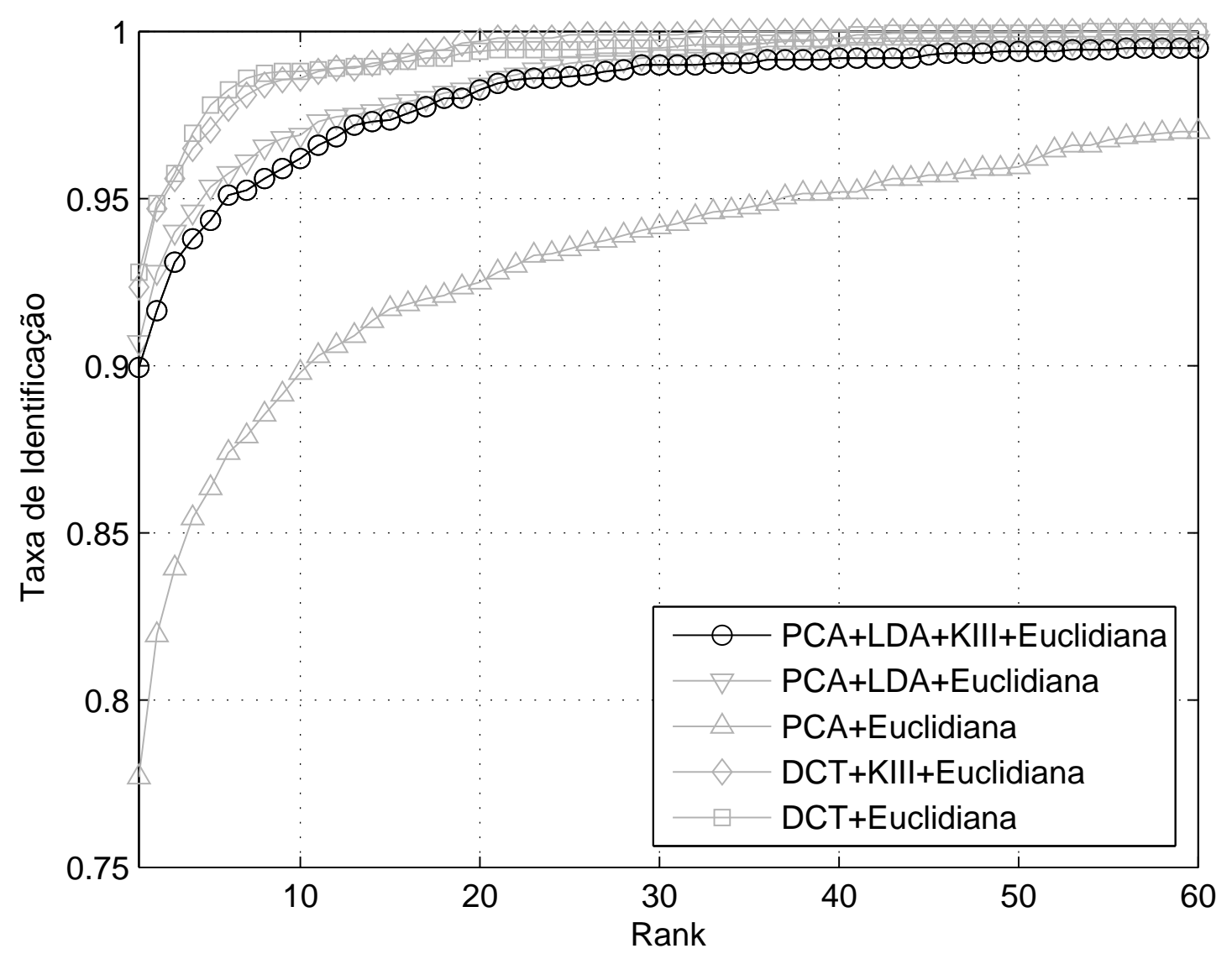

Figura 4.8: CMC para distância euclidiana.

método DCT+KIII com 0,934, neste caso observa-se que acrescentar os conjuntos KIII ao método DCT não traz nenhuma melhoria. O mesmo acontece com o método proposto PCA+LDA+KIII que alcançou uma taxa de identificação de 0,903 , e também não traz melhoria em relação ao método PCA+LDA sem KIII que alcançou 0,908. Acredita-se que isso ocorre pelo fato do banco de dados utilizado ser razoavelmente simples, sem grandes variações nas faces, e os conjuntos KIII são indicados a problemas mais complexos, desta forma apesar dos resultados dos modelos K não serem ruins eles não trazem vantagem para este tipo de dados. Nesse experimento, também é observado que o modelo de Zhang KIII+DCT supera o modelo sugerido nesse trabalho. No entanto não traz melhoria em relação ao método que utiliza somente DCT, com isso conclui-se que o motivo do método de DCT+KIII ter obtido uma taxa de identificação maior que a do método proposto PCA+LDA+KIII é devido à técnica de extração de característcas ser mais eficaz para o cenário em questão (poucas variações nas imagens utilizadas).

Em relação às medidas de distâncias utilizadas observa-se que cada técnica funciona melhor para uma distância diferente. Os métodos baseados em DCT se saem melhor quando utilizam distância de Manhattan, enquanto que os métodos baseados em PCA+LDA se saem melhor com a distância de Mahalanobis. Se considerar apenas a distância de Mahalanobis os métodos baseados em PCA+LDA superam os baseados em DCT, que é o inverso do que acontece com as a outras 


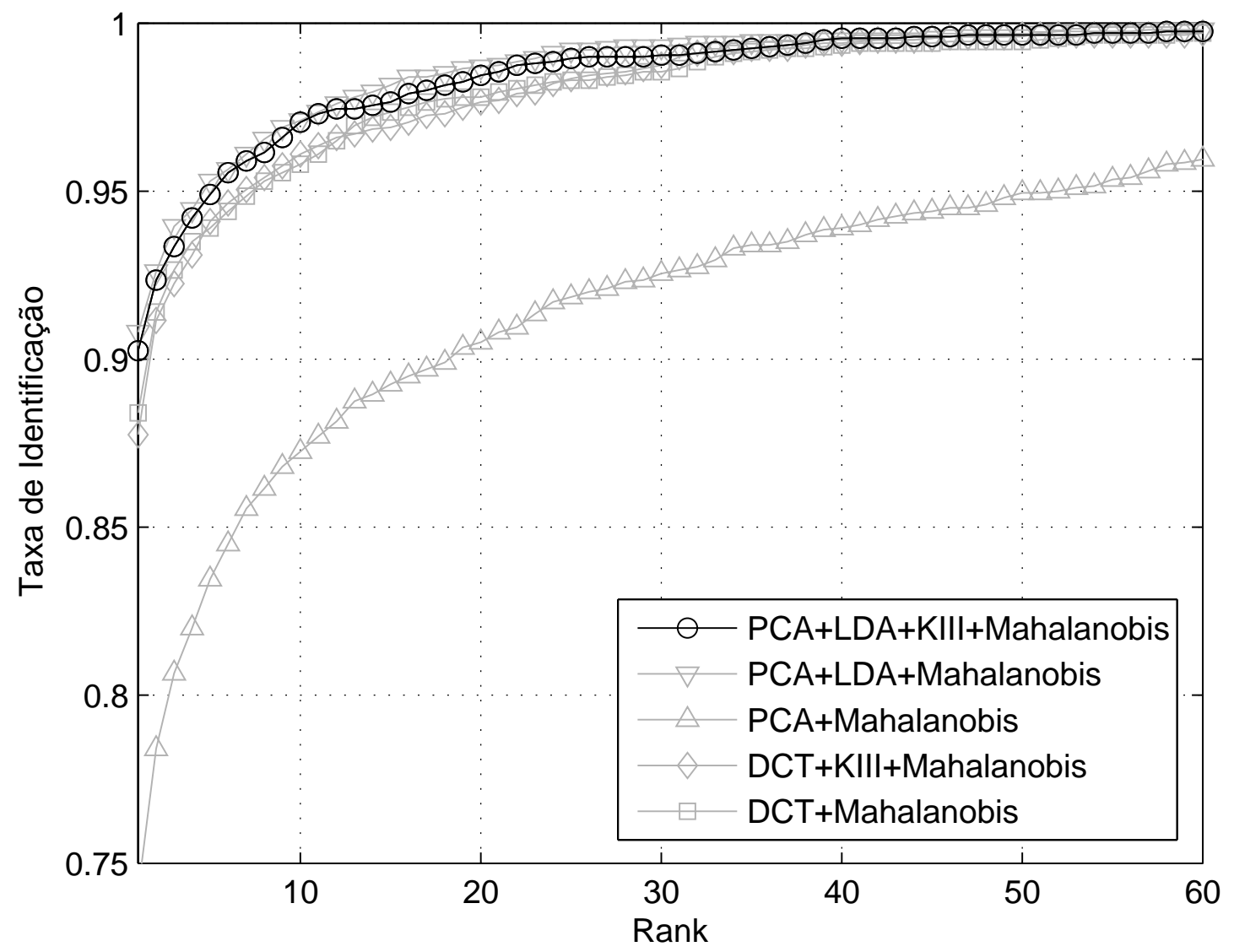

Figura 4.9: CMC para distância de Mahalanobis.

duas medidas de distância. Por fim observa-se que o método que utiliza apenas PCA tem resultados semelhantes para as distância euclidiana e Manhattan, e um pouco pior para Mahalanobis. Contudo os resultados alcançados pelo PCA são os piores dentre os métodos avaliados.

Cumulativamente os resultados estão equivalentes aos alcançados para o rank 1, não há grandes mudanças na ordem do desempenho dos métodos conforme o rank vai subindo. Para o rank 10 por exemplo, todos os métodos estão na mesma ordem de eficiência que para o rank 1. Uma obervação interessante é que para os gráficos apresentados, o da distância de Mahalanobis é o único em que os métodos baseados em PCA+LDA superam os baseados em DCT.

Desta forma propõe-se um outro experimento com um banco de dados que proporciona um maior desafio para os métodos de reconhecimento de faces. $\mathrm{O}$ banco escolhido foi o Yale $\mathrm{B}$, que possui grandes variações em relação a iluminação. Foram utilizadas um total de 450 imagens referentes a pose frontal do banco Yale B. As configurações utilizadas nesse experimento foram as seguintes:

- Banco de dados Yale B;

- Para o treinamento: 


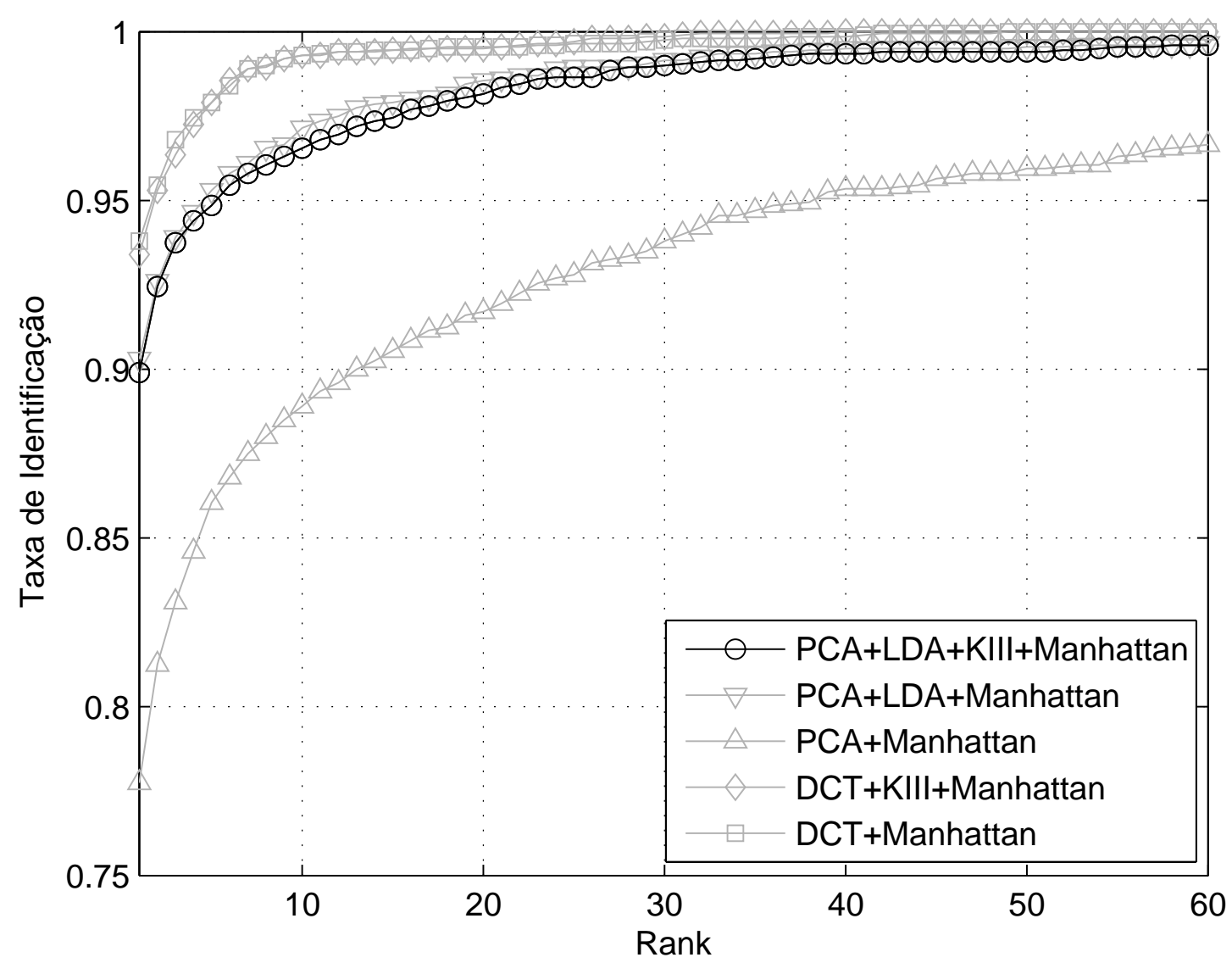

Figura 4.10: CMC para distância de Manhattan.

- Sub-conjunto 1 (10 pessoas 7 imagens por pessoa, total de 70 imagens)

- Para os testes:

- Sub-conjunto 2 (10 pessoas 12 imagens por pessoa, total de 120 imagens);

- Sub-conjunto 3 (10 pessoas 12 imagens por pessoa, total de 120 imagens);

- Sub-conjunto 4 (10 pessoas 14 imagens por pessoa, total de 140 imagens).

- Dimensão das imagens utilizadas 56 x 56 pixels;

- Sub-espaço PCA com 21 autovetores;

- Sub-espaço LDA com 9 autovetores;

- Parâmetros do KIII:

- 3 camadas de KII, com 9 KIIs em cada camada;

- demais parâmetros definidos na seção 4.1.1.

- Classificação da saída do KIII utilizando $k-N N$ com as seguintes medidas de distância: 
- Euclidiana;

- De Mahalanobis;

- De Manhattan.

Para este experimento o método de avaliação utilizado é o mesmo que o anterior e os resultados também são apresentados de duas maneiras, através da Tabela 4.5 mostrando o taxa de identificação para o rank 1 e pelas Figuras 4.11, 4.12 e 4.13 mostrando o rank cumulativo.

Tabela 4.5: Taxa de identificação obtida pelos métodos avaliados para o rank 1.

\begin{tabular}{|c|c|c|c|}
\hline \multicolumn{4}{|c|}{ Resultados para o rank 1} \\
\hline \multirow[b]{2}{*}{ Método } & \multicolumn{3}{|c|}{ Medida de distância } \\
\hline & Euclidiana & Mahalanobis & Manhattan \\
\hline & \multicolumn{3}{|c|}{ Sub-conjunto 2} \\
\hline PCA+LDA+KIII & 0,9746 & $\mathbf{0 , 9 7 4 6}$ & 0,9746 \\
\hline $\mathrm{PCA}+\mathrm{LDA}$ & 0,9831 & 0,9831 & 0,9831 \\
\hline PCA & 0,9831 & 0,9746 & 0,9831 \\
\hline $\mathrm{DCT}+\mathrm{KIII}$ & 0,8729 & 0,3475 & 0,8390 \\
\hline \multirow[t]{2}{*}{ DCT } & 0,9068 & 0,3475 & 0,8559 \\
\hline & \multicolumn{3}{|c|}{ Sub-conjunto 3} \\
\hline $\mathrm{PCA}+\mathrm{LDA}+\mathrm{KIII}$ & $\mathbf{0 , 8 3 3 3}$ & 0,8167 & $\mathbf{0 , 8 3 3 3}$ \\
\hline PCA+LDA & 0,7417 & 0,7167 & $\mathbf{0 , 7 5 8 3}$ \\
\hline PCA & 0,7083 & $\mathbf{0 , 7 2 5 0}$ & 0,7167 \\
\hline $\mathrm{DCT}+\mathrm{KIII}$ & $\mathbf{0 , 5 3 3 3}$ & 0,1333 & 0,4750 \\
\hline \multirow[t]{2}{*}{ DCT } & $\mathbf{0 , 5 7 5 0}$ & 0,1833 & 0,5167 \\
\hline & \multicolumn{3}{|c|}{ Sub-conjunto 4} \\
\hline $\mathrm{PCA}+\mathrm{LDA}+\mathrm{KIII}$ & 0,4480 & 0,4480 & $\mathbf{0 , 4 6 4 0}$ \\
\hline PCA+LDA & 0,4320 & 0,3840 & 0,4240 \\
\hline PCA & 0,3600 & $\mathbf{0 , 3 6 8 0}$ & 0,3120 \\
\hline $\mathrm{DCT}+\mathrm{KIII}$ & 0,2560 & 0,0960 & 0,2400 \\
\hline \multirow[t]{2}{*}{ DCT } & 0,3200 & 0,1280 & $\mathbf{0 , 3 2 0 0}$ \\
\hline & \multicolumn{3}{|c|}{ Sub-conjunto 2,3 e 4} \\
\hline $\mathrm{PCA}+\mathrm{LDA}+\mathrm{KIII}$ & 0,7548 & 0,7493 & 0,7493 \\
\hline PCA+LDA & 0,7190 & 0,6887 & 0,7273 \\
\hline PCA & 0,6694 & 0,6832 & 0,6694 \\
\hline $\mathrm{DCT}+\mathrm{KIII}$ & 0,5399 & 0,2204 & 0,5124 \\
\hline DCT & $\mathbf{0 , 5 9 2 3}$ & 0,2176 & 0,5758 \\
\hline
\end{tabular}

O sub-conjunto 2 é o primeiro a ser testado. É o sub-conjunto que apresenta menos variações de iluminação. As taxas de identificação mais altas foram alcançadas pelos métodos PCA e subespaço LDA com 0,9831 ambos, e em seguida está o método proposto com 0,9746, por fim os métodos DCT com 0,9068 e DCT+KIII com 0,8729. Para este sub-conjunto todos os métodos avaliados conseguem altas taxas de identificação, e o método proposto apesar de alcançar uma alta taxa de identificação, não oferece vantagem comparado aos outros.

O sub-conjunto 3 possui variações um pouco maiores na iluminação, e pode-se observar que todos os métodos avaliados alcançam uma taxa de identificação menor do que para o sub-conjunto 

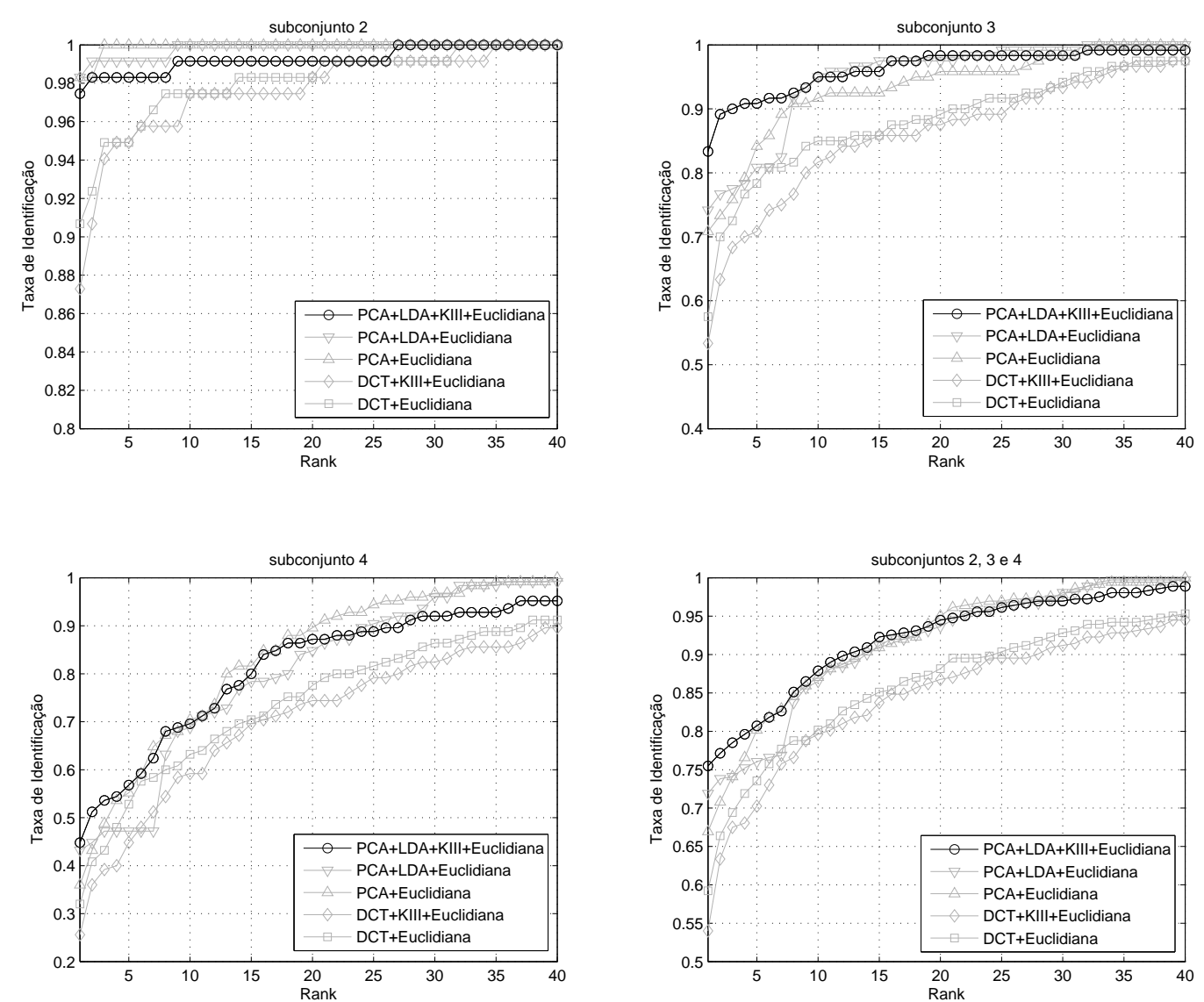

Figura 4.11: CMC para distância euclidiana.

2, o que mostra que este sub-conjunto oferece mais dificuldade que o primeiro. Para este subconjunto o método proposto alcança uma taxa de identificação mais alta que todos outros métodos avaliados com uma diferença considerável entre ele e o segundo melhor. O método proposto PCA+LDA+KIII alcançou uma taxa de identificação de 0,8333 , enquanto que o segundo melhor PCA+LDA alcançou 0,7583. Para este sub-conjunto é possível notar claramente a melhora obtida ao acrescentar o conjunto-KIII como filtro de dados ao modelo PCA+LDA.

As imagens do sub-conjunto 4 possuem variações na iluminação maiores que as encontradas no sub-conjunto 3 e consequentemente fornecem um desafio ainda maior para os métodos. Para este sub-conjunto o método proposto também alcança uma taxa de identificação maior que os outros, justificando o uso do método para problemas mais complexos. Na última parte da Tabela 4.5 temse os resultados utilizando os subconjuntos 2, 3 e 4 para testes, e pode-se observar que o método proposto continua superando os demais. Desta forma o método proposto pode ser considerado uma ótima alternativa aos métodos tradicionais.

Para esse banco de dados percebe-se que tanto o método baseado em DCT quanto o método DCT+KIII proposto por Zhang et al. (2006) conseguem baixas taxas de reconhecimento. Isso 

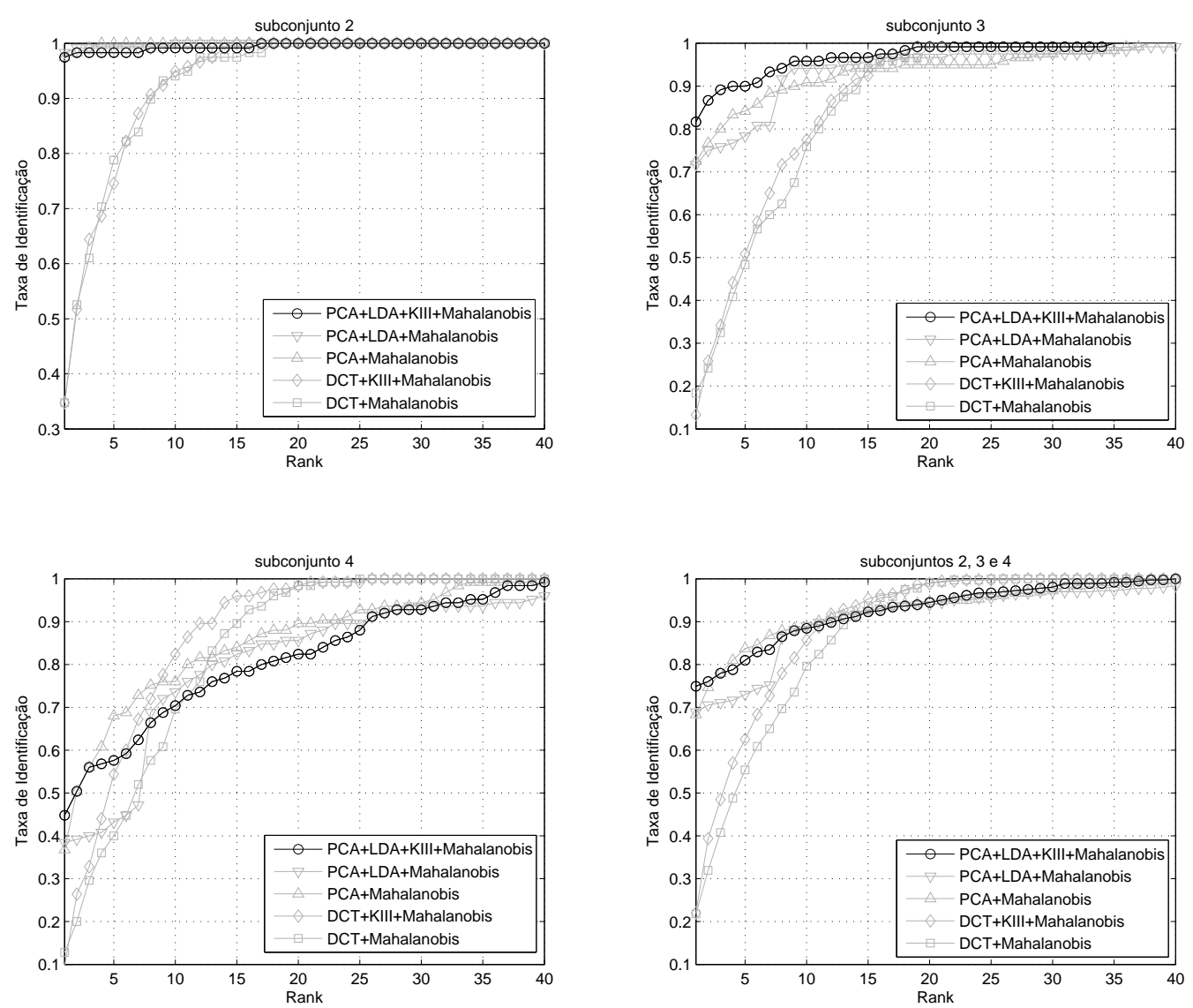

Figura 4.12: CMC para distância de Mahalanobis.

provavelmente acontece porque o DCT não consegue lidar tão bem com variações na iluminação quanto as técnicas baseados em projeção linear como PCA e LDA.

Em relação às medidas de distâncias utilizadas pode-se observar apenas sutis variações nas taxas de identificação obtidas. Analisando o resultado para os três sub-conjuntos observa-se que, cada método possui uma maior afinidade com uma determinada medida de distância, o método proposto PCA+LDA+KIII, o método DCT e o DCT+KIII alcançam uma maior taxa de identificação quando utilizado com a distância Euclidiana, o método PCA quando utilizado a distância de Mahalanobis e o PCA+LDA com distância de Manhattan. Levando em consideração esta observação foi possível concluir que uma medida de distância não pode ser considerada mais ou menos eficiente que outra, tudo é uma questão de combinação, o que torna interessante o estudo de diversas combinações com o objetivo de extrair o melhor resultado possível dos métodos. Interessante notar também que entre todos os métodos, o método proposto PCA+LDA+KIII é o que possui menor discrepância na taxa de reconhecimento comparando as medidas de distâncias utilizadas.

Os gráficos CMC são mostrados nas Figuras 4.11, 4.12 e 4.13, pelos quais é possível obter algumas informações adicionais sobre os métodos, que são muito úteis em aplicações em que o que importa não é o percentual de acerto para a primeira correspondência e sim o percentual de acerto 

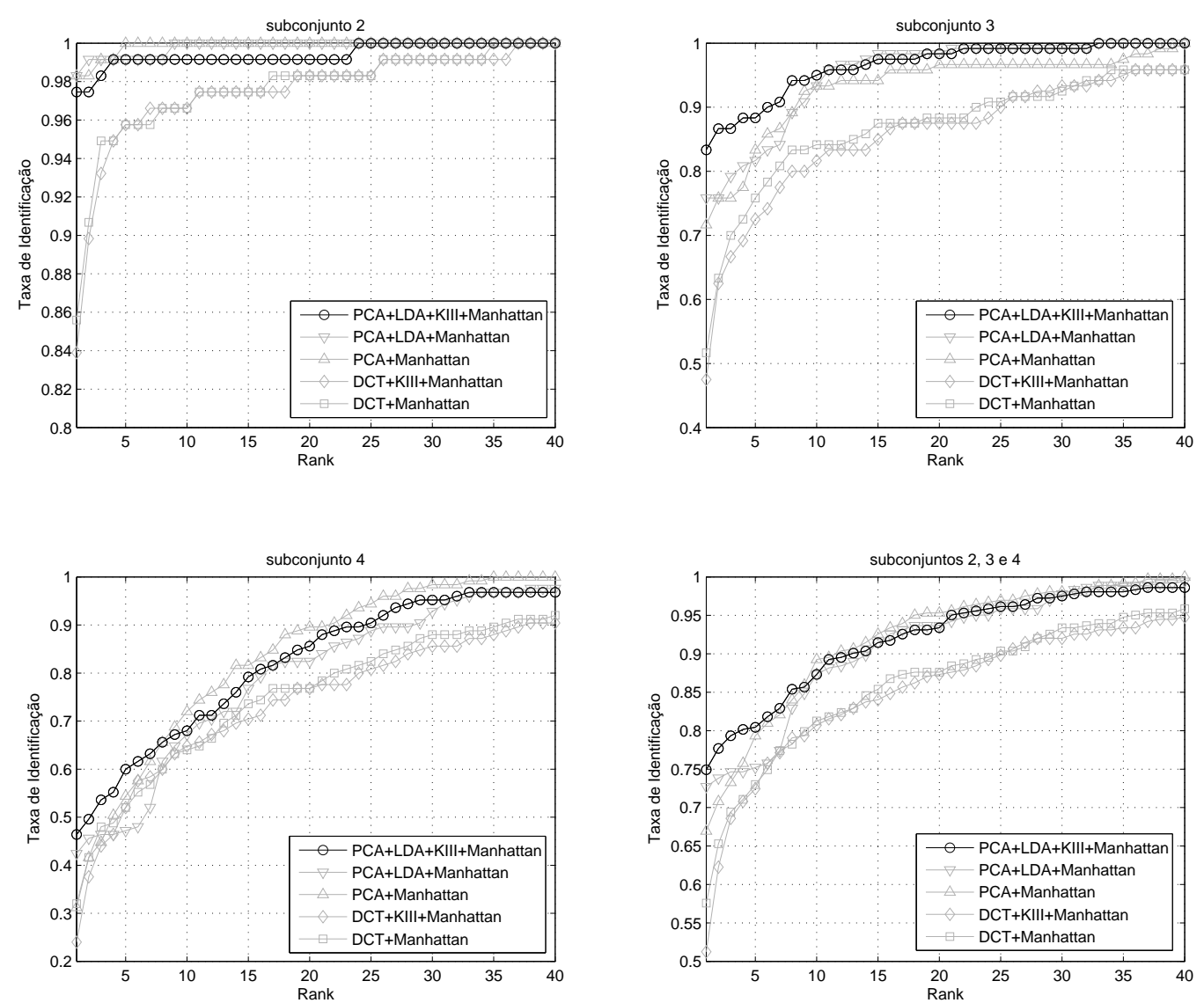

Figura 4.13: CMC para distância de Manhattan.

para as $x$ primeiras correspondências. Cada imagem mostra os resultados obtidos para uma determinada medida de distância, cada uma mostra quatro gráficos CMC, um para cada subconjunto e o último para os 3 subconjuntos juntos. Observando os resultados, para o subconjunto 2 o método proposto não oferece muita vantagens comparado aos demais, para os outros subconjuntos para um rank pequeno o método proposto alcança uma taxa de identificação maior que os outros, no entanto conforme o rank vai aumentando ele vai perdendo pontos para os outros métodos. Desta forma, pode-se dizer que o método proposto é uma boa escolha para aplicações que utilizam até o rank 5; a partir desse ponto o método começa a perder espaço para os outros deixando de ser uma opção vantajosa.

Com relação às medidas de distância, cumulativamente pode-se dizer que o método proposto consegue um resultado um pouco melhor com a distância de Manhattan. E como para o rank 1 a distância de Manhattan também produz um bom resultado, acredita-se que essa medida de distância seja a melhor opção para combinação com o método proposto. 


\subsection{Considerações Finais}

Este capítulo apresentou uma visão geral do método proposto, e detalhou seu funcionamento nas fases de treinamento e teste. Também apresentou os conjuntos de dados utilizados, os experimentos e resultados obtidos. Observou-se que o método proposto não traz uma vantagem significativa em relação a outros métodos quando aplicado a um banco de dados simples, com poucas variações (pose, expressão e iluminação). Contudo, quando aplicado a um banco de dados que proporciona um desafio maior, com grandes variações na iluminação, o método proposto consegue um resultado melhor do que os outros métodos avaliados. 



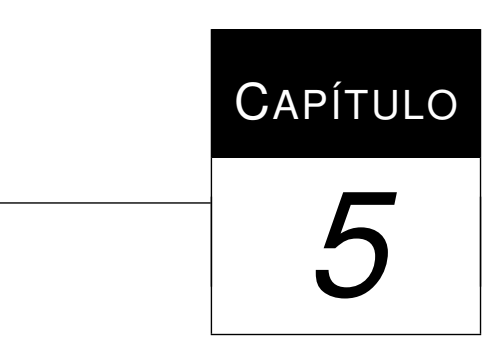

Conclusões

Este trabalho apresenta uma proposta de um método de reconhecimento de faces baseado nos conjuntos-K de Freeman. O projeto é motivado pela dificuldade que os métodos atuais têm de lidar com os grandes desafios da área e pelo fato dos conjuntos-K terem apresentado bons resultados em problemas complexos e em ambientes com ruídos. O método proposto foi avaliado em relação à tarefa de identificação e comparado com alguns dos métodos mais populares da área.

Os resultados apresentados pelo método proposto foram satifastórios. No primeiro cenário avaliado, onde é utilizado um banco de dados simples, com poucas variações (expressão facial, pose e iluminação) o método proposto consegue um resultado igual ou inferior aos métodos comparados. No entanto, no segundo cenário, onde foi criado um ambiente mais complexo, que utilizou um banco de dados com grandes variações na iluminação, o método proposto alcança uma taxa de identificação maior que os outros métodos.

A principal contribuição resultante deste trabalho foi o método de reconhecimento de faces baseado nos conjuntos-KIII, que superou os outros métodos em problemas com grandes variações na iluminação, validando a hipótese levantada. Como contribuição secundária tem-se o estudo dos conjuntos-K, abordando a arquitetura do modelo e sua integração com demais componentes de um sistema de reconhecimento de faces totalmente automático, bem como a avaliação de diferentes medidas de distâncias empregadas no k-NN para classificar o espaço de saída do conjunto-KIII.

Como sugestão para trabalhos futuros, propõe-se a união de dois conceitos adquiridos durante a concepção deste trabalho. O primeiro é a utilização de informações de contexto como informação auxiliar para a realização do reconhecimento de faces. Essa técnica já vem sendo utilizada em alguns trabalhos da área (Davis et al., 2005; Stone et al., 2010) e mostraram resultados promissores. Um ótimo exemplo de informações de contexto utilizadas são dados obtidos de redes sociais, 
como Facebook e GooglePlus. O segundo conceito foi adquirido durante a revisão bibliográfica dos conjuntos-K, em que foi visto que o conjunto-KIV é indicado para tarefas que envolvam tomadas de decisões através do processamento de dados vindos de fontes diferentes. Desta forma, a sugestão para trabalho futuro levantada é a utilização do conjunto-KIV em um método de reconhecimento de faces que receba informações vinda de duas fontes distintas, as informações contidas nas imagens da face e as informações de contexto. 
Abate, A. F.; Nappi, M.; Riccio, D.; Sabatino, G. 2d and 3d face recognition: A survey. Pattern Recognition Letters, v. 28, n. 14, p. 1885 - 1906, image: Information and Control, 2007.

Disponível em: http://www.sciencedirect.com/science/article/pii/ S0167865507000189

Adini, Y.; Moses, Y.; Ullman, S. Face recognition: the problem of compensating for changes in illumination direction. Pattern Analysis and Machine Intelligence, IEEE Transactions on, v. 19, n. 7, p. $721-732,1997$.

Alligood, K.; SAuer, T.; Yorke, J. Chaos: An introduction to dynamical systems. Chaos: An Introduction to Dynamical Systems. Springer, 1997.

Disponível em: http: / /books . google.com.br/books? id=48YHnbHGZAgC

Amit, Y.; Geman, D.; Wilder, K. Joint induction of shape features and tree classifiers. Pattern Analysis and Machine Intelligence, IEEE Transactions on, v. 19, n. 11, p. 1300-1305, 1997.

BARTlett, M. S.; LAdeS, H. M.; SeJNOWsKi, T. J. Independent component representations for face recognition. 1998.

Belhumeur, P.; Hespanha, J.; Kriegman, D. Eigenfaces vs. fisherfaces: recognition using class specific linear projection. Pattern Analysis and Machine Intelligence, IEEE Transactions on, v. 19, n. 7, p. $711-720,1997$.

BEliAEV, I.; Ilin, R.; KozMA, R. Nonlinear neurodynamics tool for system analysis and application for time series prediction. In: Systems, Man and Cybernetics, 2005 IEEE International Conference on, 2005, p. 1011-1016.

Brunelli, R.; Poggio, T. Face recognition: Features versus templates. IEEE Transactions on Pattern Analysis and Machine Intelligence, v. 15, p. 1042-1052, 1993. 
Buhmann, J.; Lades, M.; Malsburg, C. Size and distortion invariant object recognition by hierarchical graph matching. In: Neural Networks, 1990., 1990 IJCNN International Joint Conference on, 1990, p. 411-416 vol.2.

CARlos JR., L. F. M.; Ros A, J. L. G. Face recognition through a chaotic neural network model. In: Neural Networks (IJCNN), 2014 International Joint Conference on, 2014, p. 859-863.

Chang, H. J.; Freeman, W. J. Parameter optimization in models of the olfactory neural system. Neural Networks, v. 9, p. 1-14, 1996.

Chang, H.-J.; Freeman, W. J.; Burke, B. C. Optimization of olfactory model in software to give 1/f power spectra reveals numerical instabilities in solutions governed by aperiodic (chaotic) attractors. Neural Networks, v. 11, n. 3, p. $449-466,1998$.

Disponível em: http://www.sciencedirect.com/science/article/pii/ S0893608097001160

Chellappa, R.; Aggarwal, G.; Zhou, S. Face recognition, video-based. In: Li, S.; Jain, A., eds. Encyclopedia of Biometrics, Springer US, p. 366-372, 2009.

Disponível em: http://dx.doi.org/10.1007/978-0-387-73003-5_96

Chellappa, R.; Sinha, P.; Phillips, P. Face recognition by computers and humans. Computer, v. 43, n. 2, p. $46-55,2010$.

Chellappa, R.; Wilson, C. L.; Sirohey, S. Human and machine recognition of faces: a survey. Proceedings of the IEEE, v. 83, n. 5, p. 705-741, 1995.

Disponível em: http://dx.doi.org/10.1109/5.381842

Choi, J. Y.; De Neve, W.; Plataniotis, K.; Ro, Y. M. Collaborative face recognition for improved face annotation in personal photo collections shared on online social networks. Multimedia, IEEE Transactions on, v. 13, n. 1, p. 14-28, 2011.

ClARK, A. Mindware: An introduction to the philosophy of cognitive science. Oxford University Press, 2001.

Disponível em: http://books.google.com.br/books?id=yA8pN40_qneC

Cottrell, G.; Fleming, M. Face recognition using unsupervised feature extraction. In: International Symposium on Neural Networks, 1990.

CoX, I. J.; Ghosn, J.; Yianilos, P. Feature-based face recognition using mixture-distance. Proceedings of IEEE Computer Society Conference on Computer Vision and Pattern Recognition, p. 209-216, 1996.

Disponível em: http://ieeexplore.ieee.org/xpls/abs_all.jsp? arnumber $=517076$ 
Davis, M.; Smith, M.; Canny, J.; Good, N.; King, S.; Janakiraman, R. Towards context-aware face recognition. In: Proceedings of the 13th annual ACM international conference on Multimedia, ACM, 2005, p. 483-486.

Delac, K.; Grgic, M.; GrGiC, S. Independent comparative study of pca, ica, and lda on the feret data set. International Journal of Imaging Systems and Technology, v. 15, n. 5, p. 252260, 2005.

Disponível em: http://dx.doi.org/10.1002/ima.20059

ER, M. J.; WU, S.; LU, J.; TOH, H. L. Face recognition with radial basis function (rbf) neural networks. Neural Networks, IEEE Transactions on, v. 13, n. 3, p. 697 -710, 2002.

Erwin, H.; Freeman, W. J. Freeman k-set. Scholarpedia, v. 3, n. 1, p. 3238, 2008.

Disponível em: http://www.scholarpedia.org/article/Freeman_K-set

Franco, L.; TREves, A. A neural network facial expression recognition system using unsupervised local processing. In: Image and Signal Processing and Analysis, 2001. ISPA 2001. Proceedings of the 2nd International Symposium on, 2001, p. 628-632.

FreEman, W. J. Mass action in the nervous system. Academic Press, 1975.

Disponível em: http: / /www.worldcat.org/isbn/0122671503

Freeman, W. J.; Kozma, R.; Werbos, P. J. Biocomplexity: adaptive behavior in complex stochastic dynamical systems. Biosystems, v. 59, n. 2, p. 109 - 123, 2001.

Disponível em: http://www.sciencedirect.com/science/article/pii/ s0303264700001465

FReUnd, Y.; SchapIRE, R. E. A decision-theoretic generalization of on-line learning and an application to boosting. Journal of Computer and System Sciences, v. 55, n. 1, p. 119 - 139, 1997.

Disponível em: http://www.sciencedirect.com/science/article/pii/ s002200009791504X

Friedman, J.; Hastie, T.; TIBShIRAni, R. Special invited paper. additive logistic regression: A statistical view of boosting. Annals of statistics, p. 337-374, 2000.

Georghiades, A.; Belhumeur, P.; Kriegman, D. From few to many: generative models for recognition under variable pose and illumination. In: Automatic Face and Gesture Recognition, 2000. Proceedings. Fourth IEEE International Conference on, 2000, p. 277-284.

HAYKIN, S. Neural networks: A comprehensive foundation. International edition. Prentice Hall, 1999.

Disponível em: http: / /books.google.com.br/books? id=M5abQgAACAAJ 
Hotelling, H. Analysis of a complex of statistical variables into principal components. Journal of educational psychology, v. 24, n. 6, p. 417, 1933.

ILIN, R. Learning and parameterization of recurrent neural network arrays for brain models and practical applications. Tese de Doutoramento, Memphis, TN, USA, aAI3328199, 2008.

Ilin, R.; Kozma, R. Sensor integration in kiv brain model for decision making. In: Neural Networks, 2009. IJCNN 2009. International Joint Conference on, 2009, p. 1328 -1334.

JESORSKY, O.; KirChBerG, K. J.; FrischHOlz, R. W. Robust face detection using the hausdorff distance. In: Audio-and video-based biometric person authentication, Springer, 2001, p. 90-95.

KANADE, T. Picture processing by computer complex and recognition of human faces. 1973.

Kelly, M. D. Visual identification of people by computer. Tese de Doutoramento, Stanford, CA, USA, aAI7112934, 1971.

Kirby, M.; Sirovich, L. Application of the karhunen-loeve procedure for the characterization of human faces. Pattern Analysis and Machine Intelligence, IEEE Transactions on, v. 12, n. 1, p. $103-108,1990$.

Kittler, J.; Hatef, M.; Duin, R. P. W.; Matas, J. On combining classifiers. IEEE TRANSACTIONS ON PATTERN ANALYSIS AND MACHINE INTELLIGENCE, v. 20, p. 226-239, 1998.

Kozma, R. Intentional systems: Review of neurodynamics, modeling, and robotics implementation. Physics of Life Reviews, v. 5, n. 1, p. 1-21, 2008.

Disponível em: http://www.sciencedirect.com/science/article/pii/ S1571064507000243

Kozma, R.; Aghazarian, H.; Huntsherger, T.; Tunstel, E.; Freeman, W. J. Computational aspects of cognition and consciousness in intelligent devices. Computational Intelligence Magazine, IEEE, v. 2, n. 3, p. 53 -64, 2007.

Kozma, R.; Beliaev, I. Time series prediction using chaotic neural networks: case study of ijcnn cats benchmark test. In: Neural Networks, 2004. Proceedings. 2004 IEEE International Joint Conference on, 2004, p. 1609 - 1613 vol.2.

Kozma, R.; Freeman, W. J. Chaotic resonance-methods and applications for robust classification of noisy and variable patterns. International Journal of Bifurcation and Chaos, 2001.

Kozma, R.; Freeman, W. J. Basic principles of the kiv model and its application to the navigation problem. Journal of Integrative Neuroscience, v. 2, n. 1, p. 125-145, 2003.

Disponível em: http://www.ncbi.nlm.nih.gov/pubmed/15011280 
Kozma, R.; FreEman, W. J.; ERDI, P. The KIV model-nonlinear spatio-temporal dynamics of the primordial vertebrate forebrain. Neurocomputing, v. 52, p. 819-826, 2003.

Kozma, R.; Muthu, S. Implementing reinforcement learning in the chaotic kiv model using mobile robot aibo. In: Intelligent Robots and Systems, 2004. (IROS 2004). Proceedings. 2004 IEEE/RSJ International Conference on, 2004, p. 2337-2342 vol.3.

Kozma, R.; Rosa, J. L. G.; PiAzentin, D. R. M. Cognitive clustering algorithm for efficient cybersecurity applications. In: Proceedings of the IJCNN 2013 International Joint Conference on Neural Networks, 2013, p. $471-478$.

KuZnetsov, I. Elements of applied bifurcation theory. N. v. 112 in 2nd Ed). Springer, 1998. Disponível em: http: / / books.google.com.br/books? id=y0uq4qEa2 ZsC

Lades, M.; Vorbruggen, J.; Buhmann, J.; Lange, J.; Von Der Malsburg, C.; Wurtz, R.; Konen, W. Distortion invariant object recognition in the dynamic link architecture. Computers, IEEE Transactions on, v. 42, n. 3, p. 300-311, 1993.

Lawrence, S.; Giles, C.; Tsoi, A. C.; BACK, A. Face recognition: a convolutional neuralnetwork approach. Neural Networks, IEEE Transactions on, v. 8, n. 1, p. 98 -113, 1997.

Lawrence, S.; Giles, C. L.; Tsoi, A. C.; Back, A. D. Face recognition: a convolutional neural-network approach. Neural Networks, IEEE Transactions on, v. 8, n. 1, p. 98-113, 2002. Disponível em: http://dx.doi.org/10.1109/72.554195

LEIBER, T. On the actual impact of deterministic chaos. Synthese, v. 113, n. 3, p. 357-379, 1997.

Disponível em: http://dx.doi.org/10.1023/A3A1004944713074

LEWIS, J. Fast normalized cross-correlation. In: Vision interface, 1995, p. 120-123.

Li, G.; LoU, Z.; Wang, L.; Li, X.; Freeman, W. J. Application of chaotic neural model based on olfactory system on pattern recognitions. In: WANG, L.; CHEN, K.; ONG, Y., eds. Advances in Natural Computation, v. 3610 de Lecture Notes in Computer Science, Springer Berlin / Heidelberg, p. 417-417, 2005.

Disponível em: http://dx.doi.org/10.1007/11539087_47

Li, G.; Zhang, J.; WAng, Y.; Freeman, W. J. Face recognition using a neural network simulating olfactory systems. In: WANG, J.; YI, Z.; ZURADA, J.; LU, B.-L.; YIN, H., eds. Advances in Neural Networks - ISNN 2006, v. 3972 de Lecture Notes in Computer Science, Springer Berlin / Heidelberg, p. 93-97, 2006.

Disponível em: http://dx.doi.org/10.1007/11760023_14 
LI, H.; Kozma, R. A dynamic neural network method for time series prediction using the kiii model. In: Proceedings of the International Joint Conference on Neural Networks, 2003., IEEE, 2003, p. 347-352.

Disponível em: http://dx.doi.org/10.1109/IJCNN.2003.1223370

LI, S.; JAIN, A. Handbook of face recognition. Springer eBooks collection: Computer science. Springer, 2005.

Disponível em: http://books.google.com.br/books?id=amVDaTdgKYcC

LIN, S.-H.; KUNG, S.-Y.; LIN, L.-J. Face recognition/detection by probabilistic decision-based neural network. Neural Networks, IEEE Transactions on, v. 8, n. 1, p. 114-132, 1997.

Lyons, M.; Akamatsu, S.; Kamachi, M.; Gyoba, J. Coding facial expressions with gabor wavelets. In: Automatic Face and Gesture Recognition, 1998. Proceedings. Third IEEE International Conference on, IEEE, 1998, p. 200-205.

Maheshkar, V.; Kamble, S.; Agarwal, S.; Srivastava, V. K. Dct-based unique faces for face recognition using mahalanobis distance. In: Proceedings of the First International Conference on Intelligent Interactive Technologies and Multimedia, IITM '10, New York, NY, USA: ACM, 2010, p. 208-212 (IITM '10, ).

Disponível em: http://doi.acm.org/10.1145/1963564.1963599

Marszalec, E.; Martinkauppi, B.; Soriano, M.; Pietika, M.; Et Al. Physics-based face database for color research. Journal of Electronic Imaging, v. 9, n. 1, p. 32-38, 2000.

MaRTINEZ, A. M. Recognizing imprecisely localized, partially occluded and expression variant faces from a single sample per class. 2002.

Messer, K.; Matas, J.; Kittler, J.; Jonsson, K. XM2VTSDB: The Extended M2VTS Database. In: Audio- and Video-Based Biometric Person Authentication, 1999.

Mitchell, T. M. Machine learning. 1 ed. New York, NY, USA: McGraw-Hill, Inc., 1997.

Moghaddam, B.; Jebara, T.; Pentland, A. Bayesian face recognition. Pattern Recognition, v. 33, n. 11, p. $1771-1782,2000$.

Disponível em: http://www.sciencedirect.com/science/article/pii/ s003132039900179X

Nefian, A.; Hayes, M.H., I. Hidden markov models for face recognition. In: Acoustics, Speech and Signal Processing, 1998. Proceedings of the 1998 IEEE International Conference on, 1998, p. 2721-2724 vol.5.

Okada, K.; Steffens, J.; Maurer, T.; Hong, H.; Elagin, E.; Neven, H.; Malsburg, C. The bochum/usc face recognition system and how it fared in the feret phase iii test. In: 
Wechsler, H.; Phillips, P.; Bruce, V.; Soulié, F.; Huang, T., eds. Face Recognition, v. 163 de NATO ASI Series, Springer Berlin Heidelberg, p. 186-205, 1998.

Disponível em: http://dx.doi.org/10.1007/978-3-642-72201-1_10

Papageorgiou, C.; Oren, M.; Poggio, T. A general framework for object detection. In: Computer Vision, 1998. Sixth International Conference on, 1998, p. 555-562.

Pentland, A.; Moghaddam, B.; Starner, T. View-based and modular eigenspaces for face recognition. In: Computer Vision and Pattern Recognition, 1994. Proceedings CVPR '94., 1994 IEEE Computer Society Conference on, 1994, p. 84 -91.

PerlibakAs, V. Distance measures for pca-based face recognition. Pattern Recognition Letters, v. 25, n. 6, p. $711-724,2004$.

Disponível em: http://www.sciencedirect.com/science/article/pii/ S0167865504000248

Phillips, P.; Grother, P.; Micheals, R. Evaluation methods in face recognition. In: Li, S. Z.; JAIN, A. K., eds. Handbook of Face Recognition, Springer London, p. 551-574, 2011. Disponível em: http://dx.doi.org/10.1007/978-0-85729-932-1_21

Phillips, P.; Moon, H.; Rizvi, S.; Rauss, P. The feret evaluation methodology for facerecognition algorithms. Pattern Analysis and Machine Intelligence, IEEE Transactions on, v. 22, n. 10, p. $1090-1104,2000$.

Phillips, P.; Wechsler, H.; HuAng, J.; Rauss, P. J. The feret database and evaluation procedure for face-recognition algorithms. Image and Vision Computing, v. 16, n. 5, p. 295 306, 1998.

Disponível em: http://www.sciencedirect.com/science/article/pii/ s026288569700070X

PhILliPs, P. J. Support vector machines applied to face recognition. In: Advances in Neural Information Processing Systems 11, MIT Press, 1999, p. 803-809.

Phillips, P. J.; Grother, P.; Micheals, R.; Blackburn, D. M.; Tabassi, E.; Bone, M. Face recognition vendor test 2002. In: Analysis and Modeling of Faces and Gestures, 2003. AMFG 2003. IEEE International Workshop on, IEEE, 2003, p. 44.

Piazentin, D.; Carlos JR., L. F. M. ksets: Release 1.0. 2014.

Disponível em: http://dx.doi.org/10.5281/zenodo.12288

Principe, J.; TAVAres, V.; Harris, J.; Freeman, W. J. Design and implementation of a biologically realistic olfactory cortex in analog vlsi. Proceedings of the IEEE, v. 89, n. 7, p. $1030-1051,2001$. 
RIZK, M.; TAHA, A. Analysis of neural networks for face recognition systems with feature extraction to develop an eye localization based method. IEEE Electronics, Circuits and Systems, 2002. 9th International Conference on, v. 3, p. 847 - 850, 2002.

RoD, Z. P.; ADAMs, R.; Bolouri, H. Dimensionality reduction of face images using discrete cosine transforms for recognition. In: IEEE Conference on Computer Vision and Pattern Recognition, 2000.

Roth, D.; YAng, M.-H.; Ahuja, N. A snow-based face detector. Urbana, v. 51, p. 61801, 2000.

Rowley, H.; Baluja, S.; Kanade, T. Neural network-based face detection. Pattern Analysis and Machine Intelligence, IEEE Transactions on, v. 20, n. 1, p. 23-38, 1998.

SAMARIA, F.; HARTER, A. Parameterisation of a stochastic model for human face identification. In: Applications of Computer Vision, 1994., Proceedings of the Second IEEE Workshop on, 1994, p. $138-142$.

SAMARIA, F.; Young, S. Hmm-based architecture for face identification. Image and Vision Computing, v. 12, n. 8, p. 537 - 543, 1994.

Disponível em: http://www.sciencedirect.com/science/article/pii/ 0262885694900078

SAMARIA, F. S. Face recognition using hidden markov models. Tese de Doutoramento, University of Cambridge, 1994.

SCHNEIDERman, H.; KAnADE, T. A statistical method for 3d object detection applied to faces and cars. In: Computer Vision and Pattern Recognition, 2000. Proceedings. IEEE Conference on, 2000, p. 746-751 vol.1.

SiM, T.; BAKER, S.; BSAT, M. The cmu pose, illumination, and expression database. IEEE Transactions on Pattern Analysis and Machine Intelligence, v. 25, p. 1615-1618, 2003.

Solina, F.; Peer, P.; Batagelu, B.; Juvan, S.; KovaČ, J. Color-based face detection in the"15 seconds of fame"art installation. 2003.

StOne, Z.; ZICKLER, T.; DARRELl, T. Toward large-scale face recognition using social network context. Proceedings of the IEEE, v. 98, n. 8, p. 1408-1415, 2010.

Sung, K.-K.; Poggio, T. Example-based learning for view-based human face detection. Pattern Analysis and Machine Intelligence, IEEE Transactions on, v. 20, n. 1, p. 39-51, 1998.

Swets, D.; WEng, J. Discriminant analysis and eigenspace partition tree for face and object recognition from views. In: Automatic Face and Gesture Recognition, 1996., Proceedings of the Second International Conference on, 1996a, p. 192-197. 
Swets, D.; Weng, J. Using discriminant eigenfeatures for image retrieval. Pattern Analysis and Machine Intelligence, IEEE Transactions on, v. 18, n. 8, p. 831-836, $1996 \mathrm{~b}$.

Taj, M.; Cavallaro, A. Multi-view multi-object detection and tracking. In: Cipolla, R.; Battiato, S.; Farinella, G., eds. Computer Vision, v. 285 de Studies in Computational Intelligence, Springer Berlin Heidelberg, p. 263-280, 2010.

Disponível em: http://dx.doi.org/10.1007/978-3-642-12848-6_10

Tamura, S.; Kawai, H.; Mitsumoto, H. Male/female identification from $8 \times 6$ very low resolution face images by neural network. Pattern Recognition, v. 29, n. 2, p. 331 - 335, 1996. Disponível em: http://www.sciencedirect.com/science/article/pii/ 0031320395000739

TAN, X.; Chen, S.; Zhou FuyAn Zhang, Z. Face recognition from a single image per person: A survey. Pattern Recognition, v. 39, p. 1725-1745, 2006.

The Math Works, I. Computer vision system toolbox user's guide. The Math Works, Inc., 2014.

Disponível em: http://www.mathworks.cn/help/pdf_doc/vision/vision_ $u g \cdot p d f$

Turk, M.; PEntland, A. Eigenfaces for recognition. Journal of cognitive neuroscience, v. 3, n. 1, p. 71-86, 1991a.

Turk, M. A.; Pentland, A. P. Face recognition using eigenfaces. In: Proceedings. 1991 IEEE Computer Society Conference on Computer Vision and Pattern Recognition, IEEE Comput. Sco. Press, 1991b, p. 586-591.

Disponível em: http://dx.doi.org/10.1109/CVPR.1991.139758

Viola, P.; Jones, M. Rapid object detection using a boosted cascade of simple features. In: Computer Vision and Pattern Recognition, 2001. CVPR 2001. Proceedings of the 2001 IEEE Computer Society Conference on, 2001, p. I-511-I-518 vol.1.

WAnG, L.; Li, G.; LiU, X.; WAnG, B.; Freeman, W. J. Study of a chaotic olfactory neural network model and its applications on pattern classification. In: Engineering in Medicine and Biology Society, 2005. IEEE-EMBS 2005. 27th Annual International Conference of the, 2005, p. $3640-3643$.

WERNDL, C. What are the new implications of chaos for unpredictability? The British Journal for the Philosophy of Science, v. 60, n. 1, p. 195-220, 2009.

Wiskott, L.; Fellous, J.-M.; Kuiger, N.; Malsburg, C. Face recognition by elastic bunch graph matching. Pattern Analysis and Machine Intelligence, IEEE Transactions on, v. 19 , n. 7, p. $775-779,1997$. 
Xiaomin, B.; Xiaoqing, N.; Yaming, W.; Yanjiang, Z. Recognition of fabric structures based on improved olfactory neural network. In: Artificial Intelligence and Computational Intelligence (AICI), 2010 International Conference on, 2010, p. 325 -328.

YAmbor, W. S.; Draper, B. A.; BeVERIDGe, J. R. Analyzing pca-based face recognition algorithms : Eigenvector selection and distance measures. Science, p. 1-14, 2000.

Disponível em: http://www.cs.colostate.edu/evalfacerec/papers/ eemcrcsu.pdf

YANG, J.; YANG, J. Why can $\{$ LDA $\}$ be performed in $\{$ PCA $\}$ transformed space? Pattern Recognition, v. 36, n. 2, p. 563 - 566, biometrics, 2003.

Disponível em: http://www.sciencedirect.com/science/article/pii/ S 0031320302000481

ZERVOS, M. Multi-camera face detection and recognition applied to people tracking. Relatório Técnico, Citeseer, 2013.

Zhang, J.; Li, G.; WANG, L.; Freeman, W. J. Application of chaotic neural network on face recognition. In: Neural Networks and Brain, 2005. ICNN B '05. International Conference on, 2005, p. $1367-1372$.

Zhang, J.; WAnG, Y.; LI, G.; Freeman, W. J. Application of bionic neural network on face recognition based on svd and dct. In: Intelligent Control and Automation, 2006. WCICA 2006. The Sixth World Congress on, 2006, p. 2733 -2736.

Zhang, X.; GAO, Y. Face recognition across pose: A review. Pattern Recognition, v. 42, n. 11, p. 2876 - 2896, 2009.

Disponível em: http://www.sciencedirect.com/science/article/pii/ s0031320309001538

Zhao, W.; Chellappa, R.; Krishnaswamy, A. Discriminant analysis of principal components for face recognition. In: Automatic Face and Gesture Recognition, 1998. Proceedings. Third IEEE International Conference on, 1998, p. 336 -341.

Zhao, W.; ChellapPA, R.; PhILlips, P. Subspace linear discriminant analysis for face recognition. Relatório Técnico, 1999.

Zhao, W.; Chellappa, R.; Phillips, P. J.; Rosenfeld, A. Face recognition: A literature survey. ACM Comput. Surv., v. 35, n. 4, p. 399-458, 2003.

Disponível em: http://dx.doi.org/10.1145/954339.954342

Zhou, Z.-H.; WU, J.; TANG, W.; ZhOU, Z.; WU, J.; TANG, W. Ensembling neural networks: Many could be better than all. 2002. 